THIRD ANNUAL REPORT

September 15, 2000 to September 14, 2001

U.S. Department of Energy

\title{
PHYSICAL, CHEMICAL AND STRUCTURAL EVOLUTION OF ZEOLITE-CONTAINING WASTE FORMS PRODUCED \\ FROM METAKAOLINITE AND CALCINED HLW
}

Michael W. Grutzeck

Stephen Kwan

Materials Research Institute

Materials Research Laboratory

The Pennsylvania State University

University Park, PA 16802

EMSP Project Number 65366

Grant Number DE-FG07-98ER45726

Roland F. Hirsch (DOE Germantown MD)

Matesh Varma (DOE Washington DC)

Chet Miller (DOE Washington DC)

Elizabeth Dahl (DOE Idaho Falls ID)

Prepared January 15, 2002 


\section{Objectives}

Natural and synthetic zeolites are extremely versatile materials. They can adsorb a variety of liquids and gasses, and take part in cation exchange reactions. Zeolites are relatively easy to synthesize from a wide range of natural and man-made materials. One such combination is a mixture of metakaolinite and concentrated sodium hydroxide solution. ${ }^{1}$ Once mixed and cured at elevated temperatures, these ingredients react to form a hard, dense, ceramic-like material that contains significant amounts of crystalline tectosilicates (zeolites and feldspathoids) imbedded in an X-ray amorphous sodium aluminosilicate hydrate matrix. This rather unique composite material has been termed a "hydroceramic." The crystalline phases in the hydroceramic have the ability to sequester alkali, alkaline earth and a variety of higher valance cations in lattice positions or within networks of channels and voids. The matrix plays host to the crystallites and to residual amounts of insoluble hydroxide phases. Due to its gel-like character, the matrix also provides considerable strength. A previous publication ${ }^{2}$ has established the fact that a mixture of a calcined equivalent ICPP waste (sodium aluminate/hydroxide solution containing 3:1 Na:Al) and fly ash and/or metakaolinite could be cured at various temperatures to produce a monolith containing Zeolite $\mathrm{A}\left(80^{\circ} \mathrm{C}\right)$ or $\mathrm{Na}-\mathrm{P} 1$ plus hydroxysodalite $\left(130^{\circ} \mathrm{C}\right)$ dispersed in the alkali aluminosilicate hydrate matrix. Dissolution tests (PCT type) have shown these materials have superior retention of alkali, alkaline earth and heavy metal ions.

The zeolitization process is a simple one. Metakaolinte is mixed with a calcined sodiumbearing waste and enough water to make a thick paste. The paste is transferred to a metal canister and "soaked" for a few hours at $90^{\circ} \mathrm{C}$ prior to conventional oven heating or steam autoclaving at

$-200^{\circ} \mathrm{C}$ for varying periods of time. Hydroceramics could well be a viable alternative for fixation of low activity sodium-bearing waste (SBW) calcines. The objective of the current study is to adapt this technology for use on site remediation and clean up of caustic waste solutions now in storage in tanks at Hanford and Savannah River. The proposed work is meant to develop a clearer understanding of the advantages and limitations of producing a zeolite-containing hydroceramic from treated low activity SBW, i.e. the effect of processing variables, reaction kinetics, crystal and phase chemistry, and microstructure on the performance of the waste form.

\section{Completed Work}

During the tenure of our current EMSP grant, it has been possible to provide proof of concept that a hydroceramic waste form is a perfect contingency waste form, worthy of further development activities. Work in progress suggests that further research and development are needed in the area of calcination, formulations and scale-up in order to control mobile elements, and to insure viability of the technology in the real world. Details of the experiments completed during the first three years of this grant are given below.

\section{Calcination Aids}

During the first year of the grant, work focused on the evaluation of various starting materials. More than 25 aluminosilicates of all kinds were mixed with enough $12 \mathrm{M} \mathrm{NaOH}$

\footnotetext{
${ }^{1}$ Palomo, A., M.T. Blanco-Varela, M.L. Granizo, F. Puertas, T. Vazquez and M.W. Grutzeck, "Chemical Stability of Cementitious Materials Based on Metakaolin," WM'98 Proceedings March 1-5, 1998, Tucson, AZ, WM Symposia, Inc., Tucson (1998).; Palomo, A., M.W. Grutzeck and M.T. Blanco, "Alkali Activated Fly-Ashes: A Cement for the Future," Cem. Concr. Res. 29, 1323-1330 (1999).

${ }^{2}$ Grutzeck, M.W. and Siemer, D.D., "Zeolites Synthesized from Class F Fly Ash and Sodium Aluminate Slurry," J. Amer. Ceram. Soc. 무, 2449-53 (1997).
} 
solution (containing a small amount of $\mathrm{CsCl}$ ) to make a thick dough-like paste. After precuring the pastes at $90^{\circ} \mathrm{C}$ and $200^{\circ} \mathrm{C}$ in a steam autoclave, the samples were tested using a 1-day PCT test. At one day $\sim 90 \%$ of the mobile ions (in this case sodium ions) are already in solution. Conductivity was used to screen the samples. Those combinations that leached the least amount of alkali ions were selected for further study. Experiments indicated that a calcined kaolinite clay (Troy clay mined in Troy ID) was the best candidate for making the hydroceramic. This particular "metakaolinite" contained some quartz, but the hydroceramic made with it still had the best overall mechanical properties and acceptably low sodium and cesium leachability. Finer and purer types of metakaolinite such as the ones sold by the Engelhard Corporation reacted too quickly. Leachability tended to be better (lower conductivity) but reactions went to completion without the development of the needed interlocking of hydrated phases that leads to the development of strength. Additions of finely ground quartz in the form of MIN-U-SIL improved strength of the Engelhard product. Mixing Troy and Engelhard metakaolinite together also resulted in a stronger hydroceramic, but in all cases the leachability of the samples was slightly higher (more sodium ion was lost) than that obtained using pure Engelhard metakaolinite. There is an apparent trade off between ability to sequester alkali ions and strength development. An impure metakaolinite such as that mined in Troy ID that contains traces of quartz and feldspar, performs better than a very pure, almost reagent grade material. It seems that many such kaolinites should be available. Additional work is needed to identify these sources and determine their suitability to act as raw materials.

\section{Waste Simulations}

Year 2 was spent developing suitable SBW simulants, developing a method to calcine the waste simulants, and evaluating the conductivity of PCT leachates for hydroceramics made with Troy clay metakaolinite. Full chemical analyses were collected for selected samples. Two waste simulants (Cs-free Simulant 1 and Cs-containing Simulant 2) made at Penn State were based upon the chemistry of the supernate in Tank 44 at Savannah River (Table I, Column 2). The compositions given in Columns 3 and 4 of this table (Simulants 1 and 2) are based on the recipes given in Table II.

Table I. Composition of Tank 44 SBW$^{*}$ and PSU Developed Simulants (molarity)

\begin{tabular}{|l|l|l|l|}
\hline Species & Tank 44 Waste & Simulant 1 & Simulant 2 \\
\hline $\mathrm{Na}$ & 15 & 14.7 & 14.7 \\
\hline $\mathrm{K}$ & 0.16 & - & - \\
\hline $\mathrm{AlO}_{2}$ & 0.38 & 0.4 & 0.4 \\
\hline $\mathrm{OH}$ & 11.8 & 11.4 & 11.4 \\
\hline $\mathrm{NO}_{3}$ & 1.13 & 1.12 & 1.12 \\
\hline $\mathrm{NO}_{2}$ & 1.52 & 1.38 & 1.38 \\
\hline $\mathrm{Cl}$ & 0.024 & - & - \\
\hline $\mathrm{F}$ & 0.013 & - & - \\
\hline $\mathrm{PO}_{4}$ & 0.012 & - & - \\
\hline $\mathrm{SO}_{4}$ & 0.0042 & - & - \\
\hline $\mathrm{CO}$ & 0.20 & - & - \\
\hline $\mathrm{Cs}$ & $0.00012(\equiv 1.4 \mathrm{mC} / \mathrm{ml})$ & - & 0.02 \\
\hline $\mathrm{Hg}$ & $132 \mathrm{ppm}$ & - & - \\
\hline $\mathrm{Cr}$ & $450 \mathrm{ppm}$ & - & - \\
\hline
\end{tabular}


*Jantzen, personal communication.

Tank 44 waste is atypical; it is unusually high in sodium hydroxide. Sodium salts of aluminum, silica, nitrate and nitrite are only minor components of this waste. This waste would be problematic if it was to be vitrified, but, on the other hand, it is perfectly suited for making hydroceramics. In fact, because of its unusually high sodium concentration, no additional $\mathrm{NaOH}$ was needed to make a hydroceramic. Troy metakaolinite was mixed with calcined simulants and just enough DI water to make a thick paste. After precuring at $90^{\circ} \mathrm{C}$ overnight the hardened sample was autoclaved for a few days to fully develop its zeolite-like nature. Encouraged by the results obtained using Simulants 1 and 2 to make a series of exploratory hydroceramics, a third simulant was developed during Year 3 (Table III). Simulant 3 represents the "average supernate" composition for SBW now in storage in Hanford tanks ${ }^{3}$.

Table II. Recipes Used to Simulate SRL's Tank 44 Waste (wt. in grams)

\begin{tabular}{|l|l|l|}
\hline Compound & Simulant 1 & Simulant 2 \\
\hline $\mathrm{Na}_{2} \mathrm{CO}_{3}$ & 2.65 & 2.65 \\
\hline $\mathrm{NaNO}_{2}$ & 11.9 & 11.9 \\
\hline $\mathrm{NaNO}_{3}$ & 11.9 & 11.9 \\
\hline $\mathrm{NaAlO}_{2}$ & 4.04 & 4.04 \\
\hline $\mathrm{NaOH}$ & 57 & 57 \\
\hline $\mathrm{CsNO}$ & Nil & 0.583 \\
\hline $\mathrm{H}_{2} \mathrm{O}$ & 125 & 125 \\
\hline
\end{tabular}

Table III. Chemicals used to make 1 Liter of Hanford Simulant (wt. in grams).

\begin{tabular}{|l|c|}
\hline Compound & Simulant 3 \\
\hline $\mathrm{NaOH}$ & 82.682 \\
\hline $\mathrm{Al}\left(\mathrm{NO}_{3}\right)_{3} \cdot 9 \mathrm{H}_{2} \mathrm{O}$ & 133.500 \\
\hline $\mathrm{NaNO}_{2}$ & 36.911 \\
\hline $\mathrm{Na}_{2} \mathrm{CO}_{3}$ & 36.205 \\
\hline $\mathrm{NaNO}_{3}$ & 8.5812 \\
\hline $\mathrm{Na}_{2} \mathrm{HPO}_{4}$ & 27.787 \\
\hline $\mathrm{KCl}$ & 1.8323 \\
\hline $\mathrm{NaCl}$ & 2.508 \\
\hline $\mathrm{Na}_{2} \mathrm{~B}_{4} \mathrm{O}_{7} \cdot 10 \mathrm{H}_{2} \mathrm{O}$ & 0.110 \\
\hline $\mathrm{Na} \mathrm{SO}_{4}$ & 3.894 \\
\hline $\mathrm{Ni}\left(\mathrm{NO}_{3}\right)_{2} \cdot 6 \mathrm{H}_{2} \mathrm{O}$ & 0.312 \\
\hline $\mathrm{Ca}\left(\mathrm{NO}_{3}\right)_{2} \bullet 4 \mathrm{H}_{2} \mathrm{O}$ & 0.442 \\
\hline $\mathrm{Mg}\left(\mathrm{NO}_{3}\right)_{2} \bullet 6 \mathrm{H}_{2} \mathrm{O}$ & 0.034 \\
\hline
\end{tabular}

\section{Making Calcines}

Calcination drives off nitrate, nitrite and carbonate, all of which are detrimental to the zeolitization process. These anions are among the most mobile and account for the inherent

\footnotetext{
${ }^{3}$ Composition of Simulant 3 is based on a recipe in Brough, A.R., A. Katz, T. Bakharev, G-K. Sun, R.J. Kirkpatrick, L.J. Struble and J.F. Young, "Microstructural Aspects of Zeolite Formation in Alkali Activated Cements Containing High Levels of Fly Ash", in Microstructure of Cement-Based Systems/Bonding and Interfaces in Cementitious Materials, Mat. Res. Soc. Symp. Proc. Vol. 370, pp. 199-208, Materials Research Soc., Pittsburgh (1995).
} 
leachability of cement based waste forms such as Saltstone. The efficiency of the calcination process depends upon the reducing agent and temperature used. In order to convert the sodium bearing waste into oxides, one would normally have to calcine the liquid waste at $\sim 500^{\circ} \mathrm{C}$ or higher in order to drive off the $\mathrm{NaNO}_{3}$. The process is relatively straight forward, but without something to react with, the newly formed sodium oxide combines with carbon dioxide present in the air to form sodium carbonate. To prevent carbonation, calcination would have to take place at $\sim 1000^{\circ} \mathrm{C}$. Unfortunately this tends to increase the particle size and crystallinity of the product making it harder to use in subsequent reactions. It essentially becomes "dead burnt" and loses a significant amount of its reactivity. A series of tests were conducted in which varying amounts of sucrose was added to the liquid simulants prior to calcination. Testing suggested that an 8:1 ratio of waste to sucrose and $525^{\circ} \mathrm{C}$ was more or less optimal - carbon was burnt off and nitrates/nitrites were decomposed but reactivity was retained. Sucrose is an inexpensive hydrocarbon. It dissolves in the SBW and during calcination helps to catalyze the decomposition process. The mixture is well suited for use in a spray calciner. However, carbonation becomes even more of an issue. A means of avoiding carbonation was developed as follows. It was hypothesized that the newly formed $\mathrm{Na}_{2} \mathrm{O}$ was reactive and if it had something to combine with other than $\mathrm{CO}_{2}$, it might just do so. Therefore, Simulant 1 and 2 were combined with additional alumina and/or silica sources, i.e. calcination aids before being calcined. Adding the materials listed below to the liquid simulants tended to turn them into thick pastes. Calcining them would now require a rotary kiln, but the calcination process would still work. A total of six Calcines were produced from each simulant. Their compositions are as follows:

Calcine 1) $20 \mathrm{~g}$ raw waste liquid (control sample)

Calcine 2) $20 \mathrm{~g}$ raw waste liquid $+2.5 \mathrm{~g}$ sucrose (control sample)

Calcine 3) $20 \mathrm{~g}$ raw waste liquid $+2.5 \mathrm{~g}$ sucrose $+11.9 \mathrm{~g}$ boehmite

Calcine 4) $20 \mathrm{~g}$ raw waste liquid $+2.5 \mathrm{~g}$ sucrose $+11.9 \mathrm{~g} 5 \mu \mathrm{m} \mathrm{SiO}{ }_{2}(\mathrm{MIN}-\mathrm{U}-\mathrm{SIL})$

Calcine 5) $20 \mathrm{~g}$ raw waste liquid $+2.5 \mathrm{~g}$ sucrose $+11.9 \mathrm{~g}$ metakaolinite

Calcine 6) $20 \mathrm{~g}$ raw waste liquid $+2.2 \mathrm{~g}$ aluminum powder

Calcine 1 and 2 were made from the liquid simulants. Enough solid material was added to Calcines 3-5 to convert the liquid SBW into thick pastes. Calcine 6 was tested because it offered an alternate to thermal calcination. Simulants 1 and 2 contained $\sim 7 \mathrm{~mol} / \mathrm{L}$ of sodium hydroxide $(\mathrm{NaOH})$. If finely divided aluminum metal is added to a highly caustic solution at room temperature (no sucrose, no additives) the nitrates/nitrites present can be reduced producing ammonia gas. The additional aluminum content of the waste is actually beneficial since aluminum ion is needed to produce zeolites and SBW normally does not contain much aluminum.

Calcines 1 through 5 were dried at $90^{\circ} \mathrm{C}$ for 24 hours (to remove most of the water) and then calcined at $525^{\circ} \mathrm{C}$ for 18 hours. The addition of alumina and/or silica to Calcines $3-5$ gave the sodium oxide something other than $\mathrm{CO}_{2}$ to react with; rudimentary aluminosilicate phases tended to form instead of $\mathrm{Na}_{2} \mathrm{CO}_{3}$. In addition, Calcine 6 was "cold de-nitrated" by adding aluminum powder to the caustic rich solution containing nitrate/nitrite salts. After the reaction was complete, Calcine 6 was dried at $90^{\circ} \mathrm{C}$ for 24 hours.

Each of the 6 calcines for both simulants was ground to pass a 150-micron sieve. The portion retained on 74-micron sieve was used for the conductivity test. One gram of each calcine was placed in $10 \mathrm{ml} \mathrm{DI}$ water at $90^{\circ} \mathrm{C}$ for 24 hours. Sodium is normally the most mobile element; 
thus conductivity tests were used to rank hydroceramic performance in terms of amount sodium leached. Solutions were filtered through 0.45 -micron syringe filters and tested using a 1 cc YSI probe and conductivity meter. Conductivity values for Calcines 1-6 made with Simulant 1 are given in Figure 1. Representative analyses of the treated waste Calcines are given in Table IV. Nitrate/nitrite concentrations in leachates (made by boiling) Calcine powders in $\mathrm{NaOH}$ solution were determined using IC analysis. Sodium and aluminum concentrations were determined by fusing the Calcines with lithium metaborate and then dissolving them in $\mathrm{HCl}$ solution followed by ICPAES analysis. It is notable that the thermal calcination process has essentially converted all of the nitrate/nitrite in the raw solution into oxides and carbonates as the sucrose is burnt off.

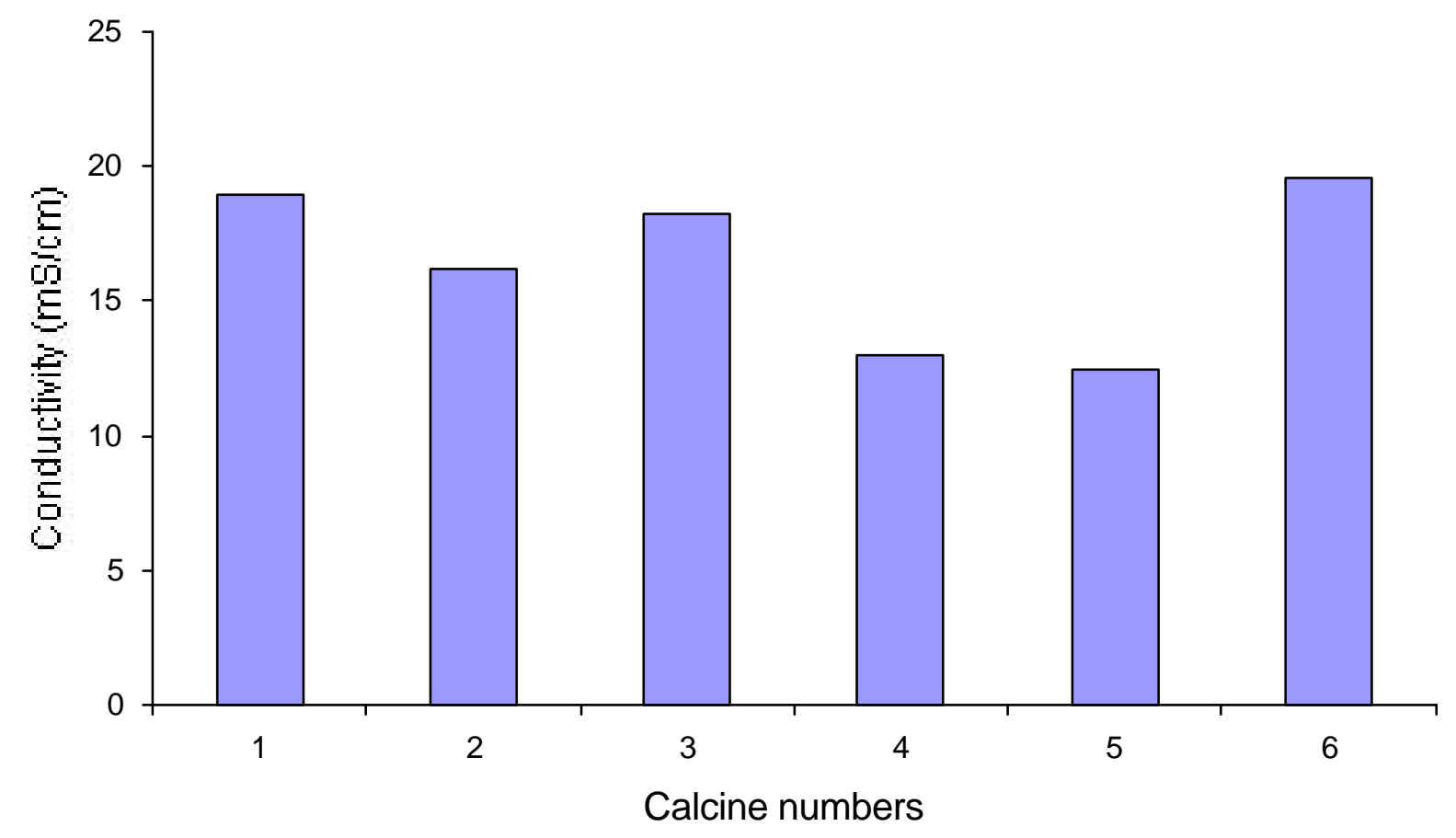

Figure 1. Leach test results of Calcines 1 through 6 derived from Simulant 1.

Table IV. Representative Chemical Analyses of Waste Calcines formulated using Simulant 1.

\begin{tabular}{|l|c|c|c|c|c|c|}
\hline Wt.\% present & $\begin{array}{l}\# 1 \text { raw } \\
\text { solution no } \\
\text { calcination }\end{array}$ & $\begin{array}{l}\text { \#2 sucrose } \\
\text { only }\end{array}$ & $\begin{array}{l}\# 3 \text { with } \\
\text { sucrose }+ \\
\text { boehmite }\end{array}$ & $\begin{array}{l}\text { \#4 with } \\
\text { sucrose }+ \\
5 \mathrm{~m} \mu \text { quartz }\end{array}$ & $\begin{array}{l}\text { \#5 with } \\
\text { sucrose }+ \\
\text { metakaolinite }\end{array}$ & $\begin{array}{l}\text { \#6 cold - Al } \\
\text { powder }\end{array}$ \\
\hline $\mathrm{NO}_{3}$ (IC) & 4.5 & $<0.1$ & $<0.1$ & $<0.1$ & $<0.1$ & 1.5 \\
\hline $\mathrm{NO}_{2}$ (IC) & 4.8 & 0.45 & 0.13 & $<0.05$ & 0.08 & 2.3 \\
\hline $\mathrm{CO}_{3}$ & 0.83 & 43 & 9 & 15.3 & 8.0 & $\sim 0.4$ \\
\hline $\mathrm{Na}$ (ICPAES) & 25.4 & 41 & 27.4 & 22.5 & 20.0 & 35.6 \\
\hline $\mathrm{Al}$ (ICPAES) & 0.8 & 1.7 & 30.2 & 0.64 & 12.1 & 14.4 \\
\hline
\end{tabular}

Carbonate is higher than one might want in the calcines due to the carbonation of the newly formed sodium oxide. This cannot be helped, but one does get less carbonate when other substances are added to the raw waste/sucrose mixture during the calcination process (e.g. 
Calcines 3-5). There is an indication that residual sodium nitrate/nitrite and/or sodium aluminate is contributing to the high conductivities noted for Calcines 1-3 and 6. In those samples containing metakaolinite and silica, conductivities are lower presumably due to the formation of tectosilicates during the calcination process. Calcine 6 contained significantly more nitrate/nitrite due in part to the fact that more than the listed stoichiometric amount of aluminum is needed to complete the process. This particular Calcine was included in order to illustrate the feasibility of using chemical calcination as an alternate means of achieving similar ends without the cost of having to construct a rotary or shaft kiln. All calcines have variable sodium and aluminum concentrations due to the denitration/carbonation and change in bulk composition due to the calcination aids. Based upon the data in Table IV, it was decided to focus on the metakaolinitecontaining Calcine 5, because it contained the smallest amount of carbonate. Using this as a guide, it was decided to calcine Simulant 3 (Hanford simulant) in the same way (i.e. with sucrose and metakaolinite at $525^{\circ} \mathrm{C}$ ). Preliminary results showed that the hydroceramics made with Hanford Calcines performed very much like their Savannah River counterparts.

If DOE were to choose hydroceramics as a waste form, DOE would be forced to pretreat their SBW. Although the advantages of such pretreatment may not be intuitively obvious, the disadvantages certainly are. First, DOE would be required to build/refurbish a calcination facility at Savannah River and Hanford. This would be costly, but less so than a vitrification facility. Second, calcination of nitrate waste mixed with sucrose could be explosive. This second issue is an emotional one, which, as pointed out in the next paragraph, is not a problem at all.

The recipe given earlier for Calcine 5 contains (by weight) $58 \%$ SBW, $7 \%$ sucrose and $35 \%$ metakaolinite. This formulation was chosen based on the premise that the aluminosilicate content of the metakaolinite would be adequate to provide roughly one aluminum ion for each sodium ion in the SBW and also enough silica to begin to assemble tectosilicate networks in the resulting calcine. Once the liquid SBW is mixed with the listed calcination aids, the product becomes thick, almost dough-like in consistency. If this mixture were to be fed into a rotary kiln the temperature would rise slowly as the mixture moves through the kiln. The reduction of the nitrate/nitrite would take place gradually and the heat given off by the process would aid the thermal efficiency of the process. There are no uncontrolled reactions. The calcines produced at Penn State were batch fired in a muffle furnace. No problems were observed at any time.

Advantages of pretreatment are numerous. First, SBW compositions vary from tank to tank. An analysis is necessary. Tank 44 has enough sodium and needs little augmentation to make a successful hydroceramic. However, the average Hanford waste is relatively low in sodium. In this instance wastewater from sludge washing operations could be used to increase the sodium content. In other words, waste streams could be blended to optimize the composition of the SBW being calcined. This a tremendous advantage in as much as the formulation being calcined on a day to day basis would not have to change; feed stock could be maintained at certain compositions making the process easier to QA. The calcination process is an integral part of the proposed technology. Work is needed to optimize the heat treatment and additive regimen in order to reduce leachability of $\mathrm{Cs}, \mathrm{Sr}, \mathrm{Tc}$ and $\mathrm{Np}$, a goal of our ongoing work.

\section{Making Hydroceramics}

A hydroceramic waste form is made from a given calcine (e.g. Calcine 5 made from Simulant 1) by mixing it with additional metakaolinite and water $(\mathrm{NaOH}$ solution can be used if calcine is low in $\mathrm{Na}_{2} \mathrm{O}$ ). The selection of metakaolinite rather than a Class $\mathrm{F}$ fly ash, which also works, was made based upon the fact that metakaolinite has a more consistent composition and 
as such is easier to QA. The mixing produces a thick dough-like material that can be kneaded until it is homogeneous. The consistency of the mixture is such that it could be extruded into 55gallon drums. Once in a container, the mixture can be precured at $90^{\circ} \mathrm{C}$ for 24 hours and then heated/autoclaved at $90^{\circ}-200^{\circ} \mathrm{C}$ for various periods of time. Hydroceramics are unique waste forms. They are strong, vitreous in appearance, and have low leachabilities. They have a tectosilicate network structure similar to glass except that their structure is less random; hydroceramics contain rudimentary zeolite and feldspathoid precursors. Due to the structural "trapping" of alkali and alkaline earth ions in aluminosilicate cavities in these structures, sodium tends to remain in place rather than leach out of the structure. It is there to balance the charge mismatch that occurs when a silicon atom is replaced by an aluminum atom in a four coordinated silicate site. When compared to the performance of a glass waste form such as DOE's benchmark EA Glass, hydroceramics perform as well as the glass in terms of their ability to contain sodium, but the loss mechanism is different. In a glass, the surface simply dissolves. Sodium comes off first, the surface becomes hydroxylated and soon dissolution becomes diffusion controlled. Hydroceramics are zeolitic and the sodium that is lost is lost as a result of cation exchange. The solubility of tectosilicates is much lower than glass. The structure does not dissolve; rather structural sodium is replaced by smaller more highly charged cations present in solution. Cation exchange is a built in protective mechanism. Given a flooded repository scenario, the waste form would tend to give up sodium as it adsorbed cesium, strontium and heavy metal ions from the surrounding solution presumably preventing their movement out of the repository environment.

In order to make a hydroceramic, calcine must be mixed with metakaolinite and water. The effect of adding metakaolinite to the 6 Calcines described above was studied by making hydroceramics from both Simulants 1 and 2 as per Table $\mathrm{V}$ recipes and then measuring their leachability. Variables included the amount of metakaolinte added as well as other ingredients (vermiculite and additional $\mathrm{NaOH}$ ). 70 and $80 \mathrm{wt} \%$ of metakaolinite was added to each of the calcines ${ }^{4}$ and enough water was added to make a stiff past. This resulted in 12 samples for both Simulants 1 and 2. The mixes were placed in Parr bombs at $90^{\circ} \mathrm{C}$ for a period of 24 hours followed by $18-24$ hours of autoclaving at $115^{\circ} \mathrm{C}$. Once cool, samples were tested using a oneday PCT test as described earlier. Rankings were based on conductivity. In addition, a secondgeneration hydroceramic was made using some of INEEL's calcines and a small amount of vermiculite to further control cesium leachability.

Table V. Recipes for PSU and Second Generation Siemer Hydroceramics

\begin{tabular}{|l|l|l|l|}
\hline Ingredient (grams) & \multicolumn{2}{|l|}{ Penn State's Hydroceramic } & Siemer's Hydroceramic \\
\hline Calcine Percentage & $20 \%$ & $30 \%$ & $33 \%$ \\
\hline Calcine & $5 \mathrm{~g}$ & $5 \mathrm{~g}$ & $5 \mathrm{~g}$ \\
\hline Metakaolinite & $20 \mathrm{~g}$ & $11.67 \mathrm{~g}$ & $9.15 \mathrm{~g}$ \\
\hline Vermiculite & -- & -- & $0.85 \mathrm{~g}$ \\
\hline $37.5 \% \mathrm{NaOH}$ solution & -- & -- & $1.09 \mathrm{~g}$ \\
\hline $\mathrm{H}_{2} \mathrm{O}$ & Sufficient to... & Sufficient to ... & Sufficient to ... \\
\hline
\end{tabular}

\footnotetext{
${ }^{4}$ These are not waste loadings because the amount of waste in each calcine is dependent upon how much aluminosilicate, alumina or silica was added prior to calcination. Waste loadings are $~ 7$ and $10 \mathrm{wt} \%$.
} 
Results of Leach Testing of Hydroceramics

PCT leach data for the 6 Hydroceramics made from Simulant 1 Calcines 1-6 are given in Figure 2. Whereas all Figure 1 Calcines were relatively soluble, adding additional metakaolinite to the calcines during the hydroceramic making process reduced their solubilities. For example, Calcine 5 had the lowest conductivity of all the Calcines in Figure 1. Note too that autoclaving Calcine 5 with extra metakaolinite (Fig. 2) provided more than a 50\% reduction in leachability. Calcine5 had a conductivity of $\sim 13 \mathrm{mS} / \mathrm{cm}$ and its equivalent hydroceramic had a conductivity in the range of $3-6 \mathrm{mS} / \mathrm{cm}$. In fact all hydroceramics performed better than their respective calcines. It is also notable that the hydroceramic made with the cold calcined SBW performed relatively well when mixed with metakaolinite. If these are acceptable leach levels, a hydroceramic could be produced without hot calcination; no calciner would be needed.

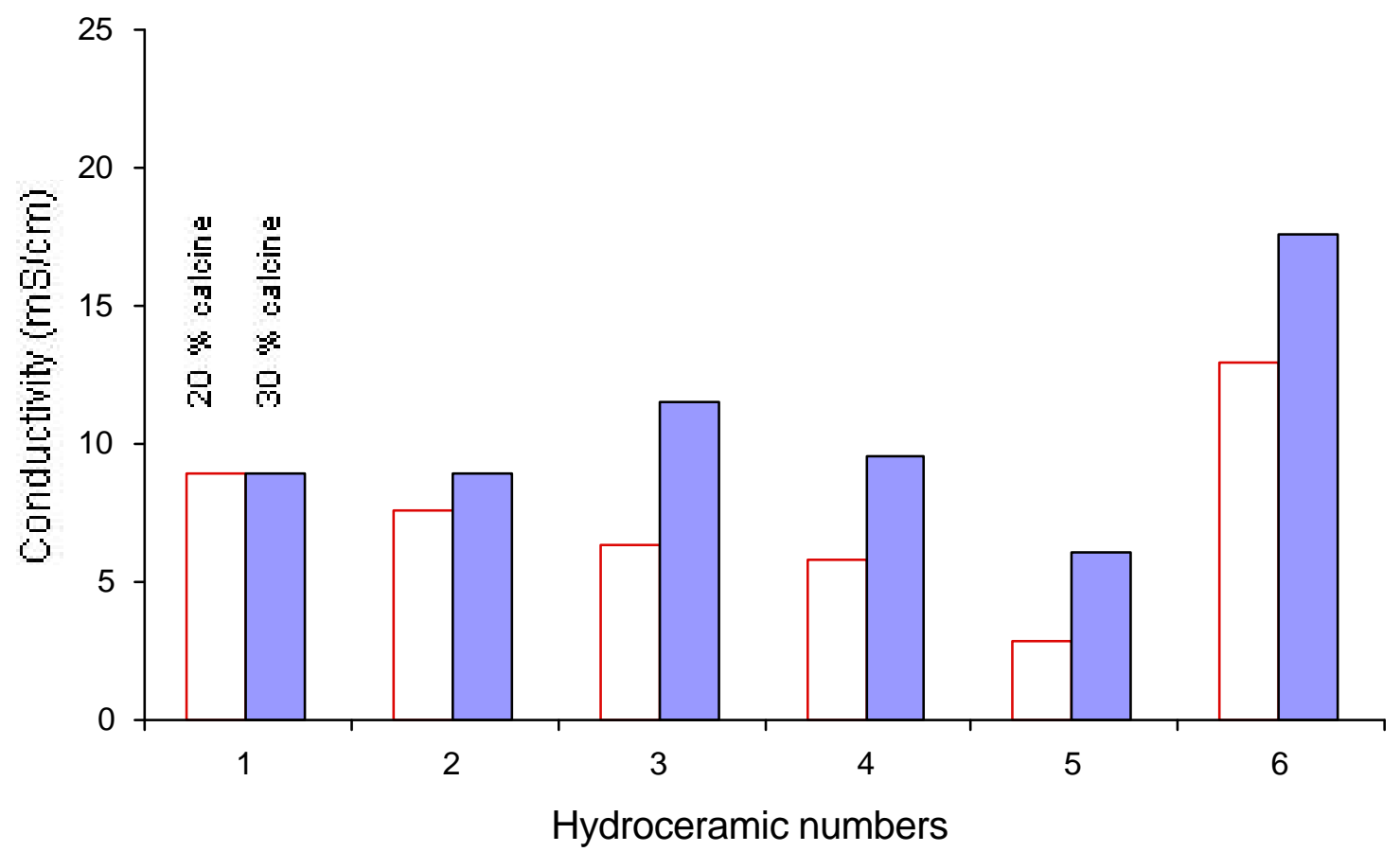

Figure 2. Leach results of hydroceramics made with $20-w t \%$ and $30-w t \%$ Calcine 1-6 derived from Simulant 1 mixed with $70 \mathrm{wt} \%$ or $80 \mathrm{wt} \%$ extra metakaolinite. Samples were precured at $90^{\circ} \mathrm{C}$ and then autoclaved cured for 24 hours at $115^{\circ} \mathrm{C}$

Calcines made with Simulant 2 (containing Cs) were also combined with metakaolinite as described above. The conductivity of the leachates was somewhat higher, especially at $30 \mathrm{wt} \%$ waste loading, presumably due to the presence of the highly mobile cesium. See Figure 3. PSU's 20 and $30 \mathrm{wt} \%$ hydroceramics perform well, but Siemer's 33wt\% sample containing vermiculite and extra $\mathrm{NaOH}$ performed significantly better. This is related to the fact that Siemer's composition was different than PSU's. Siemer used existing insoluble/low sodium INEL calcine and mixed it with concentrated $\mathrm{NaOH}$ solution and vermiculite, to tie up cesium. Siemer had also found that adding finely ground vermiculite and extra caustic to the same series of hydroceramic waste forms was beneficial (see recipes in Table V). The extra caustic helps to dissolve the 
oxides while the vermiculite sequesters the cesium. Data is included solely as an example of how hydroceramic performance can be improved by small additions of specialized materials.

Having demonstrated the long term leachability of hydroceramics made with Simulants 1 and 2 based on Savannah River SBW, work then focused on the evaluation of a third simulant, this one representing the average composition of SBW in storage at Hanford. After undergoing a

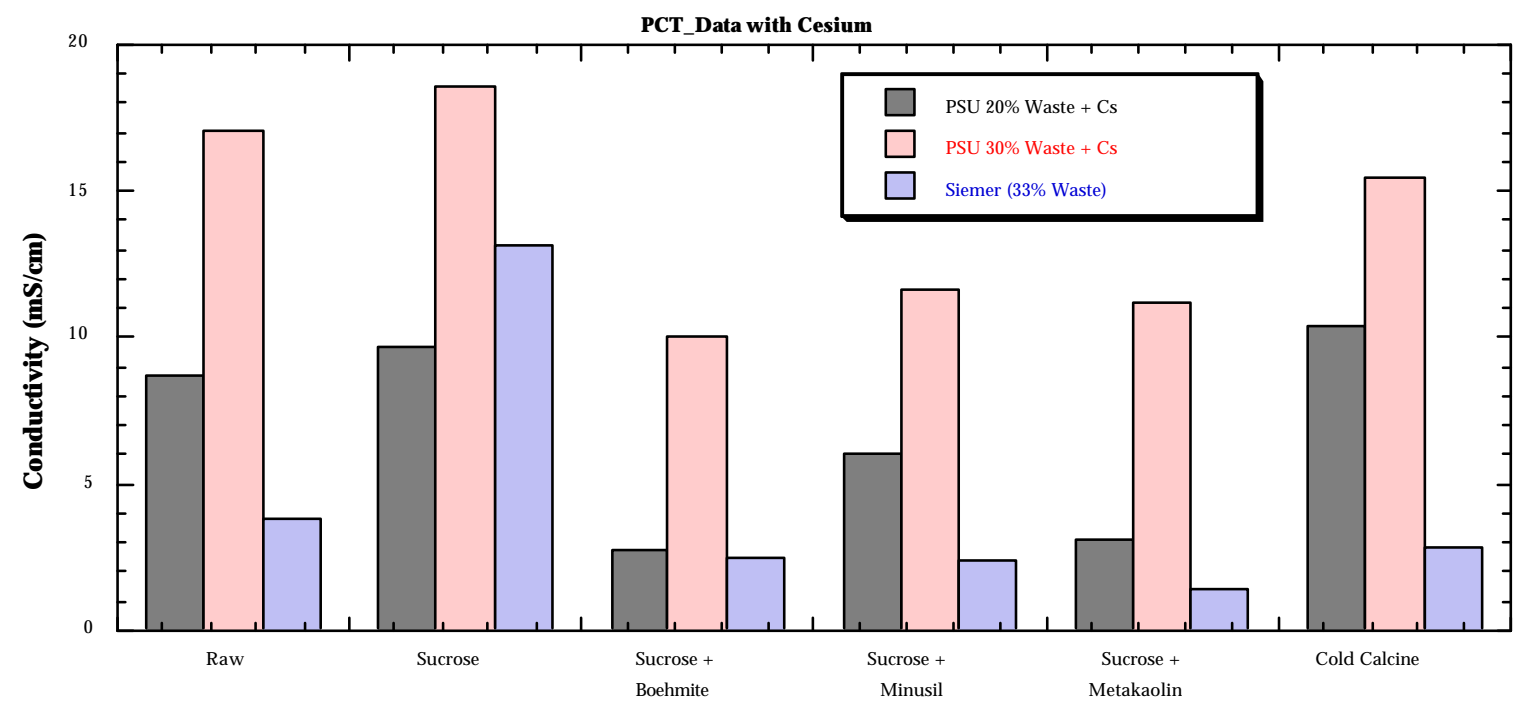

Figure 3. Comparison of leach data for 6 Calcines made from Simulant 2 (containing cesium). Columns 1 and 2 show the effect of waste loading. Column 3 charts the performance of Siemer's hydroceramic.

similar procedure for calcination and curing $\left(90^{\circ} \mathrm{C}\right.$ precure and $115^{\circ} \mathrm{C}$ autoclaving), the Hanford hydroceramics were also subjected to a 1-day PCT leach. The Hanford hydroceramics had unexpectedly lower leachabilities than their Tank 44 counterparts discussed earlier. See Figure 4. Leachabilities are about an order of magnitude less than Hydroceramics made with Simulants 1 and 2 . 


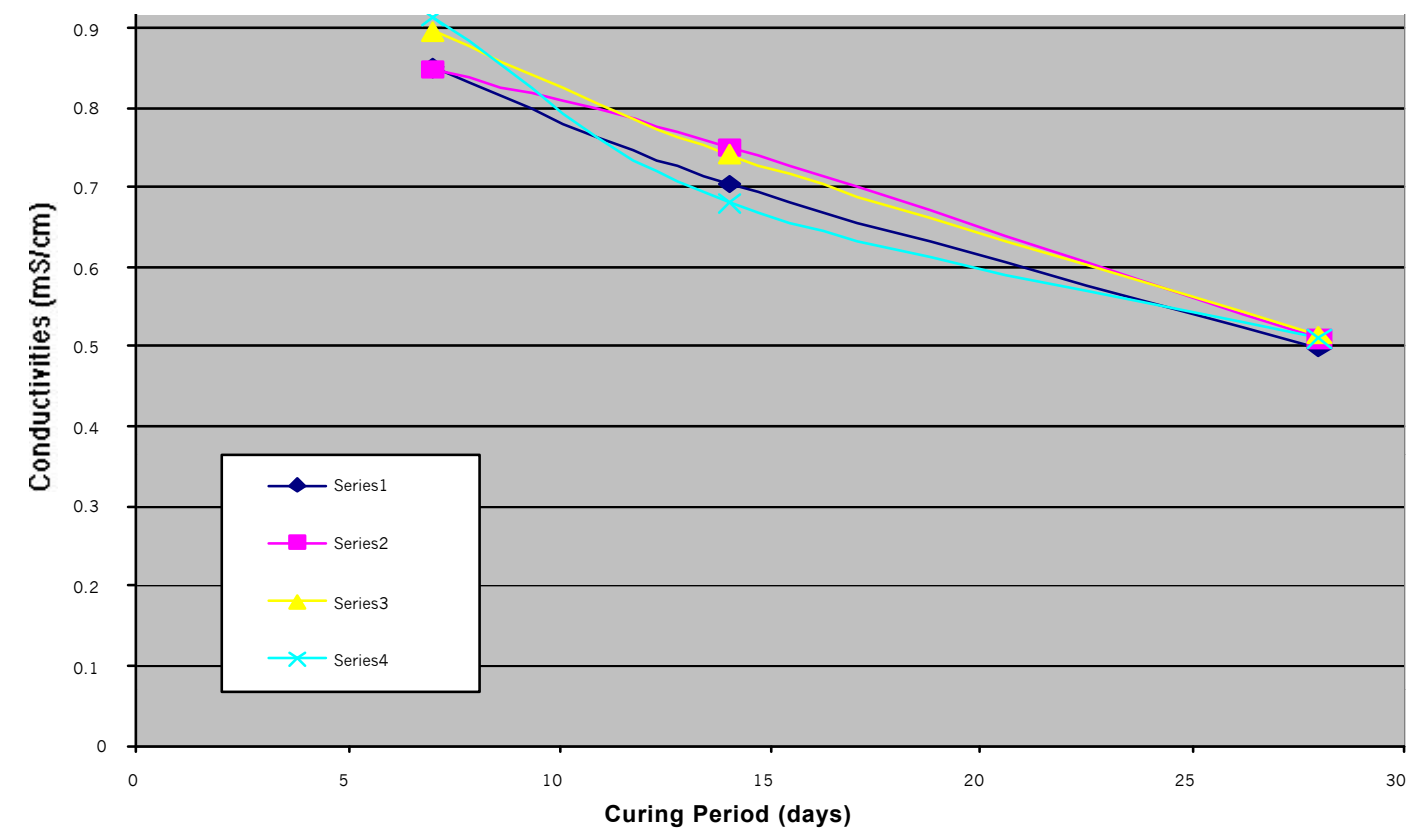

Figure 4. Leach test results of Hydroceramics made with 60\% Hanford Calcine 5 and 40\% Troy metakaolinite cured at $115^{\circ} \mathrm{C}$ after precuring for 24 hours at $90^{\circ} \mathrm{C}$. Duplicates have little scatter. Effect of Temperature and Metakaolinite Source on Performance of Hydroceramic

Up to this point, all data were obtained from hydroceramics cured at $115^{\circ} \mathrm{C}$. In as much as there were suggestions that curing at $90^{\circ} \mathrm{C}$ could provide similar leach characteristics, a series of hydroceramics were cured at $90^{\circ} \mathrm{C}$. Furthermore, the effect of metakaolinite source was tested by making the samples with both Troy and Engelhard metakaolinite. Metakaolinites were mixed with Simulants 1-3 and water and allowed to cure at $90^{\circ} \mathrm{C}$ for varying periods of time. Leach data are given in Figure 5. It is notable that the Engelhard product gave significantly better numbers than the Troy metakaolinite. The Engelhard material is made from very pure kaolinite from Georgia, whereas artists use Troy clay mined in Idaho to make pottery. The latter clay contains quartz and feldspar whereas the Engelhard material does not. Normally the Engelhard hydroceramic lacks strength, a drawback if waste forms must have a minimum strength. 


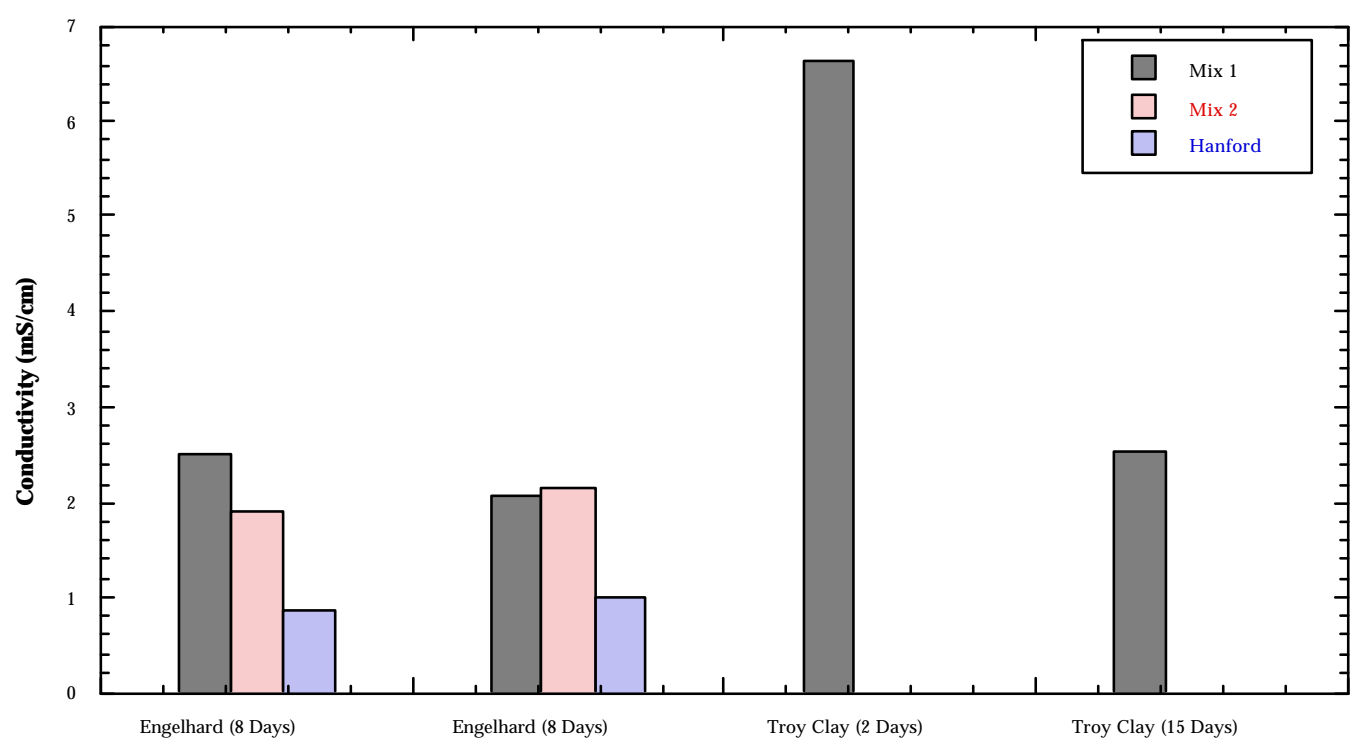

Figure 5. Modified PCT leach data for a series of hydroceramic waste forms created from $60 \%$ Hanford calcine and $40 \%$ Troy clay or Engelhard metakaolinite and cured at $90^{\circ} \mathrm{C}$ for various times. It is notable that the leachabilities obtained with longer curing begin to approach those achieved at $115^{\circ} \mathrm{C}$ reported in earlier figures.

X-ray Diffraction Results

The 12 hydroceramic waste forms depicted in Figures 2 and 3 were analyzed using a Scintag X-ray diffractometer. Patterns are given in Figures 6 and 7. The hydroceramics made with Calcine 1 and 2 contain small amounts of nitrate and carbonate. All samples contain quartz. Samples made with Calcines 3-5 contain traces of analcime and hydroxysodalite, which may account for their lower leachabilities. The pattern for a hydroceramic made with Hanford Simulant $3(60 \mathrm{wt} \%)$ and $40 \mathrm{wt} \%$ metakaolinite and cured for 7 days at $90^{\circ} \mathrm{C}$ is given in Figure 8 . Hydroxysodalite peaks dominate the pattern. It is concluded that phase development is reasonably independent of curing temperature. As a result, it now seems possible that all mixing and curing could take place at temperatures below the boiling point of water. Curing could be in a sealed canister in a warm insulated room kept at $90^{\circ} \mathrm{C}$. Time is not a factor. Actual curing prior to movement and storage could amount to tens of years. By this time, phase development will be complete and any benefit gained from autoclaving has lost its initial significance. 


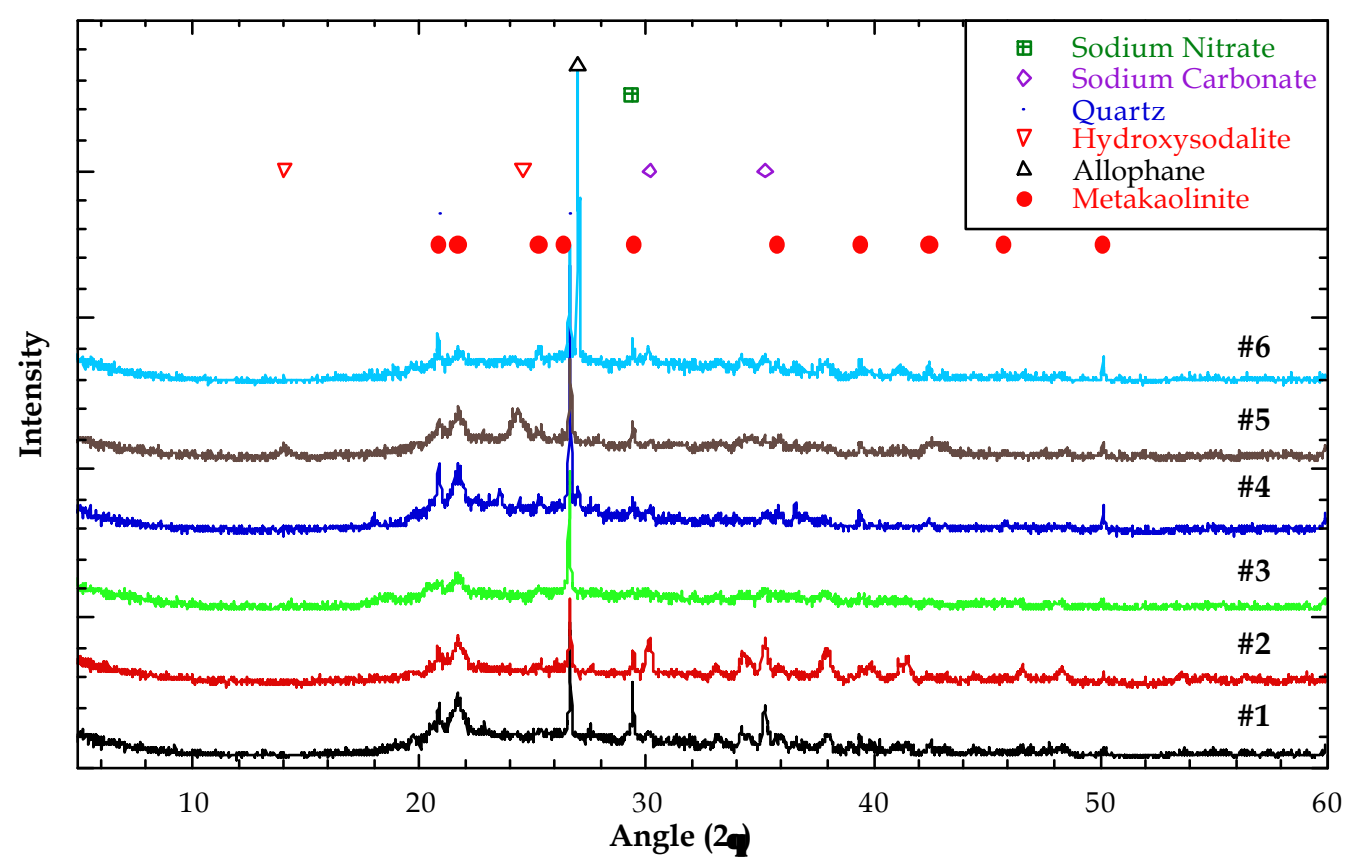

Figure 6. X-ray diffraction patterns for $20 \mathrm{wt} \%$ Calcines 1-6 mixed with $80 \mathrm{wt} \%$ Troy clay metakaolinite and water. Samples were pre-cured at $90^{\circ} \mathrm{C}$ for 24 hours and then autoclaved at $r$ an additional 24 hours.

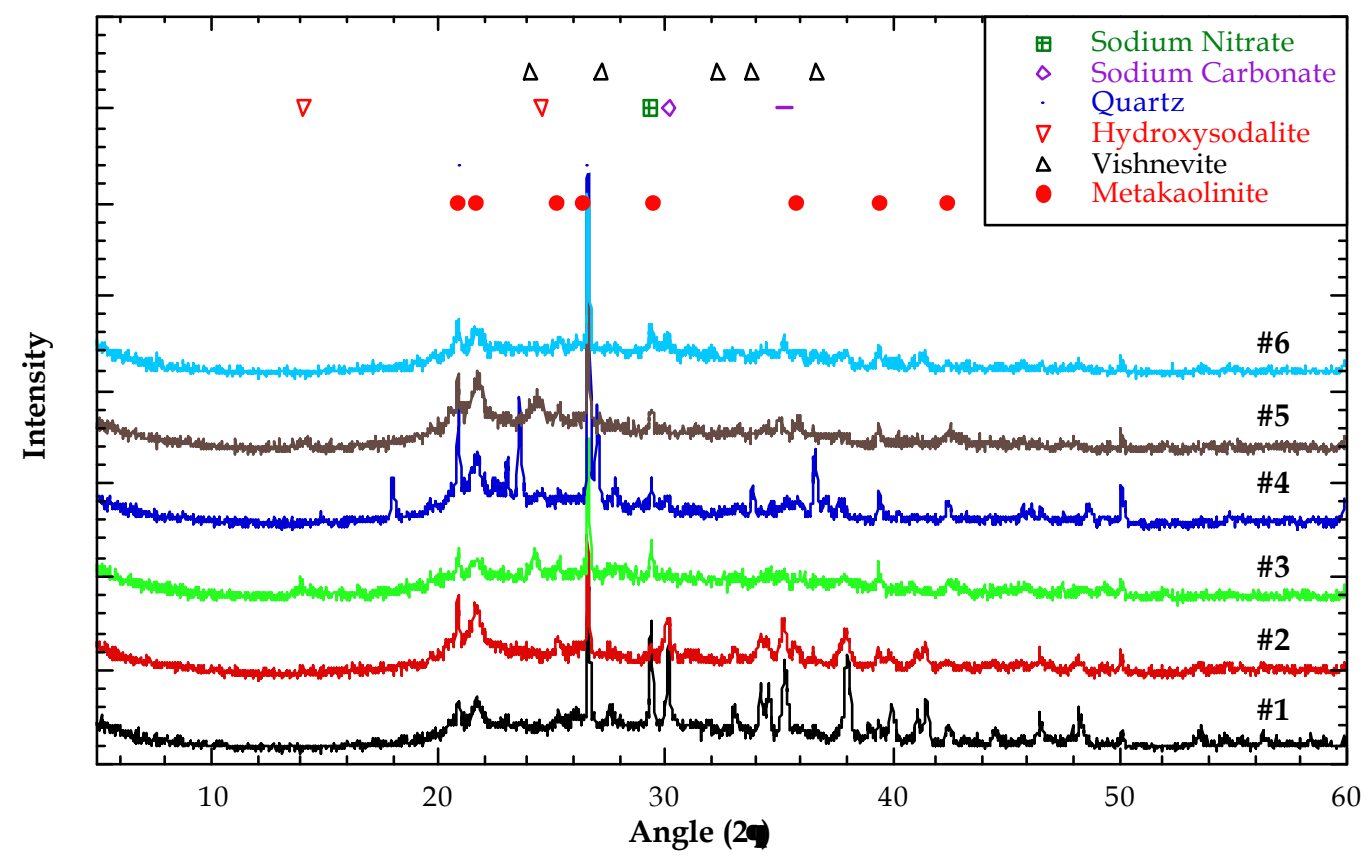

Figure 7. X-ray diffraction patterns for $30 \mathrm{wt} \%$ Calcines 1-6 mixed with $70 \mathrm{wt} \%$ Troy clay metakaolinite and water. Samples were pre-cured at $90^{\circ} \mathrm{C}$ for 24 hours and then autoclaved at $115^{\circ} \mathrm{C}$ for an additional 24 hours. 


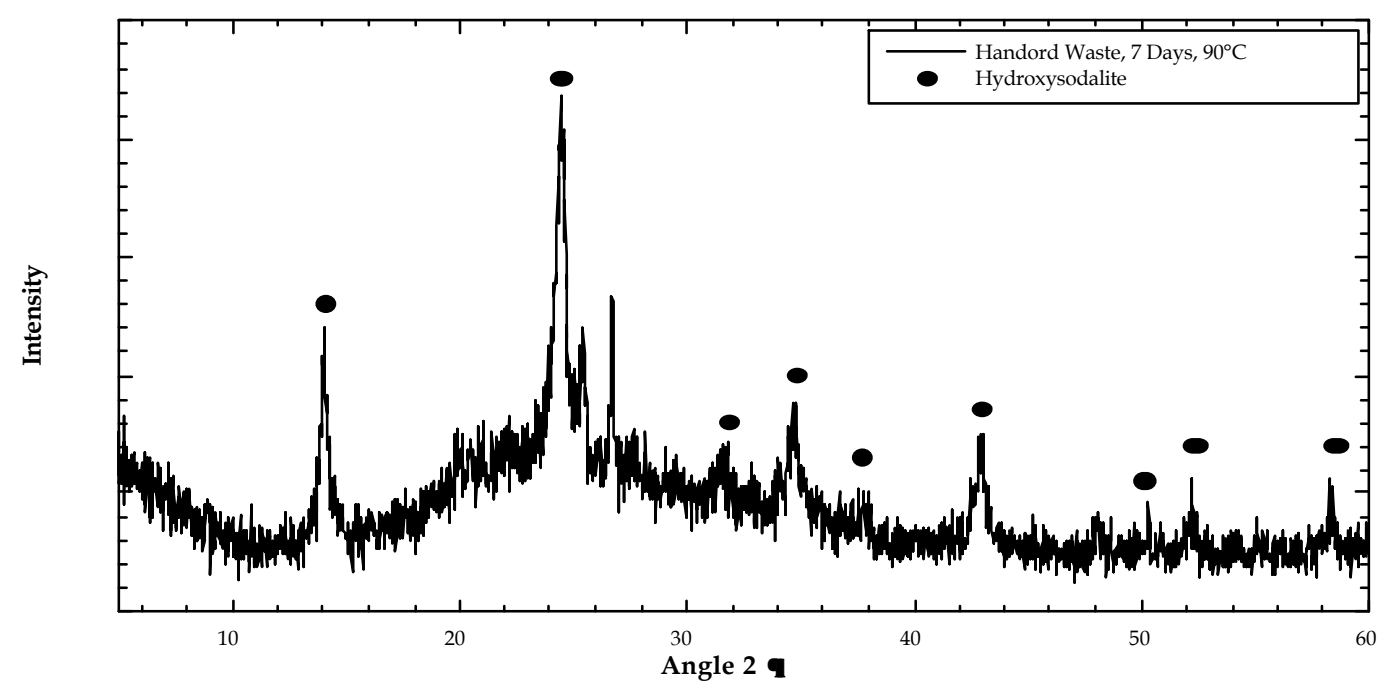

Figure 8. X-ray diffraction patterns for $60 \mathrm{wt} \%$ Hanford calcine (Simulant 3) prepared using Hydroceramic method 5 (metakaolinite was added as a calcination aid) mixed with 40 wt $\%$ metakaolinite and water. Sample was cured at $90^{\circ} \mathrm{C}$ for 7 days.

SEM Results

Micrographs were obtained for each of the hydroceramics. Microstructure was normally rather indistinct. The hydroceramic containing the raw calcine had a massive habit with just a hint of a built-up plate-like structure. Hydroceramic 5, the hydroceramic with the lowest leachability that was formulated with Troy clay metakaolinite, had the best development of microstructure. It contained spherical features suggesting the normal morphology of analcime/hydroxysodalite, which could well be precursor structures. See Figure 9a. Morphology is composed of rounded particles that could be precursor structures for hydroxysodalite detected in the X-ray diffraction patterns. Figure $9 \mathrm{~b}$ represents the microstructure of a hydroceramic made from Hanford Calcine 5 and Engelhard metakaolinite. In addition to the regular rounded shapes of hydroxysodalite, the microstructure is also decidedly plate-like.

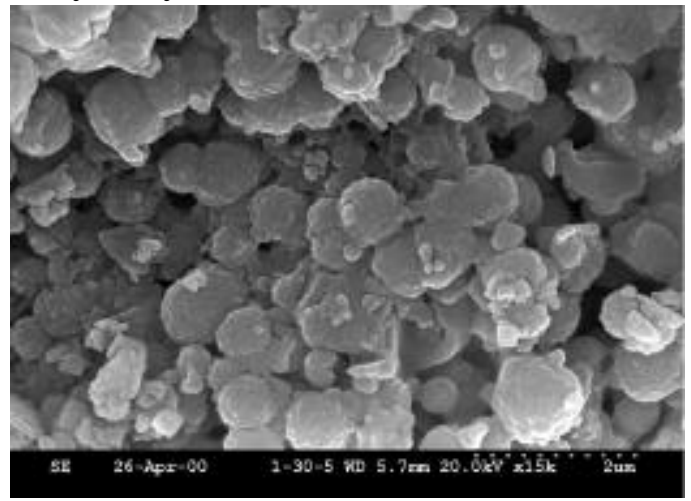

(a)

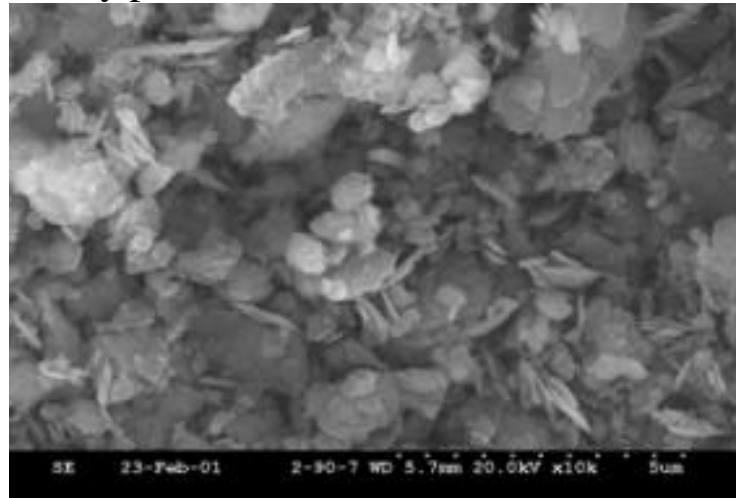

(b)

Figure 9a and b. View (a) represents a SEM micrograph of Hydroceramic 5 made with Simulant 5 (calcined with sucrose and metakaolinite) that was then mixed with $70 \mathrm{wt} \%$ metakaolinite and water, precured at $90^{\circ} \mathrm{C}$ and then autoclaved at $115^{\circ} \mathrm{C}$. In contrast, View (b) represents the structure of a Hanford Hydroceramic made with $60 \mathrm{wt} \%$ Calcine 5 and $40 \mathrm{wt} \%$ Engelhard metakaolinite and cured for 8 days at $90^{\circ} \mathrm{C}$. The microstructure is significantly more "platy". 


\section{Compressive Strength Tests}

Compressive strength tests were conducted on well-cured hydroceramics as illustrated below (Fig. 10). The graph exhibits the admirably high compressive strengths for hydroceramics made with Troy metakaolinite. Duplicate samples made with Engelhard metakaolinite did not develop strength. DOE stipulates that radioactive waste forms must possess a compressive strength of at least 60-psi. Clearly Troy metakaolinite based hydroceramics fulfill that criterion.

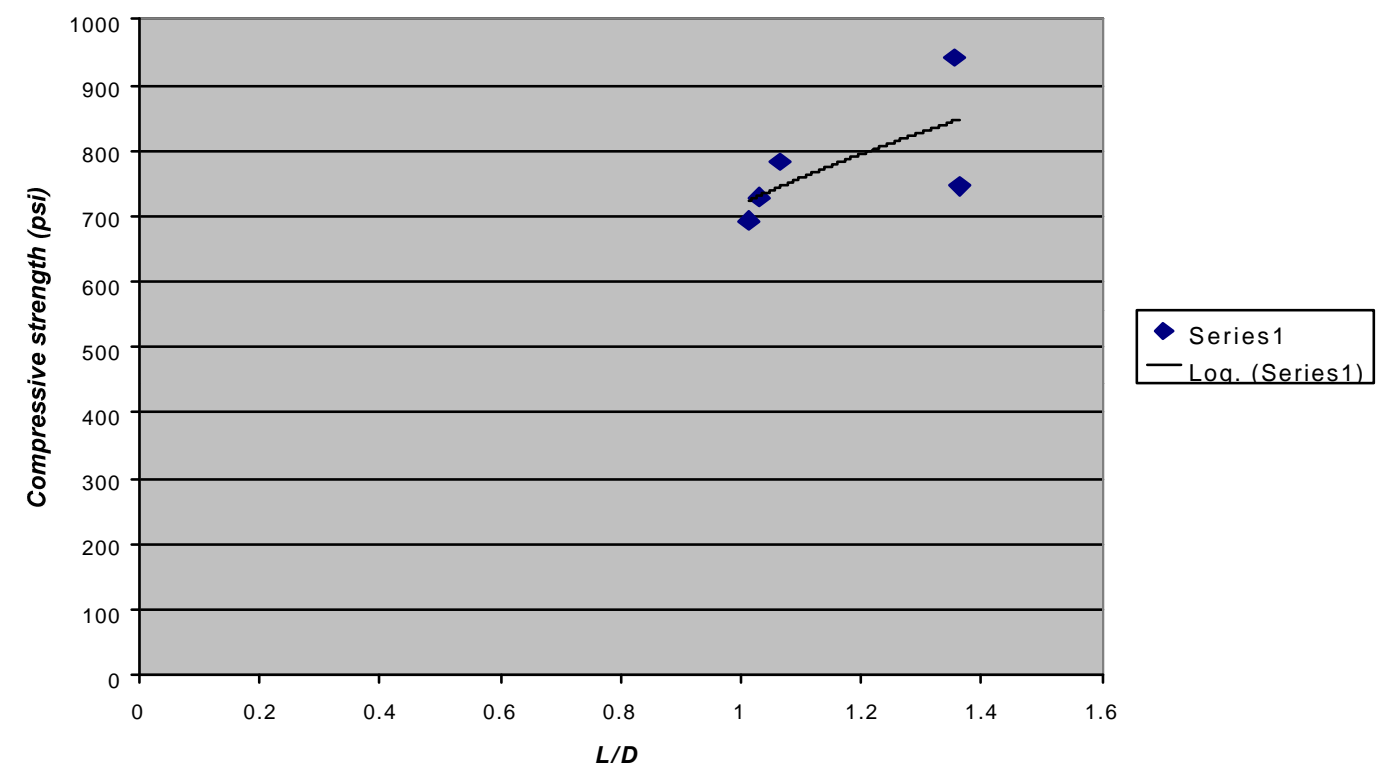

Figure 10. Comparison of aspect ratio (length to diameter ratio of cylindrical pellets) with compressive strengths of hydroceramics made from 60\% Simulant 1(Calcine 5) and 40\% additional Troy clay metakaolinite samples cured at $115^{\circ} \mathrm{C}$ for 7 days.

\section{Optimum Waste Loading}

Optimum waste loading was determined by carrying out a study wherein hydroceramics were formulated containing increasingly larger amount of Calcine 5 made from Simulant 1 . The samples were cured at $90^{\circ}$ and $115^{\circ} \mathrm{C}$ for 1 day after which they were ground to pass a $45 \mu \mathrm{m}$ sieve and subjected to a one day PCT test. The data are given in Figure 11. As suggested earlier, the leachability of the autoclave cured sample $\left(115^{\circ} \mathrm{C}\right)$ is lower th

approximately $1 / 3$ that of the $90^{\circ} \mathrm{C}$ sample. Interestingly enough there is a distinct "break point" for the curves at $70 \mathrm{wt} \%$ Calcine 5 added, which occurs at about the same place for each curing temperature. The curve rises rapidly after reaching $70 \mathrm{wt} \%$ as samples approach $100 \%$ Calcine 5 . Also, sodalite (the target composition for hydroceramics) has a chemical composition that places it close to the $70 \mathrm{wt} \%$ Calcine 5 point along a line joining the composition of Calcine 5 and metakaolinite in the phase diagram for the system $\mathrm{Na}_{2} \mathrm{O}-\mathrm{Al}_{2} \mathrm{O}_{3}-\mathrm{SiO}_{2}$. Note however that the calcine already contains some metakaolinte, so the actual waste loading is more like $30 \mathrm{wt} \%$ solid SBW. To err on the side of caution, a maximum waste loading of $60 \mathrm{wt} \%$ extra metakaolinite is recommended. 


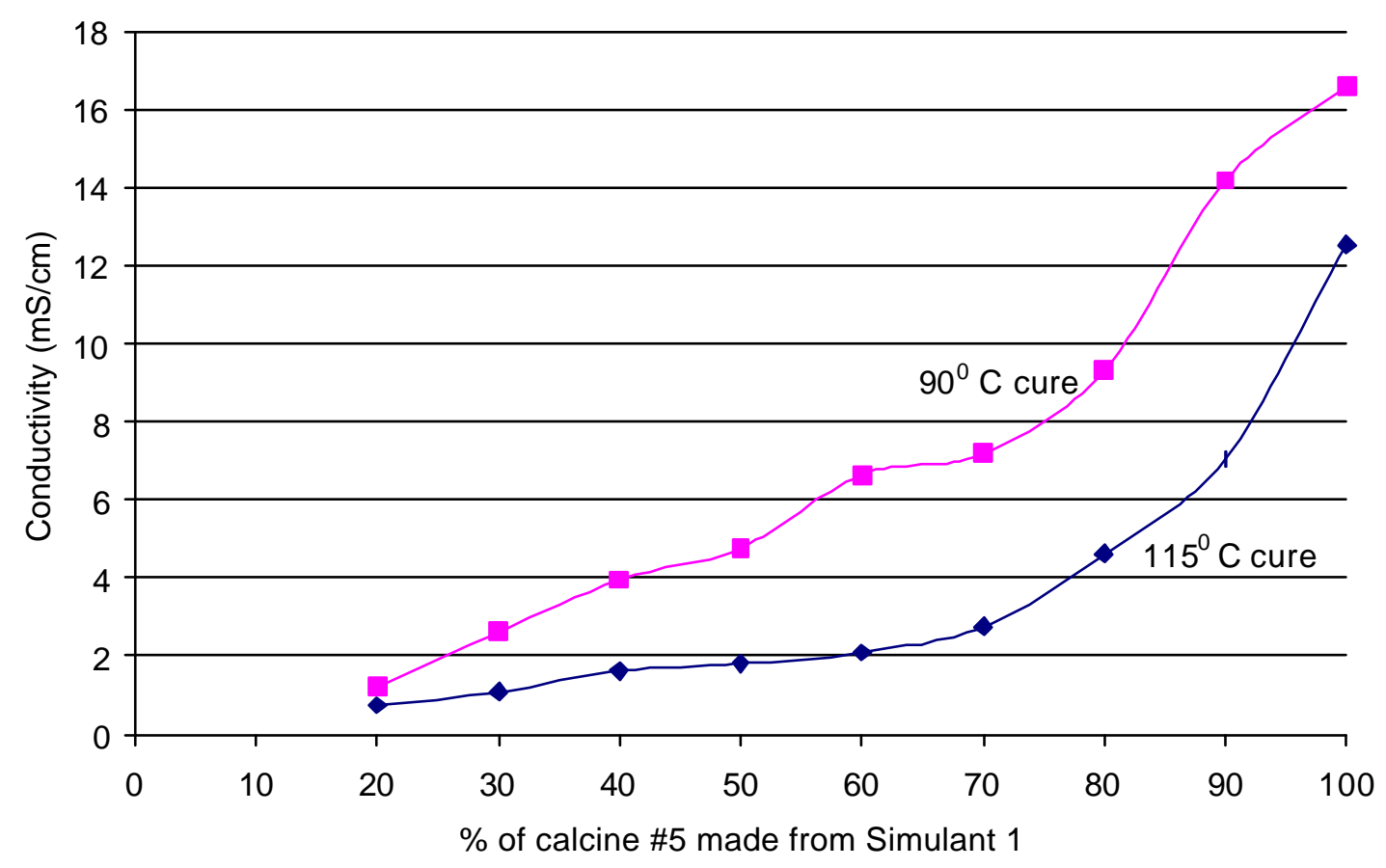

Figure 11. Effect of temperature on leachabilities of hydroceramics prepared with different proportions of Simulant 1 derived Calcine 5 and extra metakaolinite, and cured for 1 day at $90^{\circ} \mathrm{C}$ or $115^{\circ} \mathrm{C}$.

Effect of Time, Temperature and added $\mathrm{NaOH}$ on Leachability

A final set of experiments in this series was undertaken to establish curing criteria. A set of hydroceramics based on Calcine 5 made from each of the three Simulants studied were mixed with $40 \mathrm{wt} \%$ additional metakaolinite and precured at $90^{\circ} \mathrm{C}$ for 1 day and then cured as a function of time for an additional 28 days. See Figure 12. The hydroceramics were cured at $115^{\circ} \mathrm{C}$ (Curves 1, 2, 3, 4, 6, 7) and $90^{\circ} \mathrm{C}$ (Curve 5) for various amounts of time. Curve 1 tracks Simulant 1 Hydroceramic made with $2 \mathrm{M} \mathrm{NaOH}$ rather than DI water (Curve 2). Curve 3 tracks Simulant 2 made with water while Curve 3 represents Simulant 2 made with $2 \mathrm{M} \mathrm{NaOH}$. Curve 4 represents the behavior of Simulant 2 made with water while Curve 5 represents Simulant 3 made with water. Finally Curve 6 tracks the performance of Simulant 3 made with $2 \mathrm{M} \mathrm{NaOH}$ and Curve 7 Simulant 3 made with water. The data indicate the following. It was observed that at each of the time periods when samples were taken to conduct the required PCT test, those samples made with $2 \mathrm{M} \mathrm{NaOH}$ were harder than those made with de-ionized water. Samples made with Hanford calcine and water would crumble upon moderate pressure in the palm of the hand. However, the sample made with Hanford calcine and $\mathrm{NaOH}$ could only be broken with a hammer. However, as can be seen from the leach studies, the samples with extra $\mathrm{NaOH}$ also gave rise to higher conductivities, owing to increased sodium leaching out of the hydroceramics. It is concluded that adding extra $\mathrm{NaOH}$ is not necessary. It does little in terms of leachability but gives additional strength. However strength is already adequate without extra caustic. A second observation is that conductivities drop with time. Companion X-ray diffraction patterns for these samples show them to gradually develop more crystallinity with time. The zeolites that form without $\mathrm{NaOH}$ tend to be Na-P1 and hydroxysodalite. Sometimes analcime also forms. When $\mathrm{NaOH}$ is added 
Zeolite A tends to form instead of Na-P1. The Hanford hydroceramics tend to contain cancrinite as well as Na-P1. Adding $\mathrm{NaOH}$ to these samples promotes the growth of Zeolite A. It is the development of the crystallinity and the corresponding larger crystallite size that is presumed to lead to the lower leach rates with longer curing. Curve 5 represents a Hanford Hydroceramic left to cure at $90^{\circ} \mathrm{C}$ rather than $115^{\circ} \mathrm{C}$. The fact that it has nearly the same behavior as its companion samples (6 and 7) confirms earlier data suggesting the possibility that Hydroceramics could be cured in a $90^{\circ} \mathrm{C}$ controlled storage facility for a slightly longer time but have the same performance as a hydrothermally cured counterpart. This is significant. It makes it unnecessary for the DOE to build an autoclave facility (at least it is now optional). This would make the process safer and more cost efficient in as much as grouting facilities that now exist could be modified to process hydroceramics.

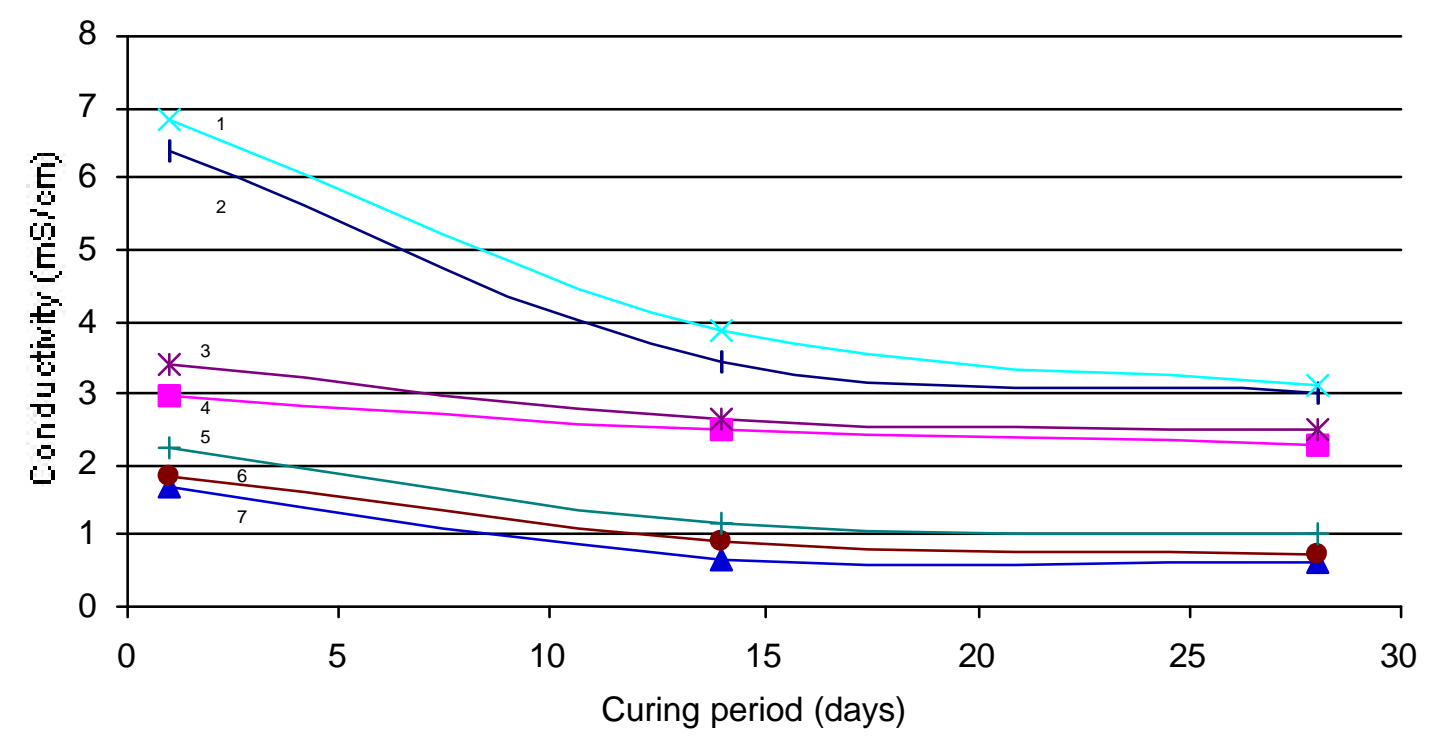

Figure 12. Leach curves of hydroceramics obtained from 60-wt\% Calcine 5 derived from the three simulants and 40 -wt $\%$ of 45 -micron Troy metakaolinite cured at $115^{\circ} \mathrm{C}$ (curves $1,2,3,4$, 6,7 ) or $90^{\circ} \mathrm{C}$ (curve 5) for various times. Curve 1: Simulant 1 with $2 \mathrm{M} \mathrm{NaOH}$; Curve 2: Simulant 1 with water; Curve 3: Simulant 2 with $2 \mathrm{M} \mathrm{NaOH}$; Curve 4: Simulant 2 with water; Curve 5: Simulant 3 with water; Curve 6: Simulant 3 with $2 \mathrm{MNaOH}$; Curve 7: Simulant 3 with water.

\section{Conclusions}

Calcines as well as hydroceramics made with Troy metakaolinite tended to outperform all other aluminosilicate additives. Hydroceramics have a ceramic structure and contain zeolitic phases such as hydroxysodalite and Na-P1. This makes them accommodate sodium within their structure with relatively little additional processing. They have low leachability and compare favorably with traditional glass waste forms. The overall low cost and low temperature processing enhance the potential utility of hydroceramics in providing a viable contingency waste form for the disposal of sodium bearing wastes. Significant findings are listed below:

- Hydroceramics made with waste calcines and metakaolinite tended to out perform other waste form alternatives. Hydroceramics have low leachability and compare favorably with traditional glass waste forms. 
- Sugar calcination of high-sodium wastes without a "calcination aid" containing aluminum and/or silicon is of questionable benefit.

- At least $75 \%$ of the sodium required to produce sodalites and cancrinites in the zeolitization phase should be present in the form of oxides, aluminates, or silicates.

- Calcining the sodium bearing waste is a well-suited method to remove most of the sodium nitrate and nitrite, besides acids and organics thus making the waste more amenable to zeolite encapsulation. In practice, calcination involves the use of a simple rotary kiln or construction of a calcination facility such as the one used by INEEL to calcine its waste.

- The effect of temperature on the curing process of hydroceramics is such that with increase in temperature, more zeolites are noticed in the microstructure. However, considering the fact that the hydroceramics will remain in underground repositories essentially forever, a lower temperature of $90^{\circ} \mathrm{C}$ may be chosen for cost and safety reasons.

- Results suggest that leachabilities of hydroceramics cured at different temperatures tend to converge upon prolonged curing.

- The addition of extra water into the curing vessel during the curing process does not seem to have any perceivable benefit. In fact, leaching of ions could occur into the water vapor when extra water is present in the autoclave. Hence, no extra water should be introduced during the autoclaving process.

- Engelhard and other high purity clays show good leachabilities but poor strengths. It is therefore necessary to choose a metakaolinite such as Troy metakaolinite, which may possess some quartz, but nevertheless displays respectable leach effectiveness. Using a blend of clays is one method of counteracting the low strength of hydroceramics caused by one of the constituent clays. However, the addition of a silica source like finely ground quartz sand or MIN-U-SIL shows more promise. Whereas with the presence of even very low proportions of Engelhard clay the strength characteristics of the resulting blended-clay hydroceramic are significantly compromised, with silica addition instead, more crystalline phases are observed, accompanied by a significant increase in hydroceramic strength.

- The PCT conducted on the DOE's benchmark borosilicate glass indicated a significantly higher leachability than the best hydroceramic waste forms studied. Although comparing DOE's EA glass with a hydroceramic violates the spirit of PCT protocol; tests show that hydroceramics could be suitable contingency waste forms.

- There is little or no change when a hydroceramic is subjected to DOE's vapor hydration test. This is due to the fact that the hydroceramic waste form is already in equilibrium with saturated steam. Glass of course, is not at equilibrium with steam and tends to form unstable secondary hydration products during the test. As a waste form, zeolitic hydroceramics make a significantly better choice than the DOE's current borosilicate glass alternative for SBW. The former already consist of the zeolitic "secondary phases" that glasses will eventually decompose to when they come in contact with the geology of the Nevada Test Site, which has been determined to be the final resting place for the nation's nuclear wastes.

- Experiments have shown that with longer and longer curing times at low temperatures, the leach characteristics of the hydroceramics approach those made at higher temperatures. This points to one more advantage. Since the waste form will remain for a significant period of time in temporary storage areas on site, there is a potential to cure the hydroceramic monoliths at relatively low temperatures during this waiting period, and still be able to achieve desired waste-form characteristics before going "on-road". 
- The highest temperature that is required to produce the contingency waste form seems to be approximately $500^{\circ} \mathrm{C}$ for waste calcination. All curing thereafter requires a temperature that is an order of magnitude less than that needed for vitrification $\left(1200^{\circ} \mathrm{C}-1600^{\circ} \mathrm{C}\right)$.

- The radioactive intensities of DOE's defense wastes are too low to cause damage to cementitious materials (such as hydroceramics), and sufficiently high to promote hydrothermal curing reactions in an insulated interim storage system. [9]

- In a drive to achieve volume reduction, vitrification appears to have immediate benefits, in that it reduces the quantity of HLW that needs to be ultimately disposed of. However, it also creates a LLW fraction that is much larger than the original waste burden itself. (It is estimated that the amount of "new" nitric oxide alone will be of the order of 20,000 tons. (Personal communication, Siemer and Grutzeck, April 2000). This LLW is proposed to be left on-site with only a cursory treatment [5]. With the use of hydroceramics, the entire waste volume - without any separation - can be suitably accommodated in one monolithic waste form. Thus, a reduction in the total waste volume will be conveniently achieved in this manner.

\section{Summary and Future Directions}

Both Savannah River and Hanford SBW waste can be solidified as a hydroceramic waste form. To date there is substantial evidence that zeolitization is a very viable option that can be the basis of a contingency plan for the Hanford and Savannah River sites should it be found that the separation of cesium and strontium from SBW can not be done in a cost effective fashion. The jury is still out on this issue at Savannah River. The current process has apparently been shut down due to the generation of hydrogen gas during the separation process. Alternate methods also seem to be problematic and all tend to ncrease the amount of liquid waste that is involved. Considering the low activity of the waste after 50 years of storage and the fact that cesium and strontium are well accommodated by zeolites in the hydroceramics, it seems that the existing waste should be calcined as outlined, mixed with additional metakaolinite and water and cured at $90^{\circ} \mathrm{C}$ for 6 months or so. At that point it will be road ready and can be shipped to Yucca Mountain. Because of the easy availability of kaolinite clay and the straightforward processing required to convert kaolinite to metakaolinite, quality control is easy to maintain. The overall low cost and low temperature processing enhance the potential utility of hydroceramics in providing an alternate means for the disposal of sodium bearing wastes.

In toto, hydroceramics have acceptably low leachabilities (measured using the PCT and MCC-1 methods) and adequate strength (Siemer et al., 1998; Krishnamurthy, 2000). Hydroceramics are perfectly suited for low activity SBW streams that contain high levels of sodium. Rather than being detrimental, as is the case for vitrification, the high sodium content actually increases the ease of producing a hydroceramic waste form. Rather than diluting the waste, one can use the sodium in the waste to its full advantage. During calcination, it should also be possible to reduce the valance states of $\mathrm{Tc}$ and $\mathrm{Np}$ so that they are more amenable to encapsulation as cations rather than their current anionic state. This can be done chemically (adding small amounts of various sulfides) or by control of oxygen fugacities in the calciner.

At this point, we are planning to continue to look at the performance of Hydroceramics made using metakaolinite as a calcination aid and starting material. We have funding for another 3 years during which time we plan to make 55 gallon drum sized samples at $90^{\circ} \mathrm{C}$ and then characterize them as a function of distance to the center line by taking a series of cross sections through the barrels at various points. It is also proposed to look at the viability of removing 
carbonate from a SBW that has been calcined at $525^{\circ} \mathrm{C}$ with sucrose. The calcine contains soluble sodium salts one of which is sodium carbonate. If the calcine is dissolved and lime is added the carbonate as well as heavy metal hydroxides will precipitate as calcium carbonate. This can be accommodated in traditional cement-based waste forms with no trouble. The soluble portions of the waste should be $\mathrm{NaOH}$ and some residual nitrate and nitrite, $\mathrm{CsOH}$ and $\mathrm{SrO}$. This solution could be concentrated and used as a starting material for making hydroceramics without adding the metakaolinte as a calcination aid. This would simplify the calcination process in as much as it could be done in existing or newly constructed spray calciners.

\section{Publications during First Three Years}

Grutzeck, M.W., D.D. Siemer, "Zeolites Synthesized from Class F Fly Ash and Sodium Aluminate Slurry", J. Amer. Ceram. Soc. 80, pp.2449-2453 (1997).

Siemer, D.D., M.W. Grutzeck, D.M. Roy, B.E. Scheetz, "Zeolite Waste Forms Synthesized from Sodium Bearing Waste and Metakaolinite", WM98, Tucson AZ, March 1-5, 1998. CD of Proceedings Published September (1998) also published on the World Wide Web.

Krishnamurthy, N., M.W. Grutzeck and S. Kwan, "Hydroceramics for Savannah River Laboratory's Sodium Bearing Waste," Accepted for Publication, Proc. Amer. Ceram. Soc. Symposium on Waste Management Science and Technology in the Ceramic and Nuclear Industries, St. Louis, MO, April 29-May 3, 2000, Amer. Ceramic Society, Westerville, OH.

Siemer, D.D., J. Olanrewaju, B.E. Scheetz, N. Krishnamurthy and M.W. Grutzeck, "Development of Hydroceramic Waste Forms," Accepted for Publication, Proc. Amer. Ceram. Soc. Symposium on Waste Management Science and Technology in the Ceramic and Nuclear Industries, St. Louis, MO, April 29-May 3, 2000, Amer. Ceramic Society, Westerville, $\mathrm{OH}$.

Siemer, D.D., J. Olanrewaju, B.E. Scheetz, and M.W. Grutzeck, "Development of Hydroceramic Waste Forms for INEEL Calcined Waste," Accepted for Publication, Proc. Amer. Ceram. Soc. Symposium on Waste Management Science and Technology in the Ceramic and Nuclear Industries, St. Louis, MO, April 29-May 3, 2000, Amer. Ceramic Society, Westerville, $\mathrm{OH}$.

Krishnamurthy, Naveen, Zeolitic Hydroceramics for Sodium Bearing Nuclear Wastes, a M.S. thesis in Environmental Engineering, The Pennsylvania State University, December 2001.

Roy, D.M., J. Olanrewaju, M.W. Grutzeck, B.E. Scheetz and D.D. Siemer, "Hydroceramics as a New Cementitious Approach to Nuclear Waste Immobilization," Abstract of a Talk, ACI Session on Concrete for Radioactive Waste Management," co-sponsored by Committees 227 and 349, Thursday November 1, 2001, Dallas, TX.

Grutzeck, M.W., Kwan, S., Scheetz, B.E. and D.D. Siemer, "Vapor Hydration Testing of EA Glass and Hydroceramic Waste Forms," In preparation. 


\section{Acknowledgements}

The authors (Grutzeck and Kwan) would like to acknowledge the help of the following people who made the work proceed faster than it would have without their help.

Naveen Krishnamurthy did the majority of the work reported herein. He was a very able and hardworking graduate student. He used to be strictly an engineer now he is something better. His M.S. Thesis in Environmental Engineering (2001) is appended to this report.

Darryl D. Siemer who works at INEEL made significant contributions to the research described in this report. He was instrumental in providing direction, testing many formulations and carrying out chemical analyses. His experience with the calcination process at INEEL, radioactive waste in general, and his many suggestions on how to make hydroceramics work allowed us to focus on the hydroceramics themselves not on the mechanisms of processing.

Johnson Olanrewaju, a graduate student working with Dr. Scheetz provided day to day encouragement and stimulating discussions about hydroceramics made using INEEL calcines. 


\section{Appendix One}

\section{INTRODUCTION}

\subsection{Background}

Radioactive nuclear wastes have been a major concern in this country for the last few decades. These wastes differ from other types of hazardous wastes in that they present a higher biological hazard, have a much higher level of persistence in the environment, and require greater care in handling and disposal. The rapid weaponization of the U.S. defense forces toward the beginning of the Cold War was fueled by the production of nuclear devices at three major locations. These were - Idaho National Engineering and Environmental Laboratory (INEEL), Idaho Falls, Idaho; Hanford, Washington; and Savannah River Plant (SRP), Aiken, South Carolina. Over the years, these three locations produced many millions of tonnes of radioactive nuclear waste. The waste is located in-situ at these sites.

This waste was initially in the form of an acidic solution of heavy metal nitrates. The proposed plan for their disposal included transfer into carbon-steel storage tanks. In order to prevent corrosion that would inevitably result with the introduction of these highly acidic wastes into the tanks, the wastes were neutralized using an excess of sodium hydroxide solution. Insoluble oxides and hydroxides of fuel cladding materials (aluminum, iron, chromium, zirconium, nickel, etc.) and added process reagents (aluminum, iron, etc.) along with some radionuclides settled at the bottom, forming a thick sludge. The supernate consisted of a thick and very alkaline sodium hydroxide broth consisting of sodium salts and radionuclides.

There is a pressing need for efficient disposition and disposal of these wastes. The National Academy of Sciences in its report in 1994 made clear the distinction between the two terms [24]. "Disposition" denotes active management, either on the surface or underground, whereas "disposal" denotes an end to the need for active management, such as when a geological repository is closed and sealed. With both techniques, demonstrated irreversibility of actions in general, and retrievability of wastes in particular, are highly desirable because of public reluctance to accept irreversible actions.

Among those alternatives to geological disposal that have received the most consideration are disposal in the seabed, partitioning and transmutation of long-lived isotopes, and continued surface storage [24]. Emplacement of radioactive waste beneath the ocean or polar ice is presently prohibited by international treaties. Disposal in space is not expected to be a practicable, safe technology. Partitioning and Transmutation can reduce the amount of actinides and long-lived fission products, but its actual efficiency in practice is unknown, and inevitably, some radioactive waste will remain, which will require management in a geological repository or in surface facilities. The surface storage of radioactive waste is appreciably less safe than deep geological disposal, especially for longlived radionuclides with half-lives of hundreds of years. Current interim storage practices 
are intended for periods of about 50 to 100 years only [24]. Therefore, space consideration will eventually negate this option.

The National Research Council's Committee on Disposition of High-Level Radioactive Waste Through Geological Isolation in its report this year concluded that after four decades of study, geological disposal remains the only scientifically and technically credible long-term solution available to meet the need for safety without reliance on active management [24].

\subsection{Department of Energy's Defense Wastes}

Since 1950, the Savannah River Plant produced nuclear materials (mainly plutonium and tritium isotopes) for defense purposes on a 300 square mile site at Aiken, South Carolina [29]. For three decades, E. I. du Pont de Nemours \& Co. operated the plant for the Department of Energy. The plant has thus far produced about 100 million gallons of nuclear wastes. This huge repository of radioactive waste that is stored in 48 underground tanks on site has been the focus of many corporate and government initiatives. The compositions of the wastes in these tanks have been aggregated in [29]. The waste sludge - about $14,000 \mathrm{~m}^{3}$ of it - has a radioactive heat generation of the order of $60 \mathrm{~W} / \mathrm{m}^{3}$. [5], [9]

Cesium is one radionuclide present in most radioactive nuclear waste tanks. At SRS, the total ${ }^{137} \mathrm{Cs}$ activity is estimated at $95 \times 10^{6} \mathrm{Ci}$. Therefore, cesium was the radionuclide of concern in experiments that are described in Chapter $3 .{ }^{137} \mathrm{Cs}$ is a strong gamma-emitting radionuclide with a half-life of 30.04 years, during which it decays to form stable, nonradioactive ${ }^{137} \mathrm{Ba}$. The radioactivity of ${ }^{137} \mathrm{Cs}$ makes it harmful to living tissues. [7]

Approximately 53 million gallons of radioactive reprocessing waste is stored in 177 underground tanks, including 149 older single-shell tanks, at the Hanford Site in Washington State. This waste originated from the production of plutonium for the U.S. defense program and has been accumulating since 1944. Sixty seven of the single-shell tanks are known to have leaked an estimated 1 million gallons of waste to the surrounding soil [8]. The radioactive heat generation in the $46,000 \mathrm{~m}^{3}$ of Hanford sludges is about 7 $\mathrm{W} / \mathrm{m}^{3}[5],[9]$.

Both at SRL and at Hanford, as will be described in the next section, vitrification remains the waste disposal alternative. At SRL, the high-level waste fraction will be vitrified and disposed off-site; the low-level waste fraction is to be grouted as saltcrete and buried on site. At Hanford, the current protocol is vitrification of both the high- and lowlevel fractions (Personal Communication: Siemer \& Krishnamurthy, November 2001).

At INEEL, the decision-makers took a different route of waste treatment. INEEL chose to calcine its reprocessing waste instead of neutralizing it with sodium hydroxide. Till date, approximately $90 \%$ of its liquid waste has been calcined to form powder and is stored in bin sets (Personal Communication: Siemer \& Krishnamurthy, November 2001). The site has approximately $4200 \mathrm{~m}^{3}$ of calcines consisting primarily of calcium fluoride, calcium oxide, alumina, zirconia, and un-decomposed sodium nitrate. They generate an average of about $40 \mathrm{~W} / \mathrm{m}^{3}$ of radioactive heat and their long-lived transuranic element content is about $3000 \mathrm{nCi} / \mathrm{g}$ [10]. A "Settlement Agreement" was signed in October 1995 by representatives from the State of Idaho and the Federal Government regarding site clean up at INEEL. Key 
provisions include completion of calcination of all liquid wastes by 2012 and to render all HLW "road-ready" by 2035 [5]. In 1997, INEEL formally rejected sugar calcination as being too dangerous a treatment process and in late 1998, they suggested the separation of

${ }^{137} \mathrm{Cs}$, neutralization of the waste, and subsequent saltcrete-type grouting as a substitute for calcination. [Personal communication. Siemer and Grutzeck, April 2000]

\subsection{Vitrification}

Vitrification was one of many treatment options, but it was chosen by the DOE because it was generally viewed as one of the easiest technologies to implement. The technology was well demonstrated, and it could accommodate a variety of waste compositions [11]. Thus, vitrification became the preferred means of disposal for Sodium Bearing Waste (SBW).

As mentioned in Section 1.1, the waste consisted of a thick sludge that settled to the bottom of the storage tanks, and a supernate that remained at the top of these tanks. In view of the thrust for vitrification as the sole disposal means for defense wastes, the DOE continues to perform the waste-glass-making process at SRL [29]. The supernate is extracted, evaporated repeatedly and the concentrate from the evaporator is cooled till the salts crystallize out and only a wet salt cake results. So there exists a set of tanks that contain the salt cake below a fairly small amount of supernate. However, some tanks have not been processed in this manner yet and so, some underground tanks still have a bottom layer of sludge and substantial amount of supernate overlying it. Thus he tank waste at SRL and at Hanford is now in three forms:

a) Sludge

b) Supernate

c) Salt cake

Currently at SRS, about $10 \%$ of the waste by volume is in the form of sludge that contains most of the actinides (i.e., uranium and transuranic elements) and ${ }^{90} \mathrm{Sr}$. This accounts for half of the total radioactivity in the tanks. The supernate contains about $95 \%$ of the cesium in the tank waste, as well as some actinides [29].

The sludge is to be removed from the tanks and washed with dilute $(\sim 1 \mathrm{M} \mathrm{NaOH})$ solution to remove aluminum and soluble salts, both of which can interfere with the glassmaking process. The washed sludge is to be incorporated in glass. The salt cake is to be redissolved, mixed with the supernate and removed from the tanks; reacted with monosodium titanate to remove actinides and ${ }^{90} \mathrm{Sr} ;{ }^{137} \mathrm{Cs}$ is to be removed in an as-yet-undetermined process; and the separated radionuclides are to be immobilized in waste glass too. The verylow activity "incidental waste" that remains from these processing steps is to be disposed onsite as saltstone, which is created by mixing the incidental waste with fly-ash, slag, and Portland Cement to create a grout slurry.

The waste glass is produced by combining the processed HLW with glass frit and melting the mixture at $1150^{\circ} \mathrm{C}$. This is then poured into cylindrical stainless steel canisters, allowed to cool, and sealed. About 700 canisters have thus been produced and an estimated 
6000 will be ultimately required [29]. The canisters are to be stored onsite, awaiting final disposal at the Yucca mountain repository.

Later, due to the work of Siemer et. al., it was found that vitrification was not the best option for defense wastes due to the high leachabilities of glass and excessively high expenses involved in the process. [6], [18] The sodium content in a borosilicate glass is limited to 20 wt \% (Personal Communication: Siemer \& Krishnamurthy, November 2001). Because SBW present in the form of supernate, salt cake and sludge wash water contains up to $90 \mathrm{wt} \%$ sodium (mostly as nitrate and nitrite) on a dry-weight basis, the vitrification process would require a great deal of dilution (via additions of glass making frit) which in turn would cause a substantial increase in volume. Although not as critical in terms of actual volumes, aluminum content of some of the SBW could also mandate further composition adjustment (dilution) needed to lower the total fraction in the finished glass to $\sim 6-\mathrm{wt} \%$ concentration. With each extra gallon, there is an added burden on storage space requirements, manpower requirements for handling, disposal and maintenance, and on financial resources.

Also, glasses are inherently unstable in repository environments. They tend to alter into zeolites, clays and other hydrated mineral species, and the nature of radionuclide interactions in these altered states and their stability is not fully understood. The results of the Vapor Hydration Test suggests that glasses would be destabilized by contact with most backfill/construction materials such as grouts, clays and soils [12].

At SRS (the Savannah River Science Center, also called the Savannah River Site), the processing of ${ }^{137} \mathrm{Cs}$ has been halted because of safety concerns over the process. This separation procedure (termed In-Tank Processing - ITP) involves precipitating ${ }^{137} \mathrm{Cs}$ with sodium tetraphenylborate (NaTPB), filtering out the solids, and passing the filtrate to the low activity waste process stream. However, it was observed during a pilot project in 1983 and again during a full-scale implementation in 1995, that the TPB anion decomposes to form alarmingly high concentrations of flammable benzene compounds [29]. The accumulation of flammable gases in close proximity to radioactive waste is not acceptable. Therefore, the ITP program was put on hold and the National Research Council designated an external committee to initiate a review of alternative cesium separation techniques. The committee concluded in 2000 that enough information was not available to pinpoint one single separation alternative.

A second problem with ITP is that of final remediation of the filtered CsTPB. The slurry would require further processing before being vitrified [13]. Borosilicate glass is also unstable at high temperatures [11]. This is highly undesirable in a radioactive waste form that must be able to withstand high temperatures, which occur in the event of canister failure in a repository.

Siemer indicates that employing vitrification for DOE's (approx. 65,000 $\mathrm{m}^{3}$ ) HLW will cost over $\$ 1$ million per cubic meter of high level glass produced [5]. Therefore, from considerations of waste volume; safety, time, cost and ease of operation; and eventual waste form stability, vitrification presents an enormous challenge to the disposal of nuclear wastes. Hence, alternatives to vitrification that are worthy of merit are discussed next. 


\subsection{Alternative Waste Forms}

Some of the alternative waste forms that have been developed and tested over the last few decades are SYNROC (a titanium based, polyphase ceramic developed at the Australian National University and the Australian Nuclear Science and Technology Organization); tailored ceramics (a polyphase assemblage developed by Rockwell International Science Center and The Pennsylvania State University); the $\mathrm{TiO}_{2}$-ceramic matrix waste from (developed at the Kernforschungszentrum Karlsruhe); glass ceramics (consisting of discrete crystals of sphene, calcium titanium silicate within a matrix of aluminosilicate glass, developed by Hahn-Meitner-Institut in Berlin and the Whiteshell Nuclear Research Establishment in Canada); monazite ( a single phase cerium phosphate waste form developed at Oak Ridge National Laboratory - ORNL); FUETAP grout (Formed Under Elevated Temperature and Pressure grout, developed at ORNL and The Pennsylvania State University); novel ceramic waste forms (such as sodium zirconium phosphate - NZP developed at The Pennsylvania State University); etc. [11]

SYNROC was proved to be superior to borosilicate glass in leach resistance by K. D. Reeve, et. al. and was selected as the alternative to borosilicate waste glass by the Alternative Waste Form Peer Review Panel in 1981 [14], [11]. Petek, et. al. showed that waste forms made using lanthanide orthophosphates (i.e. analogs of the mineral monazite have lower processing temperatures, better waste per volume loading, and lower leachabilities than borosilicate glass [15]. Dole et. al. showed that FUETAP grout had cesium and strontium leachabilities comparable to glass and transuranic leach rates below detection limits [16].

Most of the alternative treatment methods focus on converting the waste into a highly insoluble material before final storage. The more promising approaches utilize the natural geochemical systems such as the aluminosilicate mineral groups which form much of the earth's crust, thereby reducing the possibility of unfavorable reactions with the surrounding geological matrix in an underground repository. The succeeding paragraphs bring to light research directed toward that strategy.

Early studies of cesium fixation in clay minerals have been reported by Brownell, besides studies on sorption of strontium and cesium in Savannah River Plant (SRP) soil [1]. It was reported that cesium was retained in SRP soil because of fixation in mica minerals, and that fixation was greatly increased by sodium ions present in the waste solutions. Also, though strontium was readily leached from the waste-soil mixture by dilute solutions of acids or salts, cesium was not readily leached by any solution tested. Early studies of the interaction of radionuclide and soil minerals also were conducted at Hanford. During the period 1960 to 1965, extensive studies were conducted at the Hanford site on aluminosilicates, clinoptilolite in particular, to remove cesium and strontium from stored waste in preparation for the In-Tank Solidification program. Aluminosilicates were subsequently used at the Hanford reservation to remove cesium from waste liquor until 1970 [1].

Interest in aluminosilicate mineral synthesis resulted in the STOPPER process, which encapsulates individual ions such as cesium in molecular aluminosilicate lattices. STOPPER is the coined term for the Stone Process for Permanent Encapsulation of Radionuclides as described by Brownell [1]. 
The synthesis of cation aluminosilicates may be performed in different ways. Reactions in aqueous systems at temperatures of $100^{\circ} \mathrm{C}$ or less, in general, form gels prior to crystallization and are termed the "Gel Process". The term "Clay Reaction Process" is the name given to the aqueous, atmospheric-pressure process of silicification of cations in radioactive waste liquors with a clay mineral as one of the reactants. At elevated pressures and temperatures (greater than $100^{\circ} \mathrm{C}$ ), the synthesis is called "hydrothermal". Cesium aluminosilicate (pollucite), analcite, mordenite, basic nosean, basic sodalite and other crystalline species have been identified as the result of hydrothermal process [1].

The type of products obtained from reacting clays with different kinds of salts depend partly on the anions in the alkaline solution. Cancrinite is obtained when kaolinite and nitrate ion are reacted; whereas kaolinite with halides, phosphate, perchlorate and other anions produces sodalite. Also, a high $\mathrm{pH}$ and the input of thermal energy favored the process of crystallization [1].

The mechanism of entrapment is interesting. Some researchers comment that cesium ions are first fixed along the edges of the vermiculite platelets and as these positions are filled, the cesium moves to the interlayer exchange sites and cause a collapse of the vermiculite lattice [1]. The interlayer cesium is thus physically entrapped by the closing lattice and is very tenaciously held. Evidence of the stability of the pollucite cage is found in the absence of sodium aluminosilicates in the microcrystalline product even though sodium was present in solution at twice the molar concentration of cesium. Faujasite, a sodium zeolite, which was formed in the absence of cesium hydroxide, was absent among the products of pollucite entrapment studies. Cesium was thus believed to control the structure of the product. The formation of cesium ferrosilicate at atmospheric pressure in a highly alkaline solution in which ferric hydroxide has a low solubility also indicates the strong influence of cesium in producing the ferrosilicate lattice.

Some researchers observed that the affinity of bentonite for $\mathrm{Cs}^{+}$is 10 to 20 times the affinity for $\mathrm{Na}^{+}$and commented, "The usual explanation for the high affinity of clay for $\mathrm{Cs}^{+}$ is that a large cation like cesium is not hydrated and can come very close to the negative charge on the particle" [1]. Some others showed that large univalent cations like $\mathrm{K}^{+}, \mathrm{Rb}^{+}$ and $\mathrm{Cs}^{+}$will replace smaller univalent cations like $\mathrm{Na}^{+}$and $\mathrm{Li}^{+}$as well as divalent cations such as $\mathrm{Ca}^{+2}, \mathrm{Sr}^{+2}$ and $\mathrm{Ba}^{+2}$, losing their waters of hydration in this immobilization process. They consider this to be the prime cause of ion fixation. Ions such as $\mathrm{Na}^{+}$that have a high affinity for hydration do so and push the lamellae apart. Further, they state, "Cesium ions with a smaller hydration energy than $\mathrm{K}^{+}$hold the layers together more strongly than $\mathrm{K}^{+}$ions so that the hydrated $\mathrm{Ca}^{+2}$ and $\mathrm{Mg}^{+2}$ ions which can expand the layers held by $\mathrm{K}^{+}$ions are ineffective in producing layer expansion in $\mathrm{Cs}^{+}-$saturated minerals. Consequently, $\mathrm{Cs}^{+}$ions are not as easily replaced by these ions as are $\mathrm{K}^{+}$ions [1].

In the case of vermiculite loaded with cesium and an alkaline earth ion, the latter remains mobile. Brownell notes that some research workers believe that, "The presence of the non-hydrated, and consequently fixed, ion (cesium) does not inhibit the migration of other ions in the vermiculite lattice. The conclusion is that it is not lattice-contraction associated with cesium uptake, but rather the state of the particular ion in the lattice that is responsible for the fixation phenomenon" [1]. Thus these authors disagree that lattice collapse is the chief explanation for cesium fixation. 


\subsection{Zeolite structure and properties}

Zeolites are a family of complex aluminosilicates having a three-dimensional network structure containing channels and cavities [25]. The structural openings in zeolites are normally occupied by alkali and alkaline earth cations and loosely held water molecules. The structural formula of a zeolite can be expressed for the crystallographic unit cell as $\mathrm{M}_{\mathrm{k}} / \mathrm{n}$ $\left[\left(\mathrm{AlO}_{2}\right)_{\mathrm{x}}\left(\mathrm{SiO}_{2}\right)_{\mathrm{y}}\right] \cdot \mathrm{wH}_{2} \mathrm{O}$ where $\mathrm{M}$ is the cation of valence $\mathrm{n}, \mathrm{w}$ is the number of water molecules and the sum $(\mathrm{x}+\mathrm{y})$ is the total number of tetrahedra in the unit cell [26]. Crystalline zeolites are unique absorbent materials with large void volumes of $20-50 \%$.

Zeolites were discovered in 1756 by the Swedish mineralogist Cronstedt [27]. They are composed of $\mathrm{SiO}_{4}{ }^{4-}$ tetrahedra where all of the oxygen atoms are shared with adjacent tetrahedra. This arrangement reduces the overall $\mathrm{O} / \mathrm{Si}$ ratio to $2: 1$, and if each tetrahedron were to contain $\mathrm{Si}^{4+}$ as its central cation, the structure would be electrically neutral, as in quartz $\left(\mathrm{SiO}_{2}\right)$. However, in zeolites, some of the quadrivalent $\mathrm{Si}$ is replaced by trivalent $\mathrm{Al}$, giving rise to a deficiency of positive charge in the framework. This charge is balanced by monovalent and divalent cations like $\mathrm{Na}^{+}, \mathrm{K}^{+}, \mathrm{Ca}^{+}, \mathrm{Mg}^{+}$, etc elsewhere in the structure [23],[26]. There are two kinds of cations present within the zeolite structure. First, there ae exchangeable cations (e.g. $\mathrm{Na}^{+}$) that can be easily exchanged with other ions depending upon whether there are more electropositive cations in the solution that the zeolite is exposed to. Second, there are the structural cations (e.g. $\mathrm{Al}^{3+}$ ) that make up the framework of the zeolite structure along with the oxygen atoms. These are not exchangeable.

The deficiency in electrical charge on account of $\mathrm{Al}^{3+}$ substituting for $\mathrm{Si}^{4+}$ results in the acido-basic nature of zeolites [27]. Two main features characterize these properties: a purely structural one resulting from the specific connection of $\mathrm{TO}_{4}$ tetrahedra and the second, a physicochemical one. The properties of zeolites that are related to their structure include cation exchange, high degree of hydration, low density and high void volume when dehydrated, crystal structure stability even when the void volume is as much as $50 \%$ by volume of the dehydrated crystals, adsorption of gases and vapors, and other physical properties such as electrical conductivity. Typical physicochemical properties include electro-negativity and the polarizing power of ions [28].

The structural framework can be visualized as $\mathrm{SiO}_{4}$ and $\mathrm{AlO}_{4}$ tetrahedra (primary building units or PBUs) linked together into simple geometrical forms (secondary building units or SBUs). The SBUs range in complexity from simple rings of 4 to 6 tetrahedra (4 rings or 6 rings). SBUs may be linked in several ways, each giving rise to a crystal structure possessing a unique set of physical and chemical properties such as cubo-octahedron sodalite unit. This arrangement leads to a series of pores and channels. The water of hydration lies within these pores and channels surrounding the exchangeable cations. These water molecules can be removed by heating the zeolites to $350^{\circ} \mathrm{C}$ [23].

The actual water content of a zeolite is a function of temperature and the partial pressure of water in the atmosphere surrounding the zeolite. Once the water molecules have been removed, the cations fall back into positions on the inner surface of the pores and channels close to the seat of the charge (where $\mathrm{Al}^{3+}$ has substituted for $\mathrm{Si}^{4+}$ in a tetrahedron). Upon dehydration, some of the cations assume different positions in the structure. The internal pores of cages and connecting channels in a zeolite depend on the specific arrangement of SBUs in that species. The channels are bound by the oxygen atoms of the connecting tetrahedra, and their aperture sizes are governed by the size (4-, 5-, 6-, 8-, 10-, or 
12- member rings) and orientation of the rings of oxygen atoms. Channel systems may be one-dimensional, two-dimensional, or three-dimensional, and diffusion rates for adsorption and ion exchange are functions of the spatial distribution of the channels and the nature of the ions in question [28].

Synthetic zeolites were first identified in cement pastes formulated with large amounts of fly ash. Thereafter, zeolites have been utilized by industry for their unique adsorption and absorption properties. The concept of encapsulation of radionuclides and other ions in the waste stream perhaps led to the application of zeolites in radioactive waste containment. Zeolites with their cage-like structures, as has been shown earlier, epitomize an entrapment reaction.

\subsection{Hydroceramics as an innovative waste form}

Zeolite formation is the key to the performance of a hydroceramic waste form. Hydroceramics have been defined in different terms by different researchers. Siemer has called them geopolymeric concretes [5]. Yet, they perform significantly better than geopolymers on standard leach tests. The reason for this could be that because Ordinary Portland Cement (OPC) that is used to make conventional grouts is about $65-\mathrm{wt} \%$ calcium oxide, the cation fixation sites in these grouts are already saturated with calcium ions [5]. The physical characteristics (appearance, strength, porosity, density, etc.) of hydroceramics resemble those of FUETAP concretes but the mineralogy and chemical properties (especially leachability) are much different [12].

Hydroceramics are best described as a class of hydrous materials (similar to alkaliactivated cements) that have been under development for a very long time, at least since the early 1980's. They are truly unique man-made materials. They can be mixed and cured using traditional grout mixing equipment and curing chambers, but they are not cements per-se. Instead, they are hydrous materials that contain zeolites, which are formed by reacting a finely divided source of aluminosilicate and a concentrated sodium hydroxide solution. The aluminosilicate can be either Class $\mathrm{F}$ fly ash (glass) or heat-treated kaolinite (metakaolinite). Each starting material has an $\mathrm{Al}_{2} \mathrm{O}_{3} / \mathrm{SiO}_{2}$ molar ratio of approximately 0.5 . When sodium hydroxide is added to these materials, dissolution takes place followed by gel formation and partial crystallization of zeolites. With proper processing of the hydroceramic, the resultant product develops a dense matrix having sufficient strength to withstand the rigors of stacking in a repository environment. But best of all, the matrix is extremely insoluble. Leach rates are comparable to or occasionally lower than glass waste forms with equivalent waste loading, as observed by Siemer [Personal communication. Siemer and Grutzeck, April 2000].

The hydroceramic process, developed by Siemer et. al. in 1996 is a combination of the "Clay Reaction Process" attributed to Hanford's workers and the "FUETAP" technology that originated at the Oak Ridge National Laboratory (ORNL), Tennessee [6]. FUETAP grouts themselves had shown better results on the MCC-1 test when they were mixed with Indian red pottery clay or bentonite than when they were leached without clay additions [17]. 
Hydroceramics are a definite improvement over other alternative waste forms. This is obvious when one considers the nature of action of zeolites. Adsorbents retain ions via surface chemistry by chemical bonding. Thus, they can only stabilize insoluble constituents. Whereas, zeolites contain holes within their microstructure. These holes are receptive to certain ions - certainly to sodium and a range of radionuclides - and therefore entrap them inside their essential structures. Solubility of ions has little effect in the working of zeolites.

The problem of effective disposal of the massive repository of Savannah River Laboratory's wastes, combined with the failure of vitrification as the single superior waste disposal option pointed towards the need for further research in using hydroceramics as waste forms for defense wastes. Hence the objective of this study.

To devise a suitably safe, inexpensive, long-term alternative for the Savannah River Laboratory's sodium bearing radioactive waste, using zeolitic hydroceramics was the goal of this research.

Zeolitization provides an excellent alternative as shall be borne out in the succeeding sections.

\section{EXPERIMENTAL METHODS}

\subsection{Introduction}

The experimental work consisted of three phases:

1. Waste simulation,

2. Calcination, and

3. Zeolitization.

The first stage involved preparing the radioactive waste simulants, which are fairly viscous and have the appearance of a thick liquid. The next step was to treat the waste simulants with different calcination aids at an elevated temperature, in order to produce a set of calcines. The last phase involves the hydrothermal synthesis of zeolites (henceforth referred to as zeolitization) from the calcines, to produce the innovative waste form termed "hydroceramics". These processes are explained in the following sections. Subsequently, the experimental apparatus that were used to bring about these processes are described.

\subsection{Simulations of sodium bearing wastes}

Two waste simulants - Simulant 1 made without cesium, and Simulant 2 containing cesium - were prepared based on the chemistry of the supernate in Tank 44 at Savannah River Laboratory. The composition of Tank 44 in column 2 of Table 2-1 was the basis of the starting material recipes given in column 2 and column 3 of Table 22. This in turn yielded the actual elemental composition of the simulants as given in Table 2-1. 
This waste stream is atypical in that it is unusually high in free hydroxide ions. Major components consist of sodium salts of aluminum, silica, nitrate and nitrite. The only radioactive species is cesium, which made the waste in this particular tank a very good candidate for encapsulation studies of the ubiquitous inorganic constituent ${ }^{23} \mathrm{Na}$, as well as the common radioisotope ${ }^{137} \mathrm{Cs}$.

Table 2-1. Composition (molarity) of Tank 44 SBW and Simulants

\begin{tabular}{|l|l|l|l|}
\hline Species & Tank 44 Waste & Simulant 1 & Simulant 2 \\
\hline $\mathrm{Na}$ & 15 & 14.7 & 14.7 \\
\hline $\mathrm{K}$ & 0.16 & - & - \\
\hline $\mathrm{AlO}$ & 0.38 & 0.4 & 0.4 \\
\hline $\mathrm{OH}$ & 11.8 & 11.4 & 11.4 \\
\hline $\mathrm{NO}_{3}$ & 1.13 & 1.12 & 1.12 \\
\hline $\mathrm{NO}_{2}$ & 1.52 & 1.38 & 1.38 \\
\hline $\mathrm{Cl}$ & 0.024 & - & - \\
\hline $\mathrm{F}$ & 0.013 & - & - \\
\hline $\mathrm{PO}_{4}$ & 0.012 & - & - \\
\hline $\mathrm{SO}_{4}$ & 0.0042 & - & - \\
\hline $\mathrm{CO}$ & 0.20 & - & - \\
\hline $\mathrm{Cs}$ & $0.00012(1.4 \mathrm{mC} / \mathrm{mL})$ & - & 0.02 \\
\hline $\mathrm{Hg}$ & $132 \mathrm{ppm}$ & - & - \\
\hline $\mathrm{Cr}$ & $450 \mathrm{ppm}$ & - & - \\
\hline
\end{tabular}

Table 2-2. Recipes Used to Simulate Savannah River Laboratory's Tank 44 Waste (wt. in grams)

\begin{tabular}{|l|l|l|}
\hline Compound & Simulant 1 & Simulant 2 \\
\hline $\mathrm{Na}_{2} \mathrm{CO}_{3}$ & 2.65 & 2.65 \\
\hline $\mathrm{NaNO}_{2}$ & 11.9 & 11.9 \\
\hline $\mathrm{NaNO}_{3}$ & 11.9 & 11.9 \\
\hline $\mathrm{NaAlO}_{2}$ & 4.04 & 4.04 \\
\hline $\mathrm{NaOH}$ & 57 & 57 \\
\hline $\mathrm{CsNO}$ & - & 0.583 \\
\hline $\mathrm{H}_{2} \mathrm{O}$ & 125 & 125 \\
\hline
\end{tabular}

\subsection{Calcination of simulated wastes}

Calcination allows one to drive off nitrate, nitrite and some carbonate, all of which are detrimental to the zeolitization process. These anions are among the most mobile and account for the inherent leachability of cement based waste forms such as Saltstone because cement is unable to host large amounts of these ions. Calcination is also a well-established method to convert organic constituents in the waste into inorganic ashes. [5]

The efficiency of the calcination process depends upon the reducing agent and the temperature used. In order to convert the sodium bearing waste into oxides, one would 
normally have to calcine the liquid waste at $\sim 1000^{\circ} \mathrm{C}$ in order to decompose the $\mathrm{NaNO}_{3}$. This high temperature results in excessive volatilization of some of the toxic metals (e.g., $\mathrm{Cd}$ ), fission products (e.g., ${ }^{99} \mathrm{Tc}$ and ${ }^{137} \mathrm{Cs}$ ), and corrosives (e.g., $\mathrm{Cl}$ ) present in it. On the other hand, with the addition of reducing agents de-nitrification could be carried out at much lower temperatures. Therefore a series of tests was conducted in which varying amounts of sucrose was added to the liquid simulants prior to calcination. Sucrose aids in the reduction of carbonates to carbon dioxide, and nitrates/nitrates to sodium oxide. This type of sugarcalcination was used three decades ago in INEEL and then independently re-discovered at Hanford in 1995 [6]. Testing by Siemer suggested that an 8:1 ratio of liquid waste to sucrose and a temperature of $525^{\circ} \mathrm{C}$ were more or less optimum (Personal communication: Siemer and Grutzeck, October 1999).

As an additional step, various aluminosilicates were added to the simulants prior to calcination. Although sucrose brings about reduction reactions, the $\mathrm{Na}_{2} \mathrm{O}$ that is produced will react with $\mathrm{CO}_{2}$ to form soluble $\mathrm{Na}_{2} \mathrm{CO}_{3}$. The aluminosilicates provide an alternate pathway for the very reactive $\mathrm{Na}_{2} \mathrm{O}$, forming rudimentary sodium aluminosilicates instead (that are more compatible with the subsequent chemical solidification process), thus balancing a degree of reduction while maintaining calcine reactivity. The proportions of simulant to pozzolan used were such that the overall alkali: aluminum: silica atom ratio in the composite was close to $1: 1: 1$.

Simulants 1 and 2 were therefore combined with sugar and additional calcination aids (alumina and silica sources) to produce six "samples" from each simulant, as outlined below:

Sample 1: $20 \mathrm{~g}$ raw waste liquid (control)

Sample 2: $20 \mathrm{~g}$ raw waste liquid $+2.5 \mathrm{~g}$ sucrose $\left(\mathrm{C}_{6} \mathrm{H}_{12} \mathrm{O}_{6}\right)$

Sample 3: $20 \mathrm{~g}$ raw waste liquid $+2.5 \mathrm{~g}$ sucrose $+11.9 \mathrm{~g}$ boehmite $(\mathrm{AlO} .(\mathrm{OH}))$

Sample 4: $20 \mathrm{~g}$ raw waste liquid + $2.5 \mathrm{~g}$ sucrose $+11.9 \mathrm{~g} 5 \mu \mathrm{m} \mathrm{Min-U-Sil}\left(\mathrm{SiO}_{2}\right)$

Sample 5: $20 \mathrm{~g}$ raw waste liquid $+2.5 \mathrm{~g}$ sucrose $+11.9 \mathrm{~g}$ metakaolinite $\left(\mathrm{Al}_{2} \mathrm{O}_{3} .2 \mathrm{SiO}_{2}\right)$

Sample 6: $20 \mathrm{~g}$ raw waste liquid + $2.2 \mathrm{~g}$ aluminum powder (Al metal)

Samples 1 through 5 were dried at $90^{\circ} \mathrm{C}$ for 24 hours and then heated in an oven at $525^{\circ} \mathrm{C}$ for 18 hours. In an effort to de-nitrate the waste without the use of heat, sample 6 was "cold de-nitrated" at room temperature by adding aluminum powder to the caustic rich solution containing nitrate/nitrite salts. This was a very vigorous exothermal reaction and was carried out under a fume hood. The aluminum replaced sucrose as a reducing agent and caused the evolution of ammonia. After reaction in sample 6 was complete, it was dried at $90^{\circ} \mathrm{C}$ for 24 hours. These six products - one for each simulant - were then ground to fine powder. That fraction which passed through 150-micron sieve and was retained on 75micron sieve was stored for further use. These powders are henceforth termed "calcines" and are numbered as "calcine\# 1" through "calcine\# 6". These calcines were tested as described in section 3-1 to determine the best calcination process. 


\subsection{Zeolitization}

Each of the six calcines representing Simulant 1 and 2 was mixed with different quantities of additional metakaolinite and water. The metakaolinite that was used in these experiments was mined at Troy, Idaho and hence called Troy metakaolinite. Its composition is given by Siemer, et. al. [6] Metakaolinite was chosen over other pozzolans for strong reasons. Siemer et. al. had demonstrated that out of the 40 pozzolans they had tested for making their hydroceramics, calcined kaolin and Troy metakaolinite were the best candidates [18]. Hydroceramics made from either of these ingredients had the lowest PCT results for conductivity, $\%$ of $\mathrm{NO}_{3}{ }^{-}$, and cesium concentration in the leachate.

These stiff pastes were placed in Parr bombs and cured for a period of 24 hours at $90^{\circ} \mathrm{C}$. This pre-cure was performed so as to allow the "clay reaction process" to occur, whereby a zeolite gel is formed. Right afterwards, the Parr bombs were heated at the reported temperature for various durations. The resulting products were termed "hydroceramics". These were numbered as "hydroceramic\# 1" through "hydroceramic\# 6". Whereas in the calcination process, metakaolinite was added to aid the conversion of nitrates, nitrates and carbonates to oxides, in the zeolitization process extra metakaolinite is essential as a raw material for the formation of specific zeolites from the sodium available in the waste.

There are several methods available to test waste form performance. Among them are the 28-day MCC-1 (Materials Characterization Center-1) test, the ANS/ANSI-16.1 test, the TCLP test, and the 7-day Product Consistency Test (PCT). The PCT takes less time, requires little monitoring, and the test samples are quicker to prepare. It also recreates waste canister failure more accurately in that it emulates conditions when the repository is flooded while still "hot", and allows for back reactions (reactions taking material from the leachate into the waste form). For purposes of comparing the leach resistance of calcines or hydroceramics, a modified Product Consistency Test (PCT) was consistently adopted. The deviation that was made from the true PCT was chiefly in that instead of a leach time of seven days, a one-day leach time was used. This yielded much quicker results. Also, Siemer et. al. had observed that PCT leachates of hydroceramics reach steady-state within two or three days and that nothing more dissolved regardless of how long leaching was extended beyond that period [6]. Thus, the one-day "quick PCT" results were a reasonably good indicator of the net leachabilities of hydroceramics.

Since sodium and cesium are the most mobile elements in the waste composition, these two ions were indicative of the relative effectiveness of the waste forms developed. Also, Siemer (personal communication: Siemer and Grutzeck, April, 2000) showed the correlation between leachate conductivity and sodium concentration in the leachate, as seen in Figure 2-1. It follows that leachate conductivity is an excellent correlation to the amount of $\mathrm{Na}^{+}$and $\mathrm{Cs}^{+}$that have leached out of the hydroceramic. Therefore, leachate conductivity, rather than a full leachate chemical analysis was used to test hydroceramic quality. For the same reason, $\mathrm{pH}$ measurements of leachate solutions were thought to be redundant. 


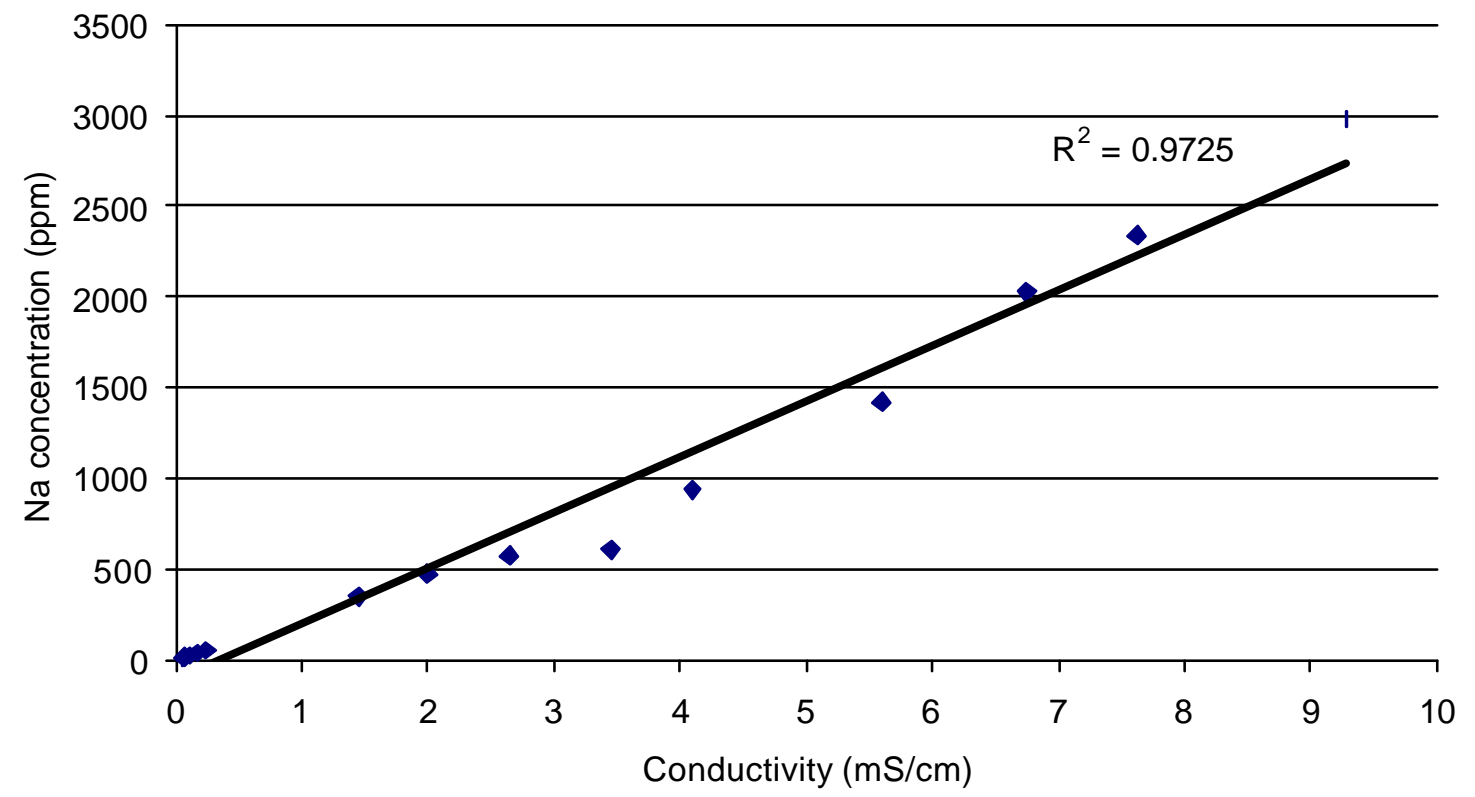

Figure 2-1: Correlation between leachate conductivity and sodium concentration in the leachate. Deviations are due to the fact that different sodium salts - $\mathrm{NaAlO}_{2}, \mathrm{NaCl}$, $\mathrm{NaOH}$, etc. - conduct differently.

\subsection{Apparatus}

The main analytical tools employed in this work were the X-ray diffractometer and the scanning electron microscope. These are described below.

\subsubsection{X-ray diffractometer}

The computer-assisted Scintag, Inc. X-ray diffractometer uses a copper target X-ray source, a Peltier-cooled detector and a theta- 2 theta goniometer. The diffractometer operates at a voltage of $45 \mathrm{kV}$ and a current of $40 \mathrm{~mA}$. The associated software supplied with the Scintag (DMSNT 1.37, Scintag, Inc) allows one to search the extensive database of the International Committee on Diffraction Data (ICDD) for relevant matches of the peaks recorded and thereby identify the phases present. 


\subsubsection{Scanning electron microscope}

The Scanning Electron Microscope (SEM) was used to study the morphology of the hydroceramics. The Hitachi S-3500N instrument uses a pre-centered tungsten filament and two different vacuum modes, one high and the other low. Two kinds of images can be recorded - a secondary electron image (taken only in the high vacuum mode) and a back scattered image (scintillator method). The high vacuum mode with the scanning electron image was used in this study.

\subsubsection{Digital conductivity meter}

For all conductivity measurements, a 1 c.c. conductivity probe connected to a model\# 3200 digital conductivity meter was used. The meter, manufactured by YSI, Inc., Yellow Springs, Ohio, was standardized using a $0.1 \mathrm{~N} \mathrm{KCl}$ solution. All conductivity values are reported at $25^{\circ} \mathrm{C}$.

\subsubsection{Chemical analysis}

All chemical analysis of leachates, unless otherwise specified, was performed by Scott Atkinson, Materials Research Laboratory's resident analytical chemist. Cations were determined by dc-plasma emission spectrometry on a Spectrametrics Inc. Spectraspan III. Anions were determined by ion chromatography on a Dionex 2010i. All standards used were dilutions of NIST traceable stock solutions. Standards and sample dilutions were prepared with ASTM Type I de-ionized water in ASTM Class A volumetric flasks.

\subsubsection{Experimental precautions}

Glass containers were not used in any mixing, curing, or leaching processes. This ensured that the highly alkaline simulants and later products did not leach silica from the glass and affect the $\mathrm{Al} / \mathrm{Si}$ ratio. Plastic and Teflon vials, beakers, funnels, syringes, etc., nylon filters, and mortar and pestle made from glazed china clay were utilized. All curing to produce hydroceramics was carried out inside tightly sealed hydrothermal bombs made by Parr, Inc., Moline, Illinois. Each bomb had an inner Teflon cylinder (having a volume of 20 c.c.) and an outer steel casing and lid. 


\section{RESULTS AND DISCUSSION}

\subsection{Preliminary studies}

The principal goal of the initial studies was to solidify the liquid simulants of Savannah River Laboratory's Tank 44 waste, to yield insoluble products. To this end, simulants (reference may be made to Table 2-1 and Table 2-2 for compositions) were calcined with the use of various calcination aids as described in Section 2.2.

\subsubsection{Determination of a suitable calcination aid}

With the intention of screening these calcines for the best calcination process, modified (one-day) PCT was conducted on them. The results are plotted in Figure 3-1. The graph shows that calcination process\# 5 yields the best calcine. Further proof of this fact is seen in Table 3-1, which displays Siemer's chemical analysis on the same calcines (Siemer, Grutzeck and Scheetz: DOE grant continuation proposal, April, 2001).

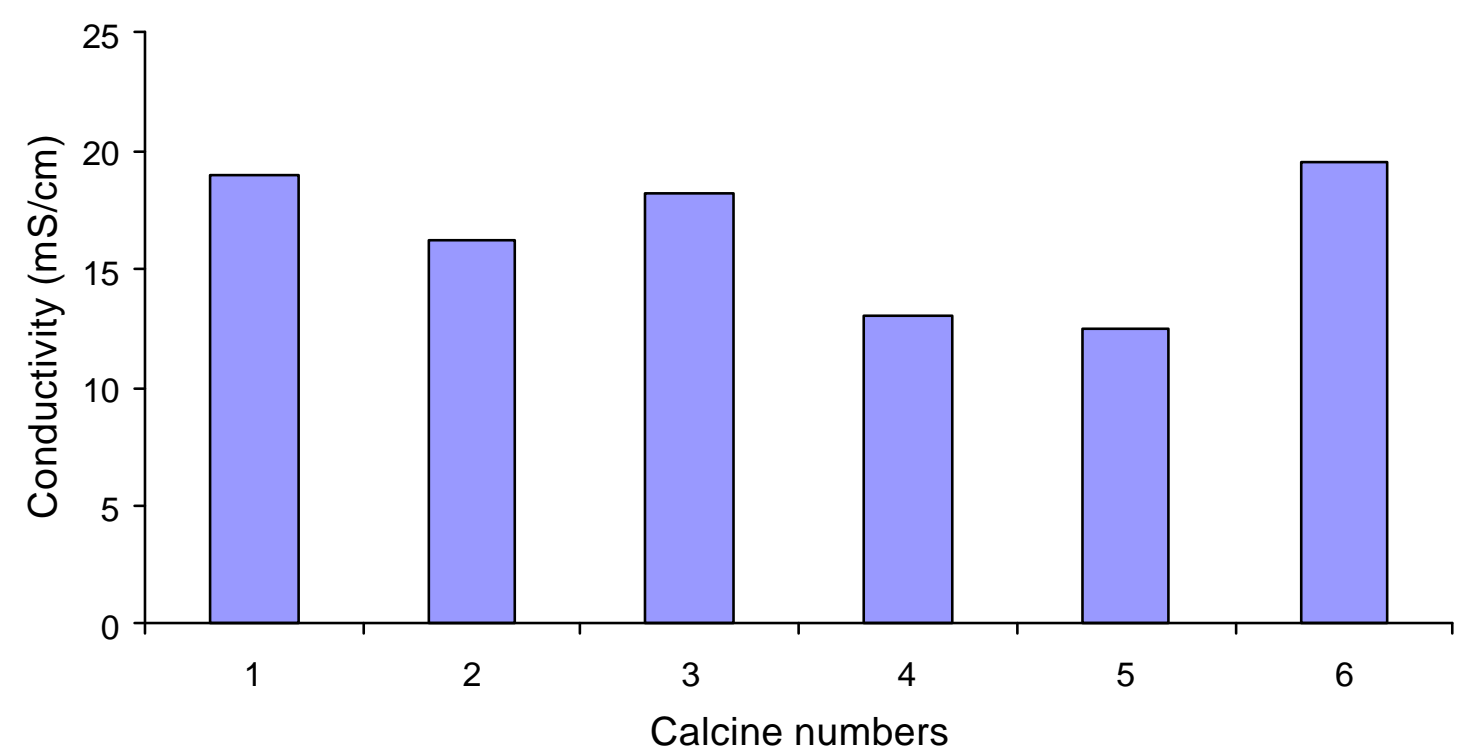

Figure 3-1: Leach Test results of calcines 1 through 6 derived from Simulant 1. Calcine compositions are outlined in Section 2.2. 
Table 3-1: Chemical composition of waste calcines derived from Simulant \#1. All values are shown as wt\% present in calcine sample.

\begin{tabular}{|c|c|c|c|c|c|c|}
\hline $\begin{array}{l}\text { Ions } \\
\text { present }\end{array}$ & $\begin{array}{l}\text { \#1 } \\
\text { raw solutio } \\
\text { no calcinatio }\end{array}$ & $\begin{array}{l}\text { \#2 wi } \\
\text { sucrose } \\
\text { only }\end{array}$ & $\begin{array}{l}\text { \#3 wi } \\
\text { sucrose } \\
\text { boehmite }\end{array}$ & $\begin{array}{l}\text { \#4 wit } \\
\text { sucrose } \\
5-\mu m \text { min-l } \\
\text { Sil }\end{array}$ & $\begin{array}{l}\text { \#5 wit } \\
\text { sucrose } \\
\text { metakaolinite }\end{array}$ & \begin{tabular}{|l|}
$\# 6$ \\
with cold \\
Al \\
powder
\end{tabular} \\
\hline $\mathrm{NO}_{3}$ & 4.5 & $<0.1$ & $<0.1$ & $<0.1$ & $<0.1$ & 1.5 \\
\hline $\mathrm{NO}_{2}$ & 4.8 & 0.45 & 0.13 & $<0.05$ & 0.08 & 2.3 \\
\hline $\mathrm{CO}_{3}$ & 0.83 & 43 & 9 & 15.3 & 8.0 & $\sim 0.4$ \\
\hline $\mathrm{Na}$ & 25.4 & 41 & 27.4 & 22.5 & 20.0 & \begin{tabular}{|l}
35.6 \\
\end{tabular} \\
\hline$A l$ & 0.8 & 1.7 & 30.2 & 0.64 & 12.1 & 14.4 \\
\hline
\end{tabular}

It is notable that the thermal calcination process has converted almost all of the nitrate and nitrite in the raw solution into oxides and carbonates as the sucrose is burnt off. Carbonate is higher than preferable due to the carbonation of the newly formed sodium oxide. The cold de-nitrated calcine (calcine \#6) contained significantly more nitrate and nitrite due in part to the fact that more than the stoichiometric amount of aluminum is needed to complete the process. Calcine \#2 (with sucrose addition alone) still has high amounts of carbonate and sodium. Calcine \#5 (made with sucrose and metakaolinite) shows the least percentages of sodium, nitrate and carbonate. Thus, it became obvious that if a waste calcine were to be chosen as a potential waste form, then it would have to be produced using calcination process \#5.

Although calcination achieved de-nitrification, the conductivities were still considerably higher than desirable. The calcines did not possess much mechanical strength either. In fact, preserving them in bin sets, as is being practiced at INEEL, makes fine calcine particles vulnerable to dispersion into the surrounding environment in the event of bin failure. It was necessary to convert the calcines into a durable monolithic solid.

The addition of an excess amount of clay to the calcines was thought to have a favorable effect on their leachabilities. The extra clay would provide the alumina and silica needed to form stable sodium aluminosilicates, leading to a further decrease in sodium leach rates. Numerous authors had shown earlier that metakaolinite reacts with $\mathrm{NaOH}$ to produce zeolites. [6]

This initiated the zeolitization phase of the work.

\subsubsection{The evolution of a zeolitic hydroceramic waste form}

In the scoping stages on zeolitization, enough metakaolinite was added to each of the calcines so that the resulting mixes had $20-\mathrm{wt} \%$ and $30-\mathrm{wt} \%$, respectively of each of the calcines, as described in Table 3-2. Enough water was added to make a stiff paste, resulting in 12 samples each for Simulant 1 and Simulant 2. The mixes were then inserted in Parr bombs and cured at $90^{\circ} \mathrm{C}$ for a period of 24 hours of pre-cure followed by another autoclaving interval of 24 hours at $115^{\circ} \mathrm{C}$. Upon cooling, each sample was tested using a one-day PCT test. 
Table 3-2: Recipes for hydroceramics made during scoping studies

\begin{tabular}{|l|l|l|}
\hline Calcine Percentage & $20 \%$ & $30 \%$ \\
\hline Calcine weight & $5 \mathrm{~g}$ & $5 \mathrm{~g}$ \\
\hline Metakaolinite weight & $20 \mathrm{~g}$ & $11.67 \mathrm{~g}$ \\
\hline $\mathrm{H}_{2} \mathrm{O}$ & Sufficient & Sufficient \\
\hline
\end{tabular}

As may be observed by comparing Figure 3-1, and Figure 3-2, all calcines are relatively soluble, but adding extra metakaolinite to them tends to reduce their solubilities considerably.

Calcine \#1 through calcine \#6 made with Simulant 2 (containing Cs) were also combined with metakaolinite as described above. The resulting hydroceramics were leached and their solutions were analyzed for conductivity. The values were higher, as can be seen in Figure 3-3, especially at 30-wt\% calcine loading, presumably due to the presence of the more mobile cesium ion.

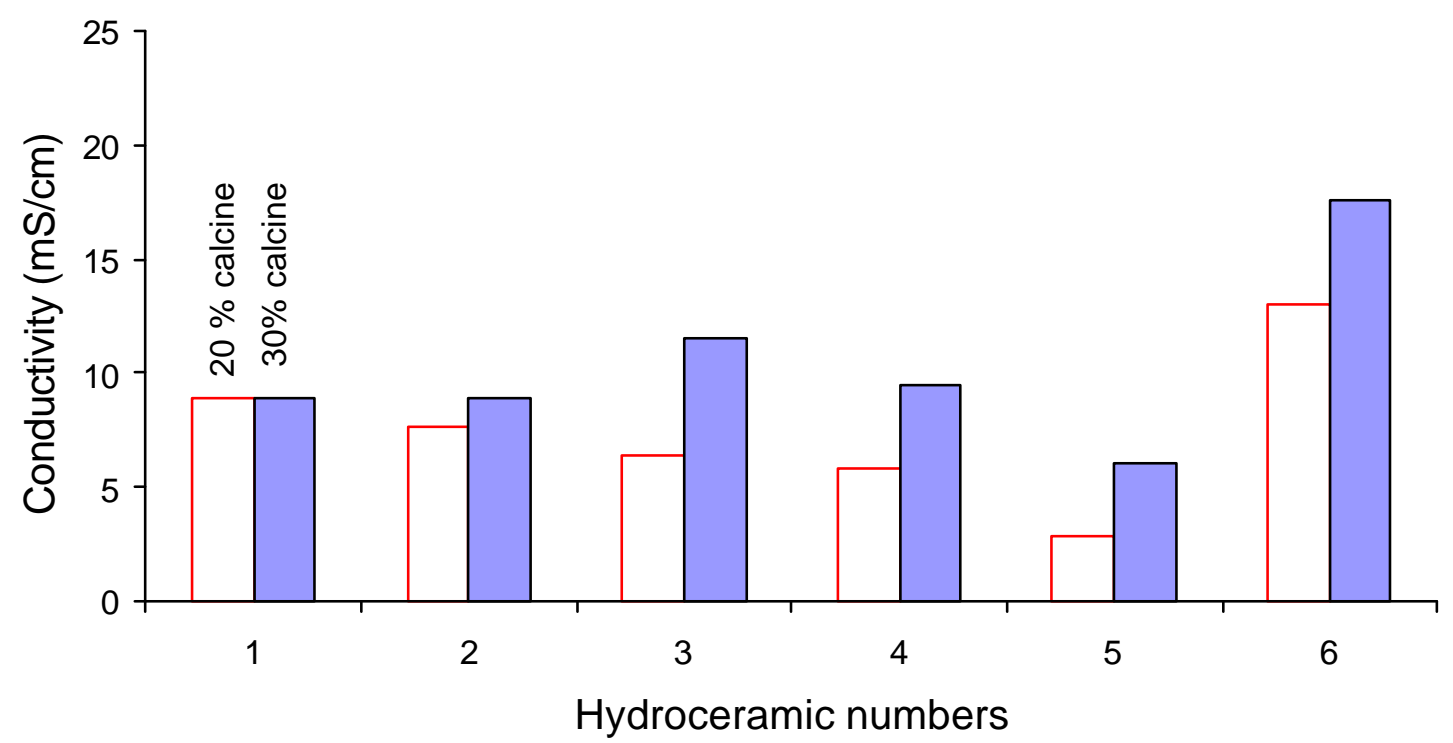

Figure 3-2: Leach results of hydroceramics made with 20-wt\% or 30-wt\% calcine \#1 through calcine \#6 derived from Simulant 1, and 80-wt\% or 70-wt\% respectively of extra metakaolinite; cured for 24 hours at $115^{\circ} \mathrm{C}$.

Siemer et. al. compared the 7-day PCT results of their hydroceramics made with 30wt\% calcine (prepared using Savannah River Site's simulant) and 70-wt\% Troy metakaolinite with borosilicate glass and determined that the leachabilities of their hydroceramics were at least $27 \%$ lower than that of waste glass [6].

It was becoming clear from these results that the addition of extra metakaolinite was essential for significant reductions in leachate conductivities. It was now necessary to verify these results with long-term curing experiments whereby the behavior of these waste forms could be graphed at different intervals. Figure 3-4 shows the leach behavior of the hydroceramics produced with $30 \%$ by weight of calcine \#1 through calcine \#6 (produced 
from Simulant 1), and $70 \%$ by weight of extra metakaolinite. The long-term curing and leach test results help one make the following inferences.

(1) Conductivity values decrease with curing time.

(2) Overall, hydroceramic \#5 performed the best.

(3) Hydroceramics \#3, \#4 and \#6 performed variably throughout the curing period

(4) Hydroceramics \# 1 and \#2 gave very poor results.

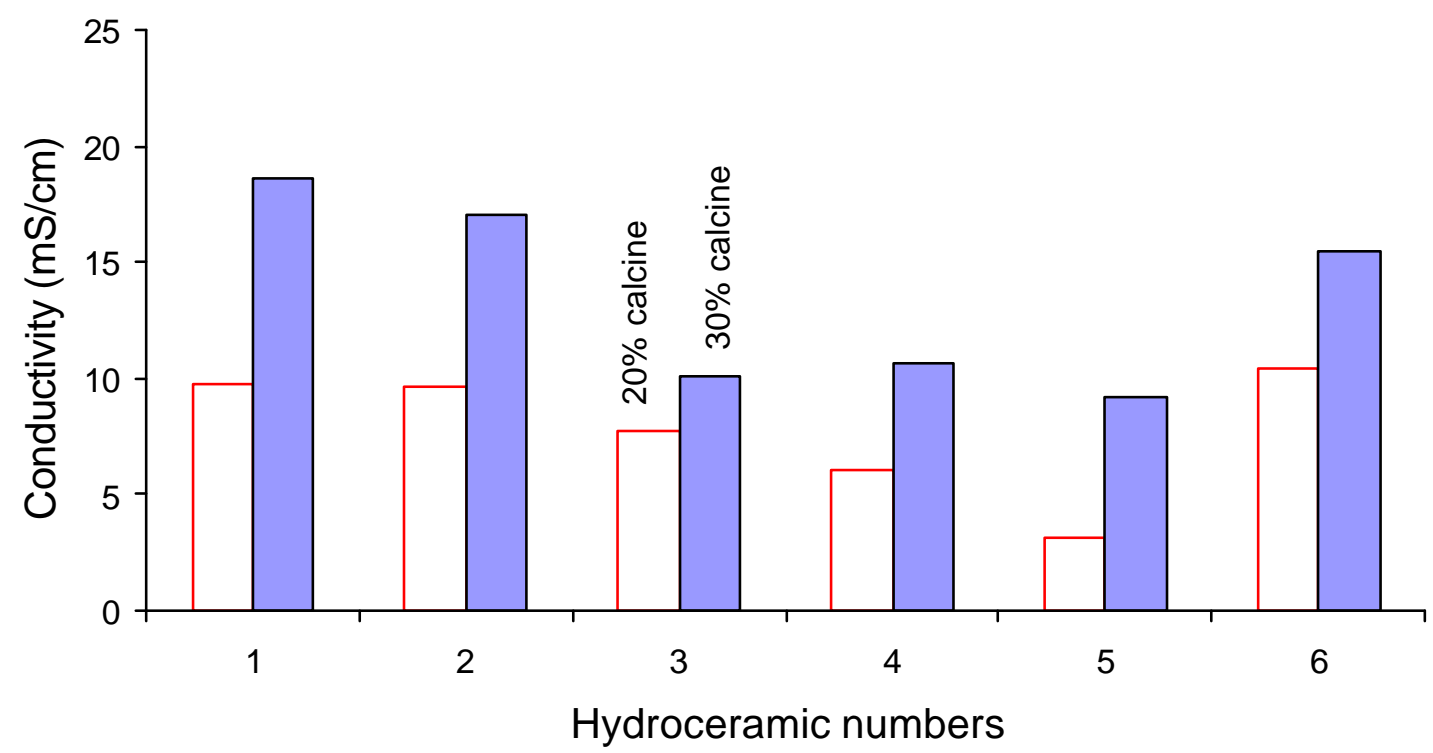

Figure 3-3: Leach results of hydroceramics made with 20-wt\% or 30-wt\% calcine $\# 1$ through calcine \#6 derived from Simulant 2, and 80-wt\% or 70-wt\% respectively of extra metakaolinite; cured for 24 hours at $115^{\circ} \mathrm{C}$.

The twelve hydroceramic waste forms (six each for Simulant 1 and Simulant 2) were then analyzed using a Scintag X-ray diffractometer. Patterns are given in Figure 3-5 and Figure 3-6. Hydroceramic \#1 contains significant amounts of nitrate and carbonate. All samples contain quartz, presumably left over from the clay. Hydroceramics \#3, \#4 and \#5 contained traces of analcime/hydroxysodalite, which could account for their lower leachabilities.

Subsequently, SEM micrographs were obtained. The hydroceramic containing the raw calcine had a massive habit with a hint of a built-up plate-like structure as seen in Figure 3 $7(\mathrm{a})$.

It is observed in Figure 3-7(b) that hydroceramic \#5, the hydroceramic with the lowest leachability that was formulated with metakaolinite, had the best structure development. It contains spherical features suggesting the normal morphology of analcime and hydroxysodalite, which could be precursor structures for other zeolites that form at higher temperatures and prolonged curing durations. The hydroceramic made with cold denitrated calcine contained tabular crystals as seen in Figure 3-7(c). 


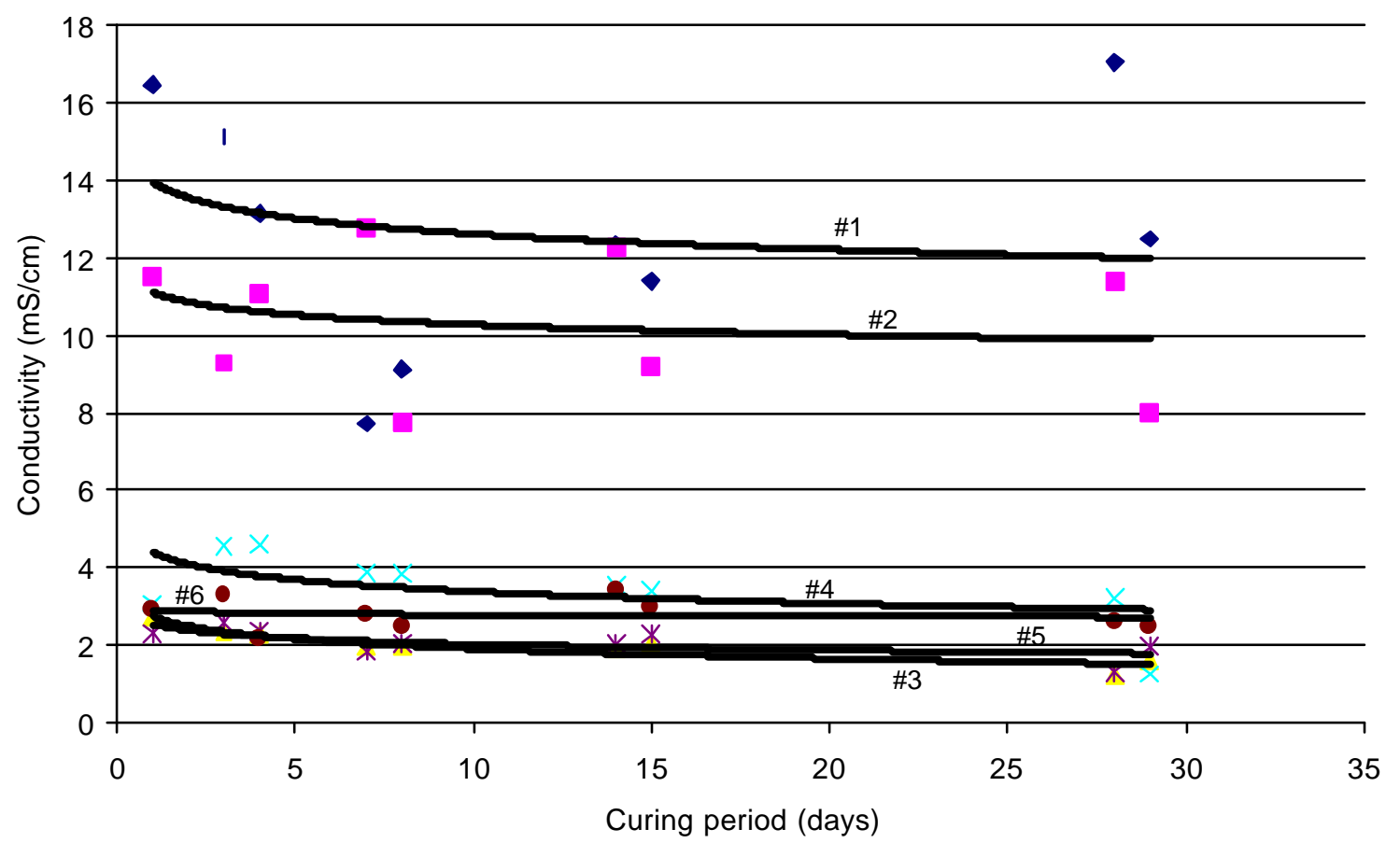

Figure 3-4: PCT leach results of hydroceramics prepared with 30-wt\% of calcines \#1 through \#6, and 70-wt\% of extra metakaolinite; cured at $90^{\circ} \mathrm{C}$ for various periods.

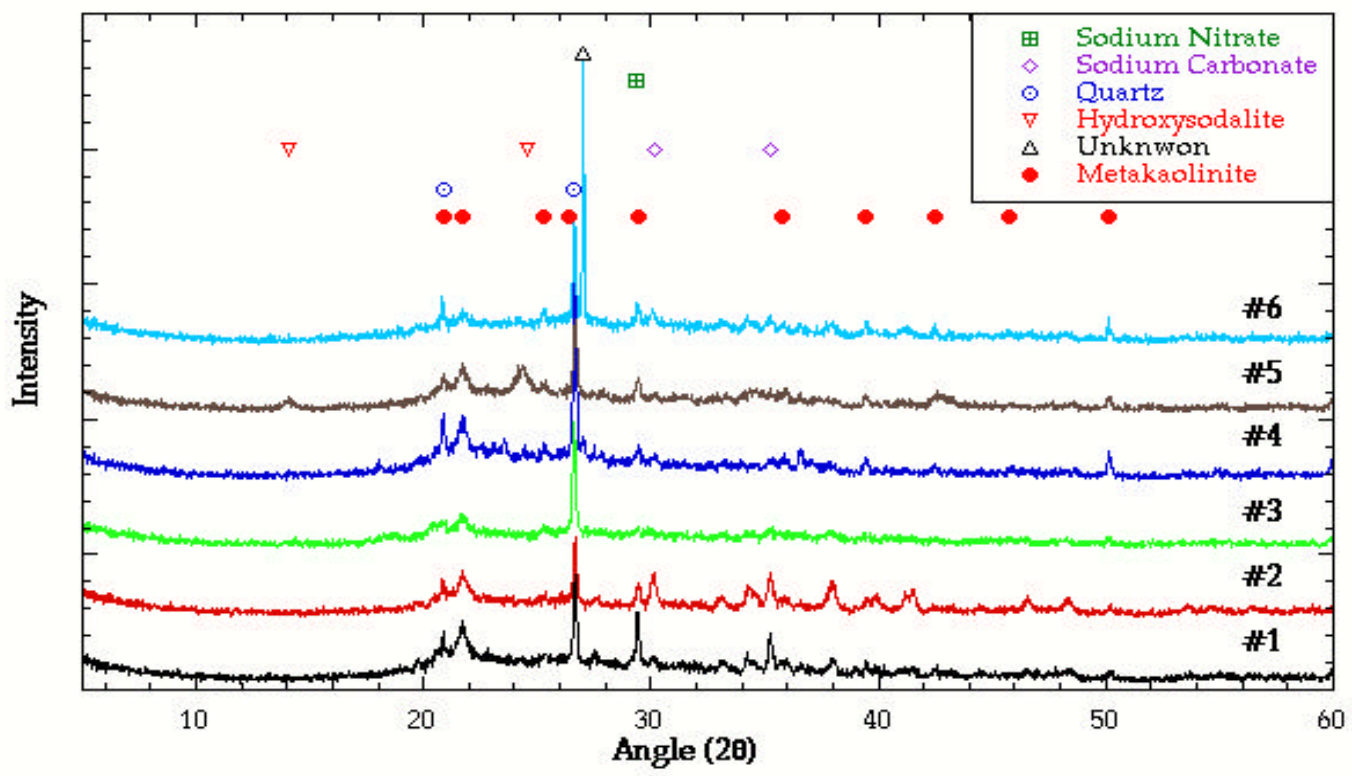

Figure 3-5: X-ray diffraction patterns for 20-wt\% calcines 1 through 6 (produced from Simulant 1), mixed with 80-wt\% Troy metakaolinite and water. Samples were precured at $90^{\circ} \mathrm{C}$ for 24 hours and then autoclaved at $115^{\circ} \mathrm{C}$ for an additional 24 hours. 


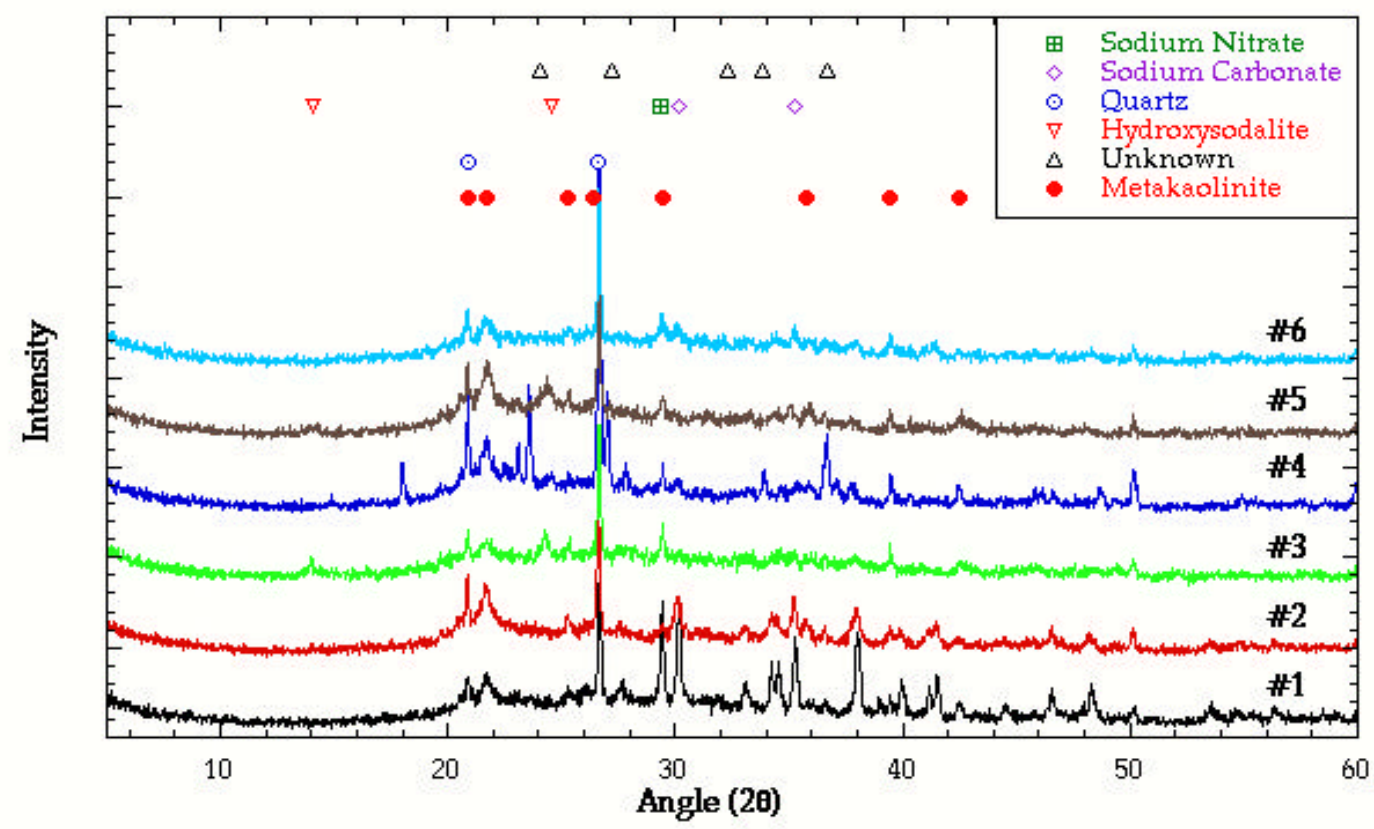

Figure 3-6: X-ray diffraction patterns for 30-wt\% calcines 1 through 6 (made from Simulant 2), mixed with 70-wt\% Troy metakaolinite and water. Samples were pre-cured at $90^{\circ} \mathrm{C}$ for 24 hours and then autoclaved at $115^{\circ} \mathrm{C}$ for an additional 24 hours.

Metakaolin is derived from kaolin by heating it at $400^{\circ} \mathrm{C}-450^{\circ} \mathrm{C}$ at normal humidity whereupon there is a destruction of the crystal structure in kaolinite. During dehydoxylation, the layers retain their topological configuration but considerable atomic rearrangement occurs which results in partial positional disordering of the remaining atoms [19]. This contributes to metakaolinite's relatively higher degree of pozzolanic reactivity (i.e., it will react with lime water, and alkaline solutions in general) than kaolinite. Thus, it is the preferred starting material under regimes that favor gel formation. This explains the enviable leach values obtained in hydroceramics made with extra metakaolinite.

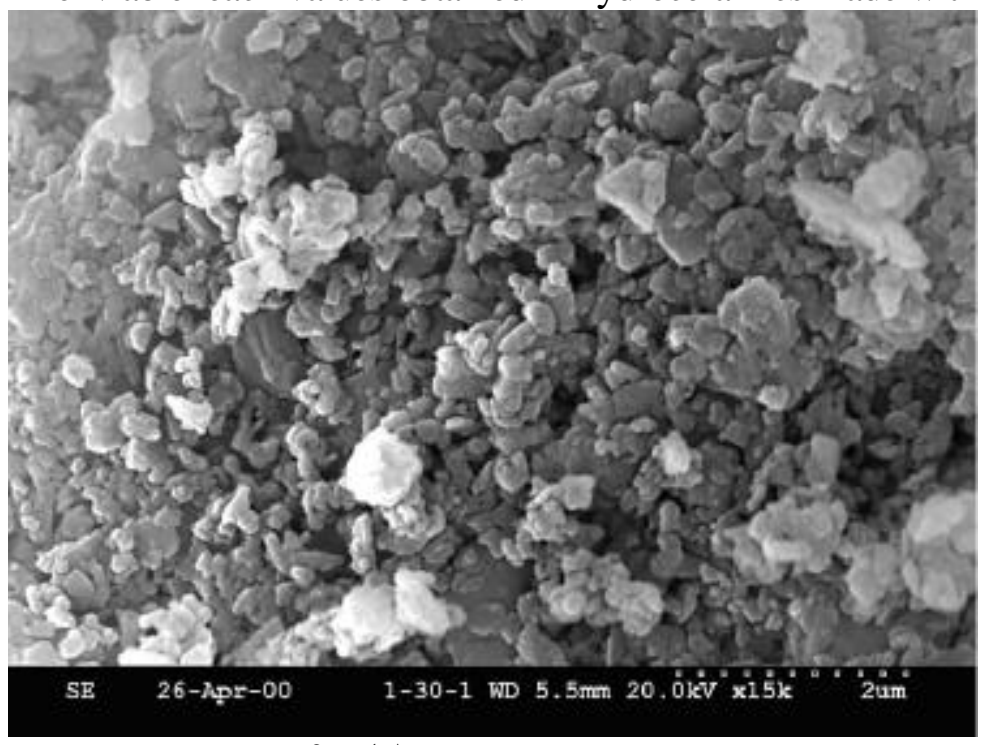

Figure 3-7(a) 


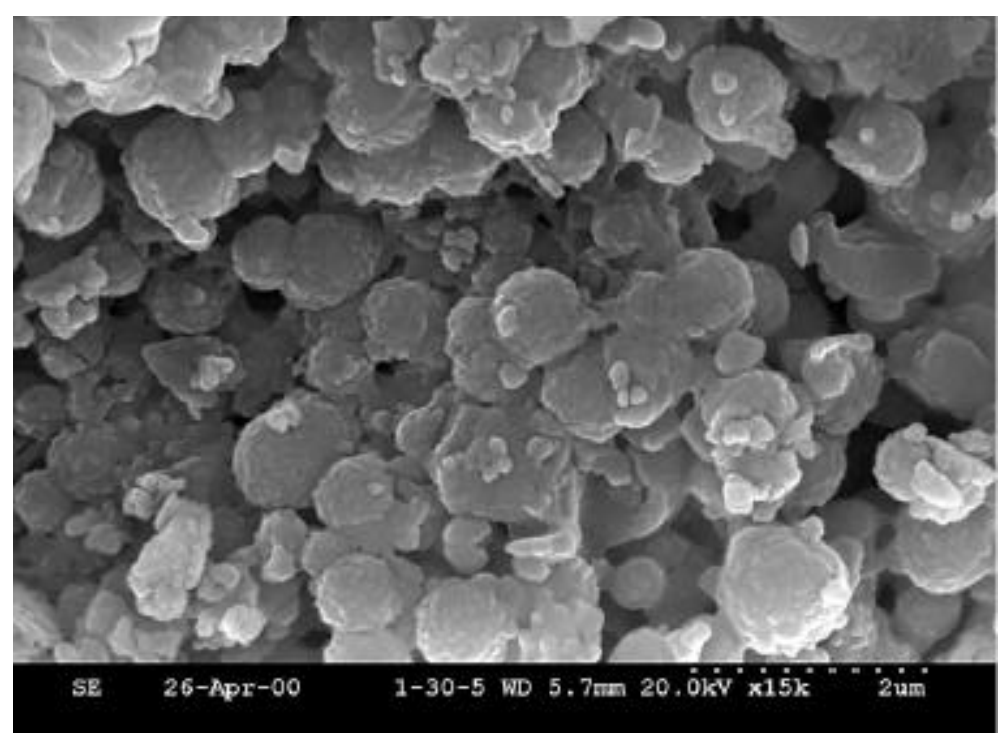

Figure 3-7(b)

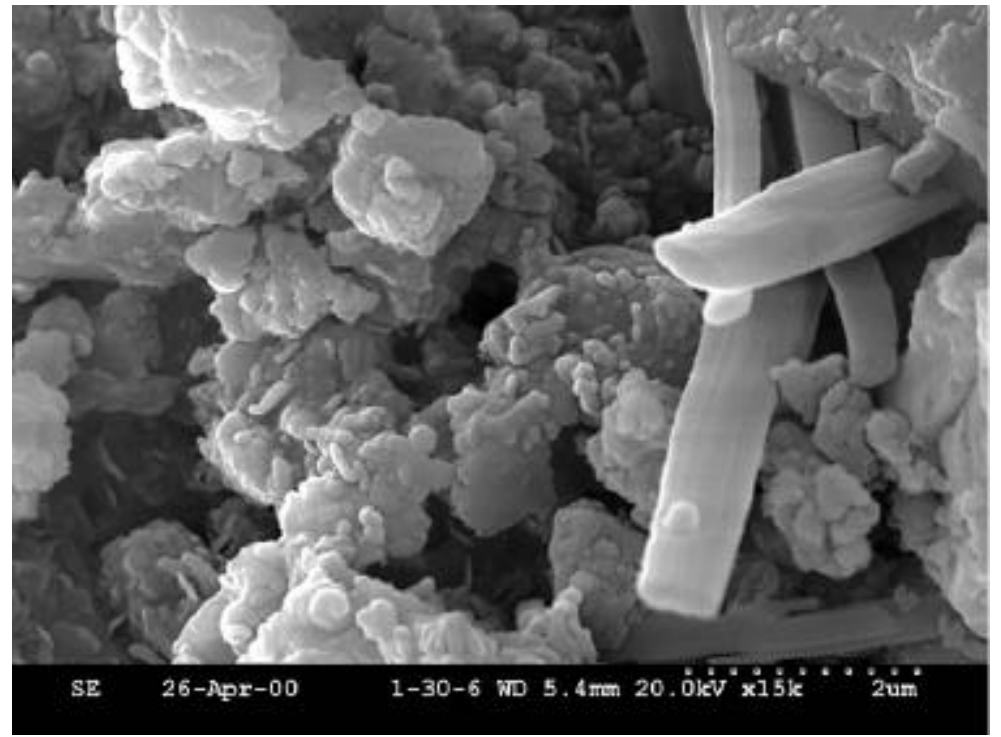

Figure 3-7(c)

Figure 3-7 (a), (b), (c): SEM micrographs at $15 \mathrm{~K}$ magnifications of the simulated hydroceramics composed of:

(a) Simulant 1; no calcination aid,

(b) Simulant 1; calcined with sugar and metakaolinite,

(c) Simulant 1; cold de-nitrated with aluminum; and then mixed with 70-wt\% metakaolinite and autoclaved.

Due to the consistently low leachabilities of hydroceramic \#5 for both Simulant 1 and Simulant 2; and due to the presence of zeolites precursors in that hydroceramic, for all further zeolitization experiments, calcination process \#5 followed by an addition of extra metakaolinite (to yield hydroceramic \#5) was adopted. 


\subsection{In-depth hydroceramic improvements and characterization}

The previous phases of our work can be summarized as an endeavor to find the basic ingredients of a hydroceramic waste form. What follows is a detailed discovery process of the exact composition of this waste form.

\subsubsection{Determining the optimum proportion of calcine and extra clay}

The next step was to determine the optimum proportion of calcine and extra metakaolinite in order to obtain a hydroceramic with the highest quantities of zeolites. With Troy metakaolinite as the calcination aid, it was important to observe the effect of different ratios of metakaolinite and calcine $\# 5$ on leach results. In the next determination, different proportions of the two ingredients were mixed with sufficient water to make a thick paste. Each of these pastes was introduced nto individual Parr bombs and cured at $115^{\circ} \mathrm{C}$ for 24 hours, after a pre-cure of 24 hours at $90^{\circ} \mathrm{C}$.

It can be clearly observed from Figure 3-8 that conductivities increase with increase in the proportion of calcine with respect to the metakaolinite. Therefore the highest amount of metakaolinite feasible would have to be added to the calcine to derive a hydroceramic with lowest leachability.

However, addition of metakaolinite adds to the volume of the waste form. Also, though leach results show a decreasing trend with increasing metakaolinite ratios, there exists an optimum stoichiometric proportion that will ensure the production of the maximum amount of zeolites. This particular proportion depends on the chemical composition of the target zeolite. Pollucite was initially conceived as a host for radioactive wastes because of its excellent ability to encapsulate cesium. However, Vance and Adl inferred that sodium has little, if any, solubility in pollucite[20]. So, Pollucite could not be used for high-sodium bearing wastes. Christensen showed that krypton-85 could be entrapped in sodalite and that it could be routinely and reproducibly encapsulated in zeolite 5A [21]. From previous experiments with zeolites, Siemer had shown that sodalite is a good candidate for radionuclide encapsulation. With that in view, sodalite became the target zeolite in the preparation of these hydroceramics.

In this specific instance where substantial amounts of water-soluble sodium salts were present in the simulant, the proportion of $\mathrm{NaOH}$ (already present in the waste simulant) to metakaolinite was adjusted so that the product would having the generic sodalite formula $-\left\{\left(\mathrm{NaAlSiO}_{4}\right)_{3} \mathrm{NaX}\right.$, where $\mathrm{X}$ can be $\mathrm{SO}_{4}{ }^{2-}, \mathrm{NO}_{3}{ }^{-}, \mathrm{Cl}$, etc. $\}-$ could be produced. Siemer, et. al. have called this the "sodalite rule of thumb" [6]. This was expanded later to accommodate cesium and potassium as: $(\mathrm{Na}+\mathrm{K}+\mathrm{Cs})_{\mathrm{a}}: \mathrm{Al}_{\mathrm{b}}: \mathrm{Si}_{\mathrm{c}}: \mathrm{X}_{\mathrm{d}}$ where $\mathrm{b}$ $>=\mathrm{a} ; \mathrm{c}>=\mathrm{a} ; \mathrm{d}<=0.25 \mathrm{a}$; and $\mathrm{X}=$ sum of all "heteroanions" (i.e., $\mathrm{SO}_{4}{ }^{2-}, \mathrm{NO}_{3}{ }^{-}, \mathrm{Cl}$, etc.) [5].

From Figure 3-8 and from phase diagram calculations, it was determined that a calcine: metakaolinite ratio of 60:40 would produce the greatest amount of sodalite with the least amount of clay addition. Therefore, for future experiments, this was the proportion that was used in making the waste forms. 


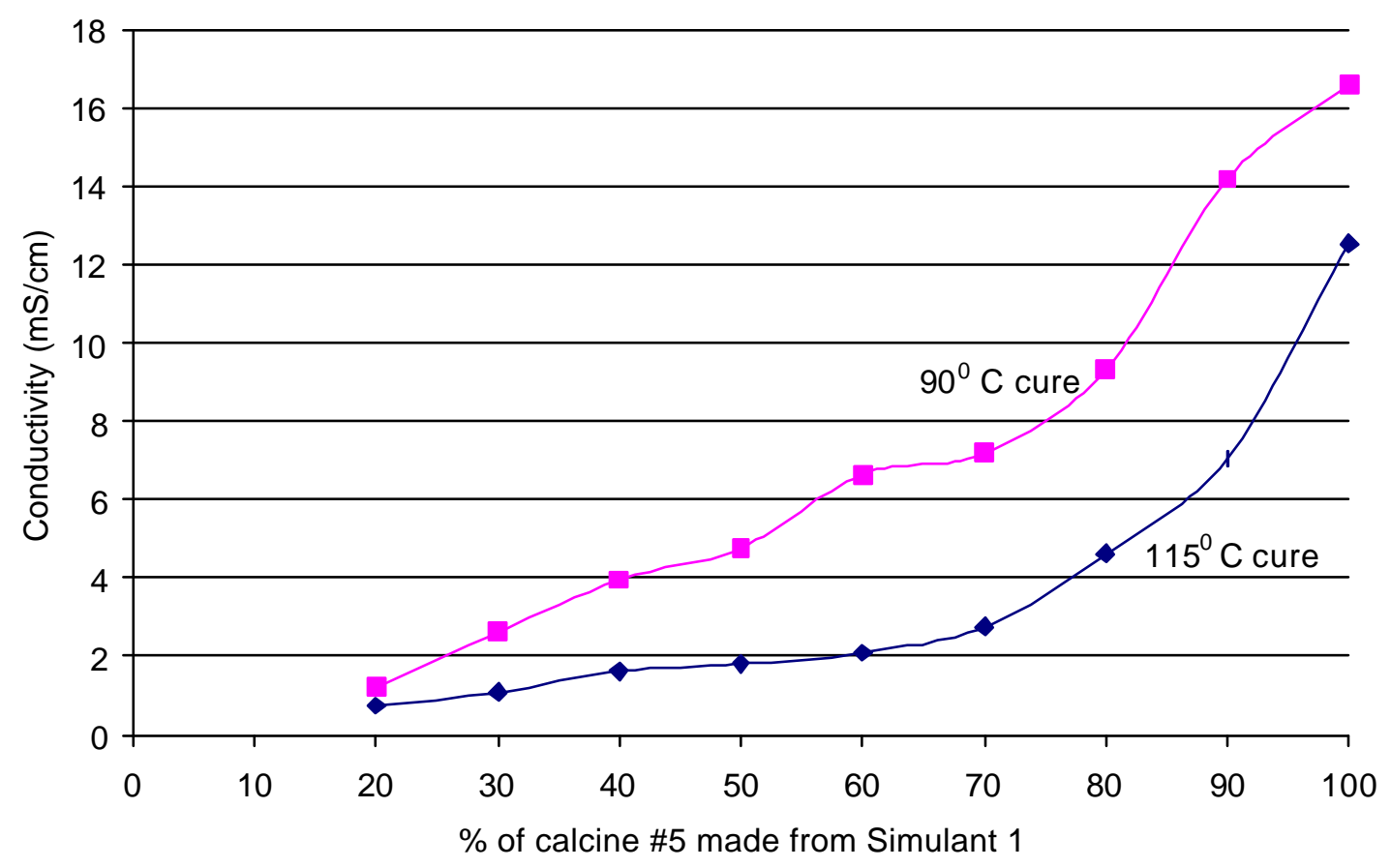

Figure 3-8: Effect of temperature on leachabilities of hydroceramics prepared with different proportions of Simulant 1 derived calcine \#5 and extra metakaolinite, and cured for 1 day at $90^{\circ} \mathrm{C}$ or $115^{\circ} \mathrm{C}$.

It is generally observed that there is a correlation between temperature and zeolite formation. Therefore, some runs were performed to compare the leachabilities of hydroceramics obtained after a curing at $90^{\circ} \mathrm{C}$ as opposed to at $115^{\circ} \mathrm{C}$, as is illustrated in Figure 3-8. The hydroceramics that were prepared at the higher temperature demonstrated lower leachabilities. However, the graph above suggests that with longer and longer duration of curing, the two curves will merge at some point.

This graph substantiates the fact that hydroceramics can be created at lower temperatures (below the boiling point of water) than originally thought. This also draws out one more advantage of hydroceramic waste forms over HLW glass. Vitrification requires very high temperatures (upwards of $1000^{\circ} \mathrm{C}$ ) of operation in making molten glass, whereas hydroceramic waste forms can be produced at relatively very low temperatures.

\subsubsection{Introduction of extra water during curing}

From initial experiments, it was observed that when extra water is introduced inside the Parr bombs during curing, the hydroceramics that were obtained had lower concentrations of analytes in their leach water than when the Parr bombs did not have extra water in them. However, a clear picture did not emerge regarding a correlation between the amount of extra water added and the concentrations of those analytes. All curing 
experiments were therefore carried out without the addition of extra water inside the bombs. Conditions within the bombs were assumed to be at $100 \%$ relative humidity throughout the curing periods.

\subsubsection{Compression Test results}

Compression strength tests were conducted on Simulant 1 derived hydroceramics. No extra water was added to the Parr bombs during curing. Figure 3-9 illustrates the high compressive strengths for hydroceramics. The DOE stipulates that radioactive waste forms must possess a compressive strength of at least 50 psi. Clearly, these hydroceramics fulfill that criterion.

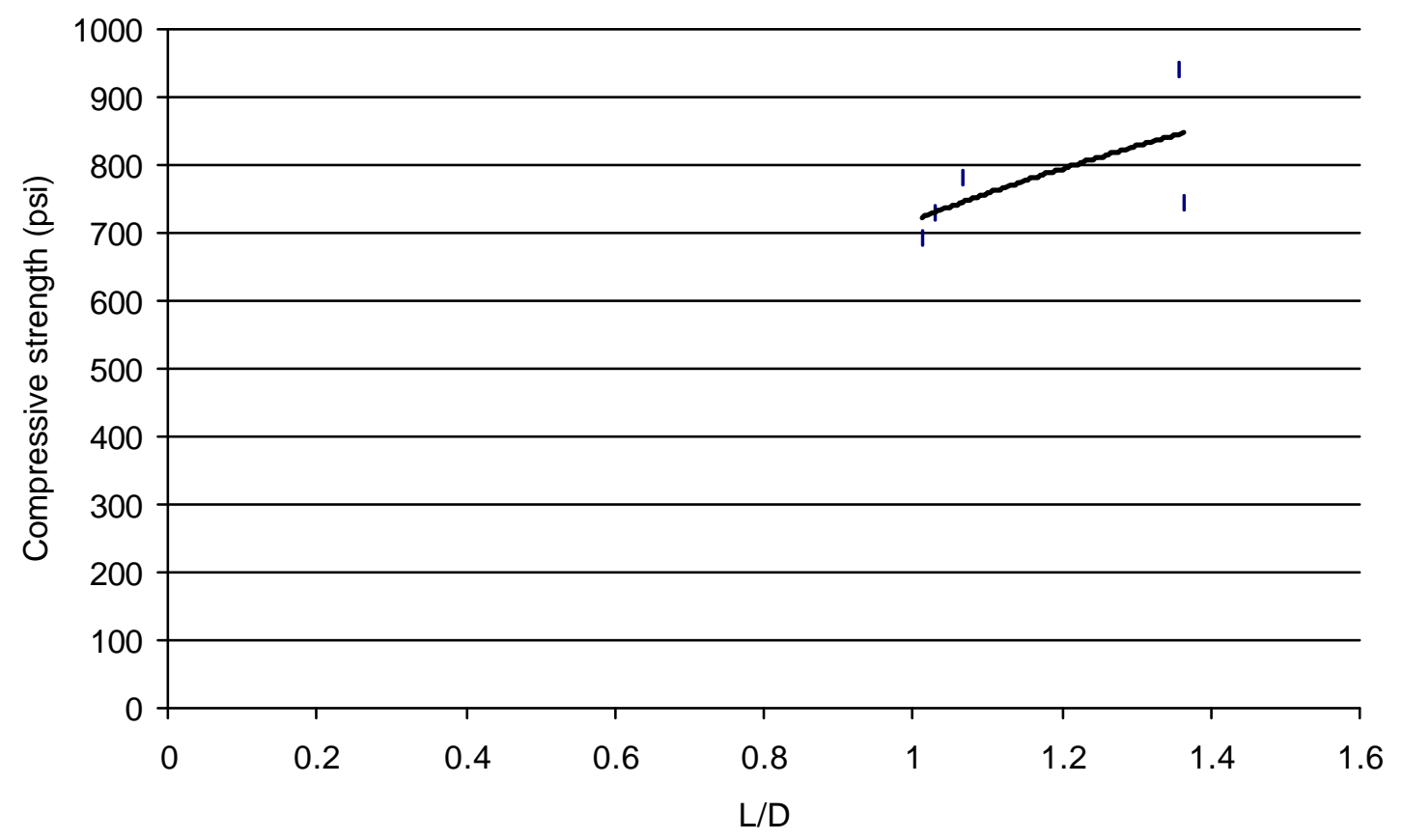

Figure 3-9: Comparison of aspect ratio (length to diameter ratio of cylindrical pellets) with compressive strengths of hydroceramics made from 60-wt\% Simulant 1 derived calcine \#5 and 40-wt\% metakaolinite; cured at $115^{\circ} \mathrm{C}$ for 7 days.

\subsection{Extension of the process to Hanford waste}

Encouraged by the results obtained using Simulants 1 and 2, a third simulant was developed as described in Table 3-3. Simulant 3 represents an average supernate composition of SBW in Hanford tanks. The simulant was based upon a recipe by Brough et. al. (1995). 
Table 3-3. Hanford Simulant to make One Liter (weights in grams)

\begin{tabular}{|l|l|}
\hline Compound & Hanford \\
\hline $\mathrm{NaOH}$ & 82.6819 \\
\hline $\mathrm{Al}\left(\mathrm{NO}_{3}\right)_{3} \bullet 9 \mathrm{H}_{2} \mathrm{O}$ & 133.5 \\
\hline $\mathrm{NaNO}_{2}$ & 36.9106 \\
\hline $\mathrm{Na}_{2} \mathrm{CO}_{3}$ & 36.2049 \\
\hline $\mathrm{NaNO}_{3}$ & 8.5815 \\
\hline $\mathrm{Na} 2 \mathrm{HPO}_{4}$ & 27.7873 \\
\hline $\mathrm{KCl}$ & 1.8328 \\
\hline $\mathrm{NaCl}$ & 2.5077 \\
\hline $\mathrm{Na}_{2} \mathrm{~B}_{4} \mathrm{O}_{7} \bullet 10 \mathrm{H}_{2} \mathrm{O}$ & 0.1096 \\
\hline $\mathrm{Na} \mathrm{SO}_{4}$ & 3.8945 \\
\hline $\mathrm{Ni}\left(\mathrm{NO}_{3}\right)_{2} \cdot 6 \mathrm{H}_{2} \mathrm{O}$ & 0.3115 \\
\hline $\mathrm{Ca}\left(\mathrm{NO}_{3}\right)_{2} \bullet 4 \mathrm{H}_{2} \mathrm{O}$ & 0.4420 \\
\hline $\mathrm{Mg}\left(\mathrm{NO}_{3}\right)_{2} \bullet 6 \mathrm{H}_{2} \mathrm{O}$ & 0.0337 \\
\hline
\end{tabular}

After undergoing a similar procedure for calcination and curing as was performed on Simulates 1 and 2, the zeolitic Hanford waste form showed leachabilities as shown in Figure 3-10.

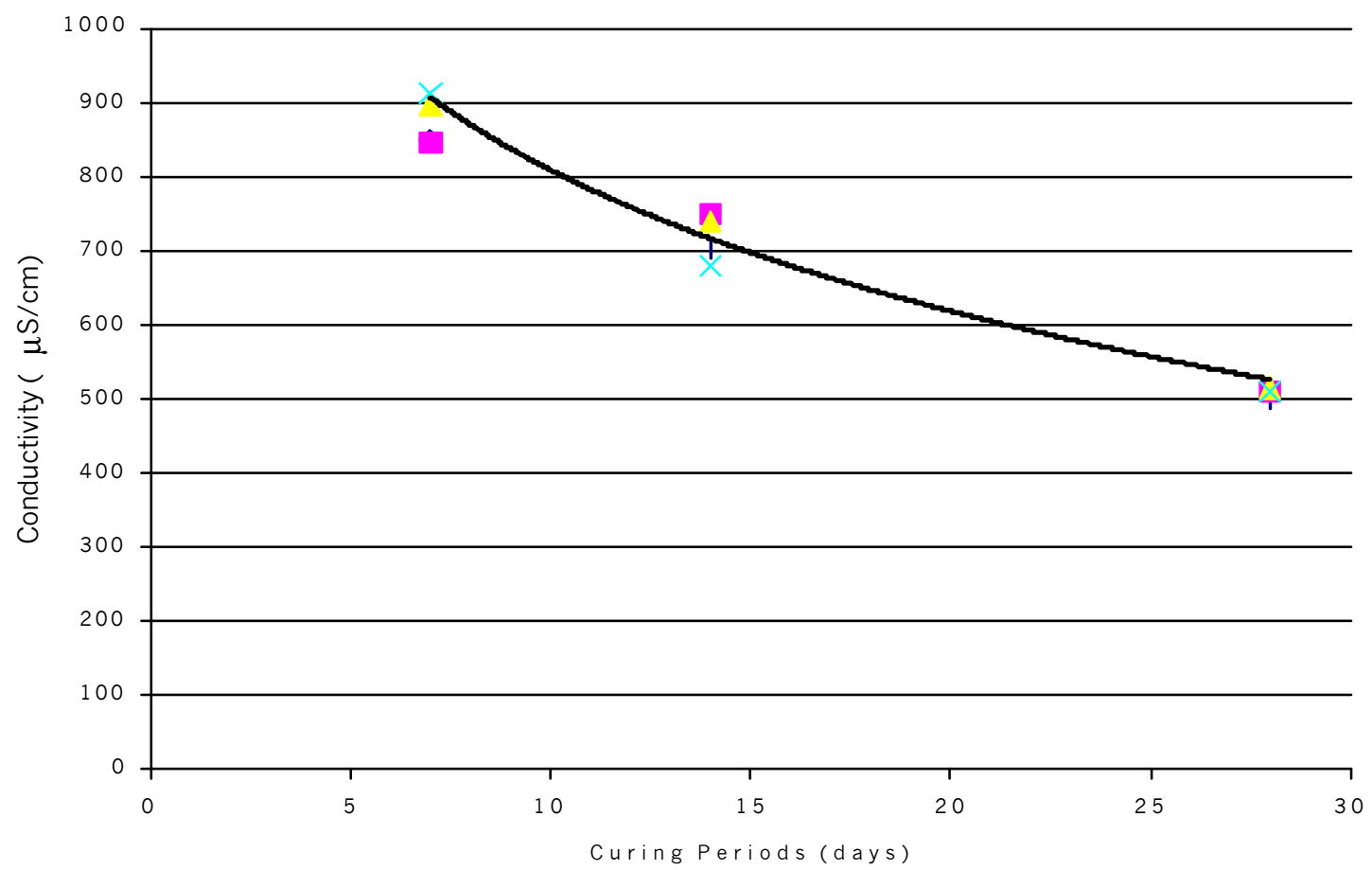

Figure 3-10: Leach Test results with waste form created from 60-wt\% calcine \#5 derived from Hanford simulant and 40 -wt\% extra metakaolinite and cured at $115^{\circ} \mathrm{C}$. Points on the graph represent four similar samples. Deviations are minimal. 
The phase development for a $90^{\circ} \mathrm{C}$ cured hydroceramic is given in Figure $3-11$. The pattern is dominated by hydroxysodalite peaks. The SEM picture in Figure 3-12 shows some spherical zeolites that appear to be those of hydroxysodalite, and many clay plates.

\subsection{Comparison of metakaolinite sources}

Siemer contends that the nature of the substrate pozzolan (clay) is the single most important variable in the manufacture of hydroceramics. [12] By this time, metakaolinite had proved itself as an ideal hydroceramic ingredient. Different sources of metakaolinite could now be tested to see if there existed any significant variations in the qualities of the hydroceramics produced. To this end, a batch of calcined clay was procured from Engelhard Corp., Illinois. Each of the three waste calcines was mixed with it in the ratio 60:40 (as before) and enough water to make a stiff paste. These were cured in Parr bombs inside a $90^{\circ} \mathrm{C}$ furnace for different times.

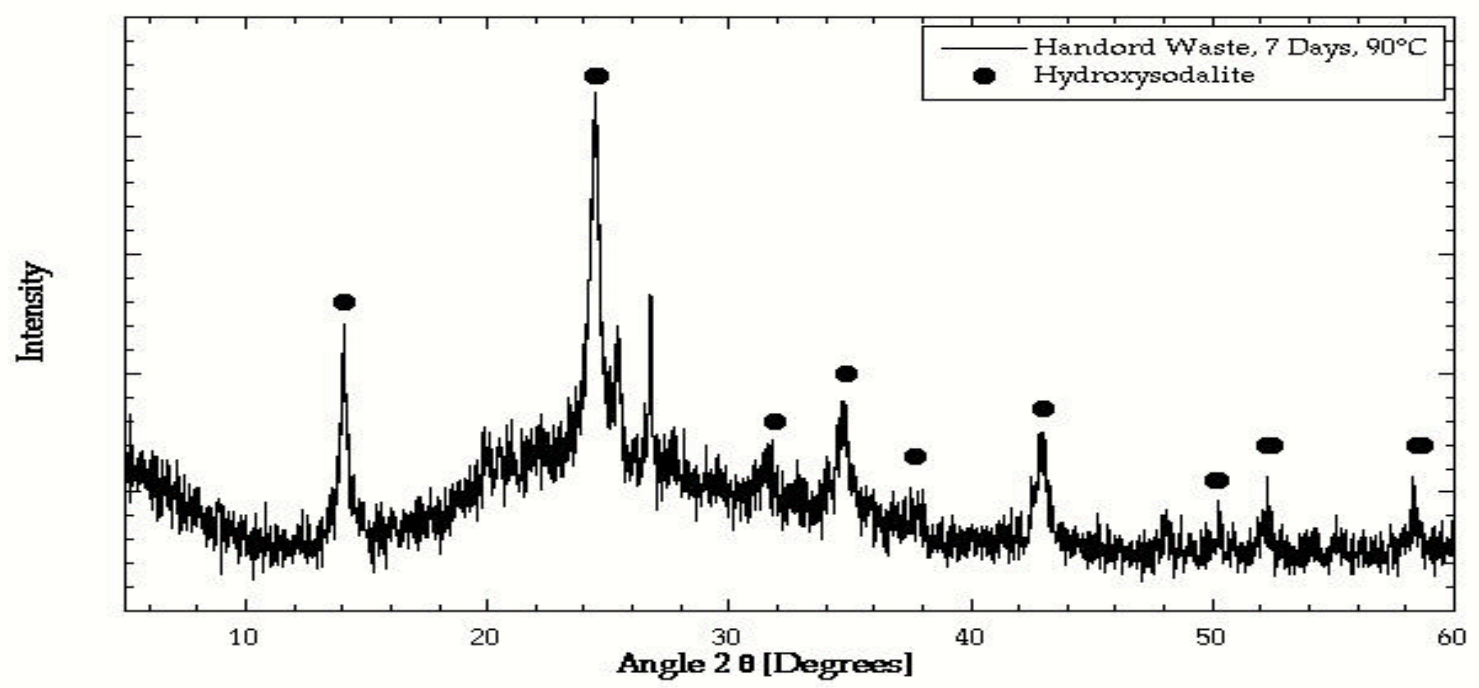

Figure 3-11: X-ray diffraction pattern for 60-wt\% calcine \#5 derived from Hanford Simulant and 40-wt\% Troy metakaolinite, plus water. Sample was cured at $90^{\circ} \mathrm{C}$ for seven days.

\subsubsection{Engelhard metakaolinite as hydroceramic ingredient}

Leach tests for the hydroceramics made with the three simulants and Engelhard metakaolinite are illustrated in Figure 3-13. Hydroceramics prepared from Simulant 2 or Simulant 3, and Troy metakaolinite leached as shown in Figure 3-14. By comparing Figure 3-13 to Figure 3-14, one sees that for each curing period, the leach values of hydroceramics made with Engelhard metakaolinite are equal to or lower than for those made with Troy metakaolinite. The difference in conductivities becomes more obvious when one considers 
the fact that the Engelhard derived hydroceramics were only cured at $90^{\circ} \mathrm{C}$ whereas the Troy metakaolinite hydroceramics were cured at $115^{\circ} \mathrm{C}$. We know from Figure 3-8 that there is significant temperature-conductivity dependence. Thus, it can be inferred that the leachabilities of hydroceramics made with the Engelhard material are always noticeably lower than those made with Troy metakaolinite.

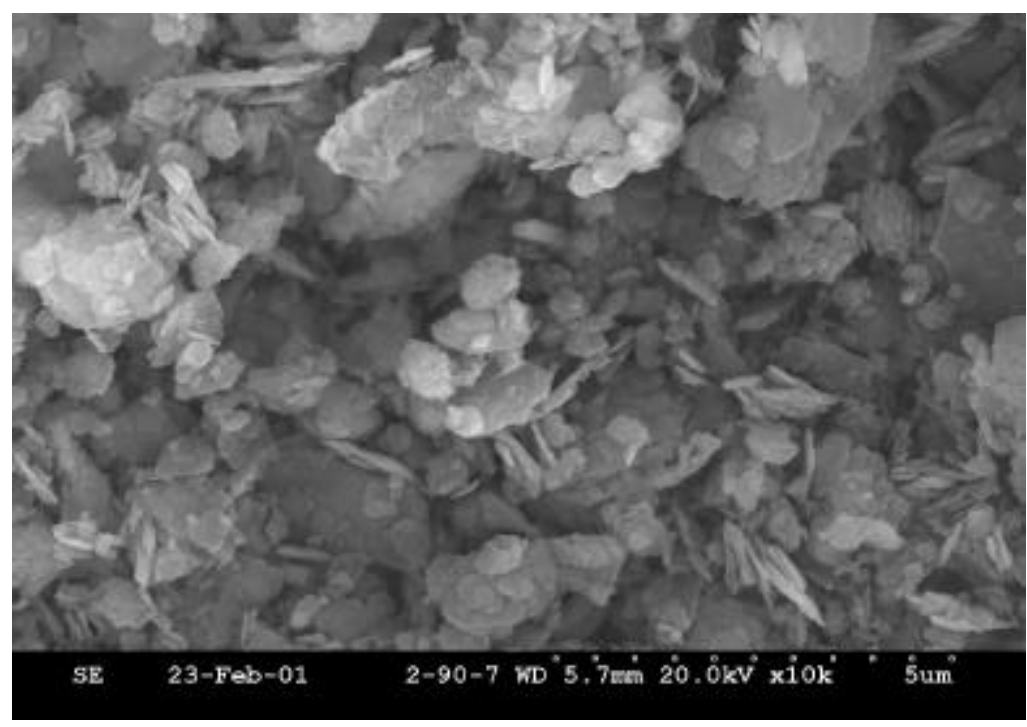

Figure 3-12: View represents a $10 \mathrm{~K}$ magnification of the microstructure of hydroceramic made with 60-wt\% calcine \#5 derived from Hanford Simulant and 40-wt\% extra metakaolinite; cured for 7 days at $90^{\circ} \mathrm{C}$.

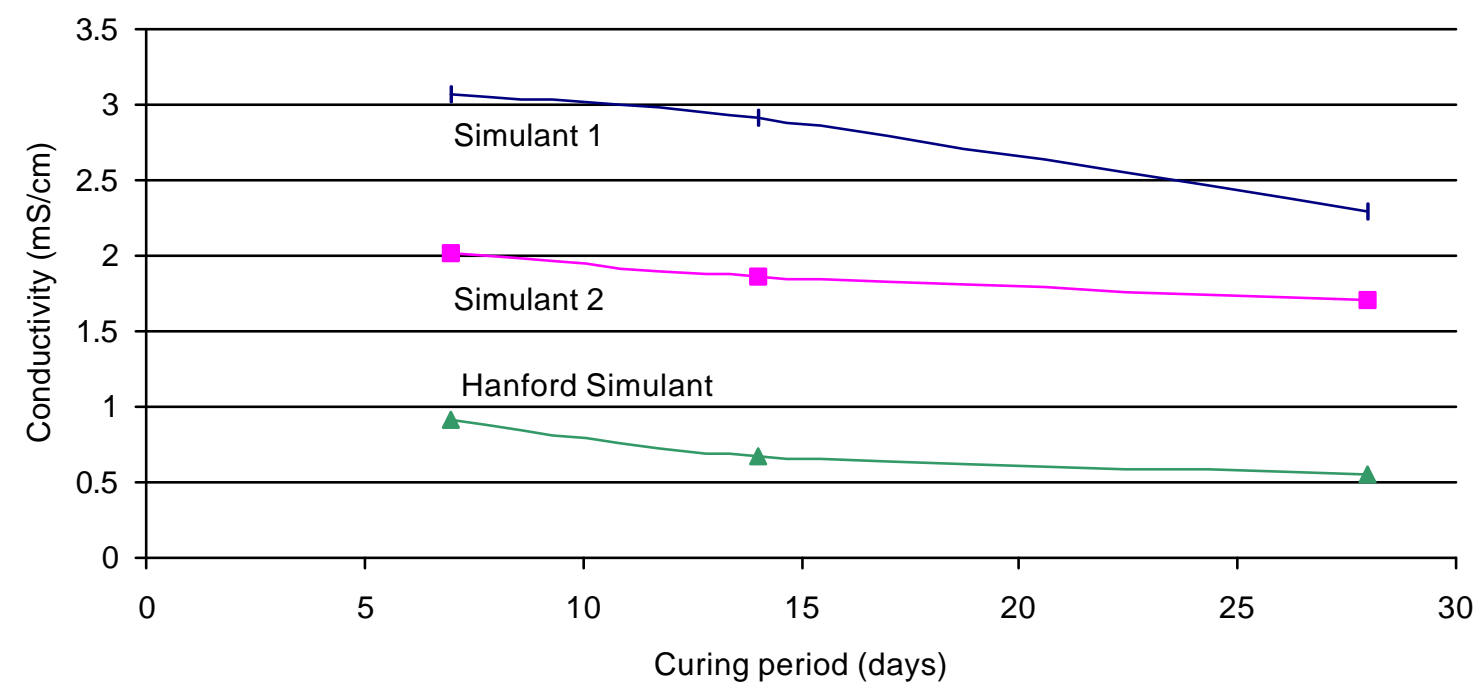

Figure 3-13: PCT leach data for hydroceramic waste forms created from 60-wt\% calcine \#5 derived from three simulants and 40-wt\% Engelhard metakaolinite; cured at $90^{\circ} \mathrm{C}$ for various durations. 
However, another notable observation was made. In spite of curing for a period of 7 days, the hydroceramics made with Hanford calcine still displayed some viscosity; they never hardened. The hydroceramics prepared from the calcines derived from Simulant 1 and Simulant 2 were in a solid form but were still weak relative to those made from Troy metakaolinite. The X-ray patterns for the hydroceramics derived from Simulant 2 and from Hanford simulant; mixed with Engelhard metakaolinite are displayed in Figures 3- 15 and Figure 3-16.

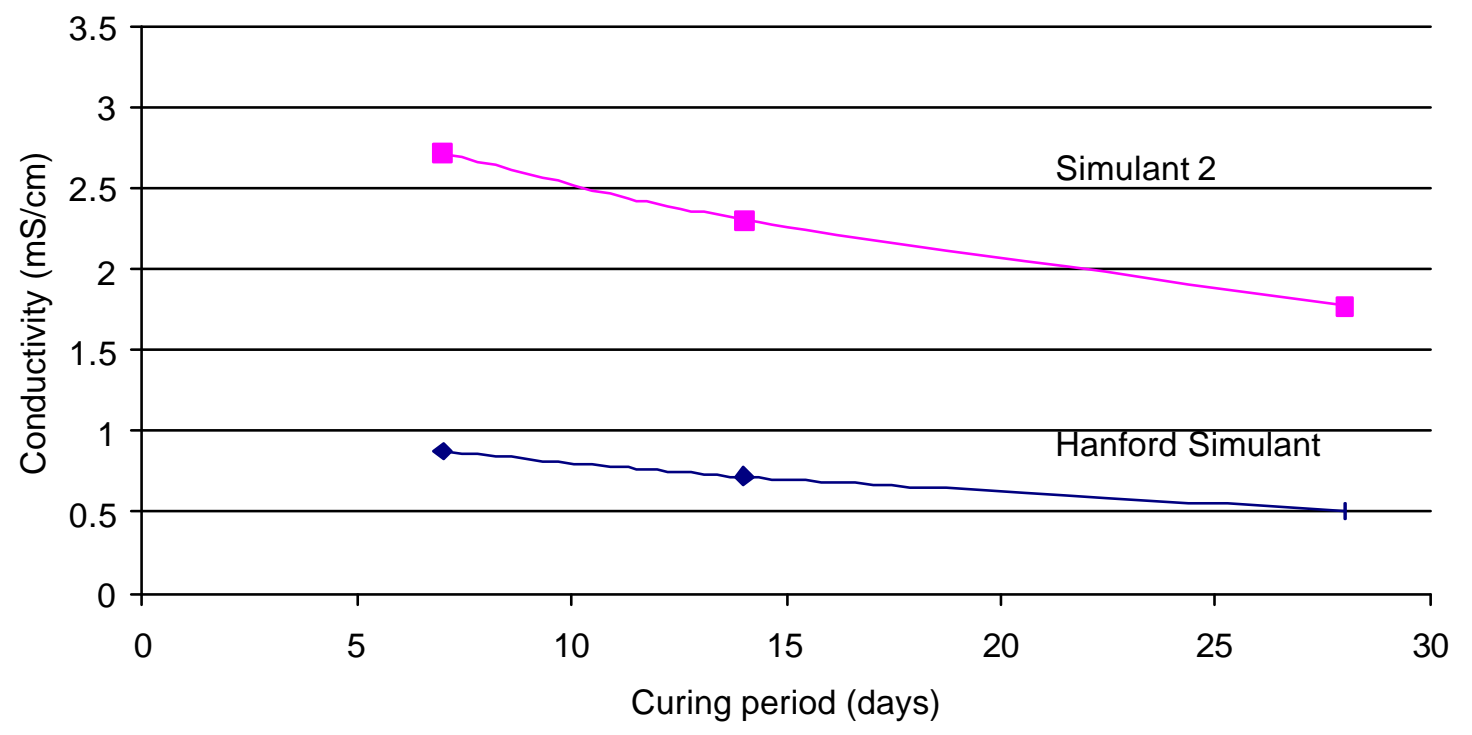

Figure 3-14: PCT leach data for hydroceramic waste forms created from 60-wt\% calcine \#5 derived from two simulants and 40-wt\% Troy metakaolinite; cured at $115^{\circ} \mathrm{C}$ for various times.

As may be observed, there is little indication of crystalline phases with the use of Engelhard clay, especially with Hanford simulant. This suggests that most of the Engelhard metakaolinite has reacted, but the highly disorganized crystallites that formed have not yet developed a long-range order needed to be detected by the X-ray diffraction analysis. Engelhard clay is a very fine material with a high surface area to weight ratio. This property leads to low leachabilities in the hydroceramics because this clay lends itself to rapid reaction with the sodium bearing waste in the calcine. Yet, this same characteristic gives the resulting hydroceramic poor strength properties. This is due to the lack of formation of cohesive microstructures in the hydroceramic. It is necessary for the waste form to have a minimum compressive strength of 50 psi to undergo without disintegration the rigors of stacking, transporting and long-term storage at repositories. Given the very weak hydroceramics that were formed using Engelhard clay (the hydroceramics were simply too fragile to even be prepared for strength testing), it may be safely asserted that Engelhard clay does not yield suitable hydroceramics. 


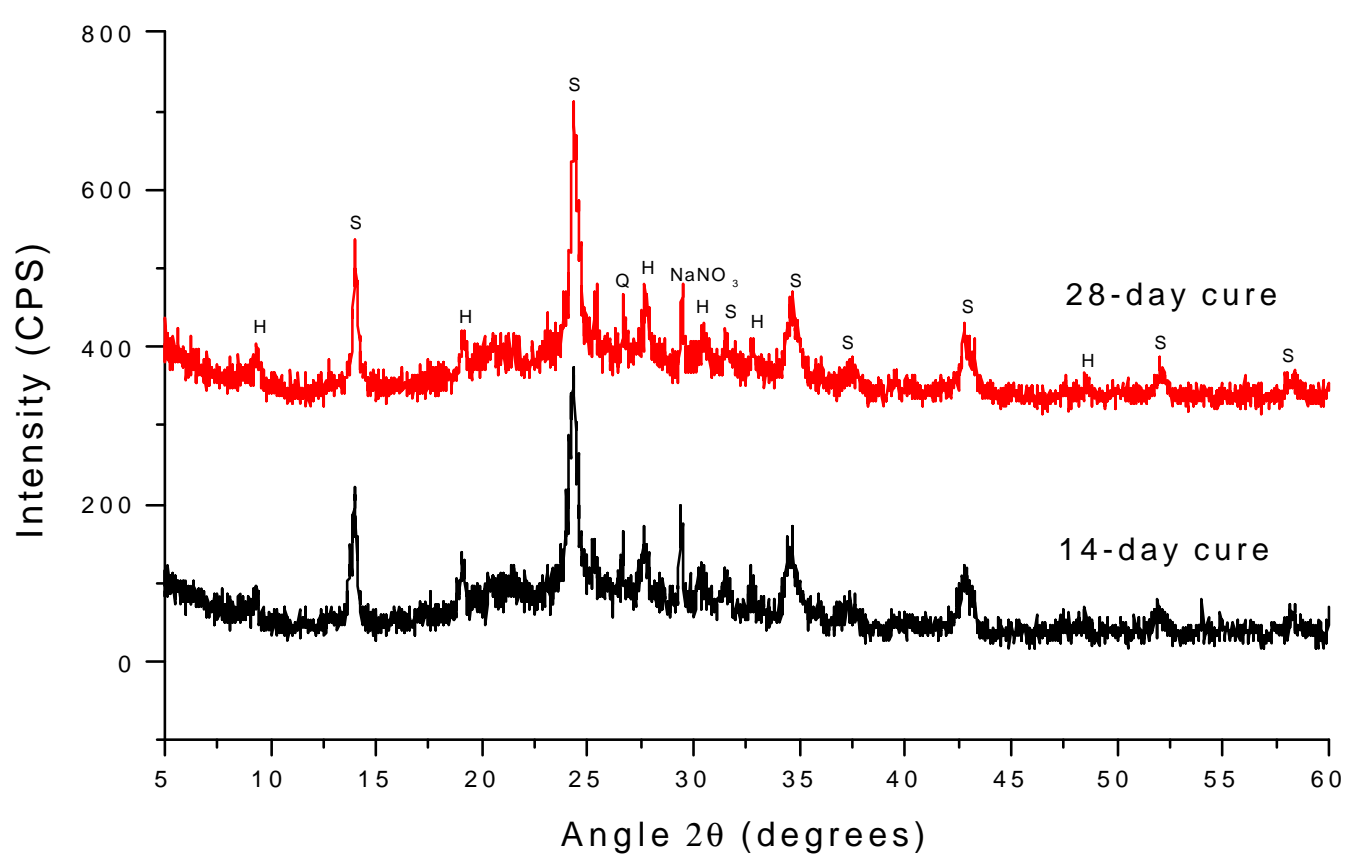

Figure 3-15: X-ray diffraction patterns of hydroceramics obtained from 60-wt\% calcine \#5 derived from Simulant 1 and 40 -wt of Engelhard clay; cured at $90^{\circ} \mathrm{C}$ for 14 days and 28 days. S: Sodalite; Q: Quartz; H: Hershellite; $\mathrm{NaNO}_{3}$ : sodium nitrate.

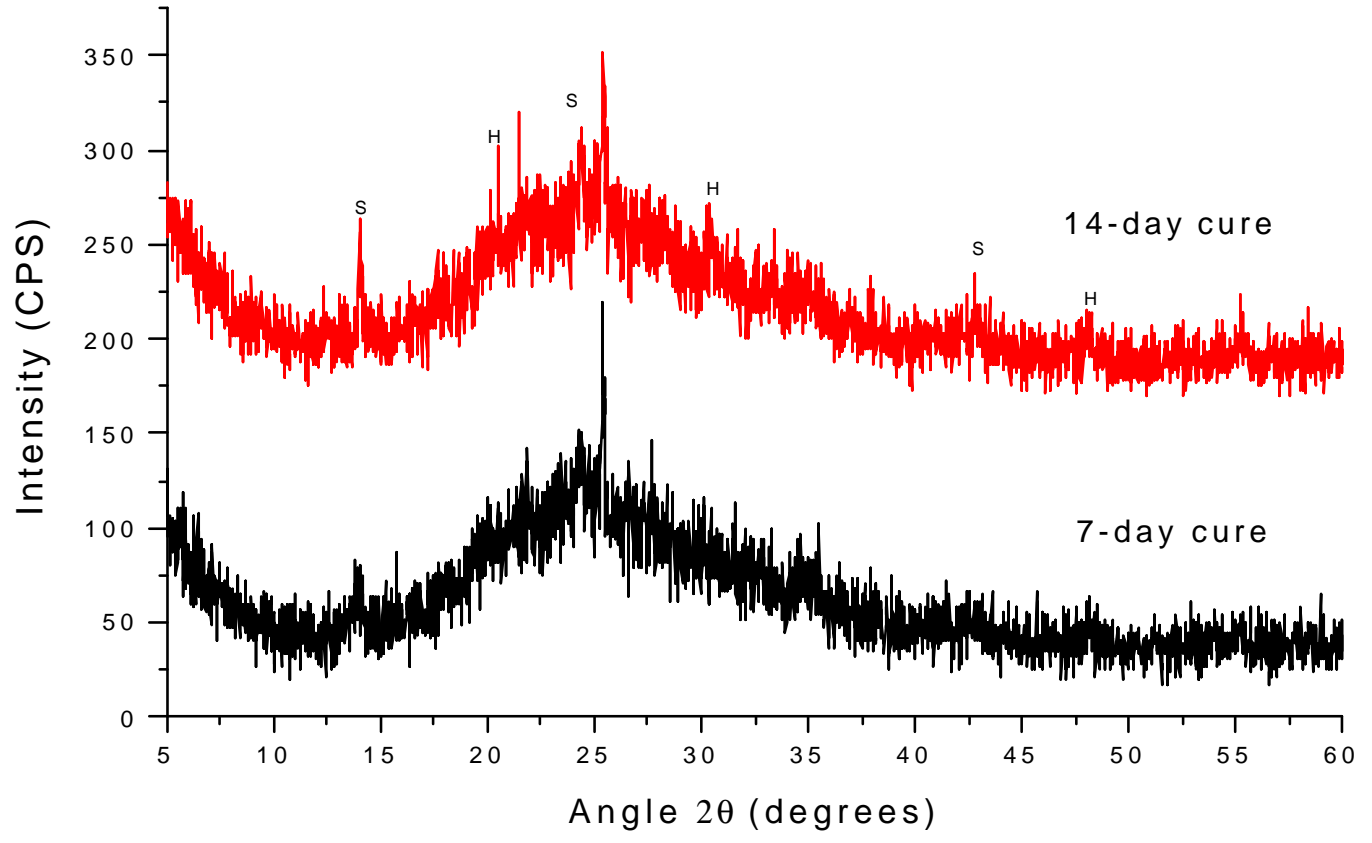

Figure 3-16: X-ray diffraction patterns of hydroceramics obtained from 60-wt\% calcine $\# 5$ derived from Simulant 3 and 40 -wt o of Engelhard clay; cured at $115^{\circ} \mathrm{C}$ for 7 days and 14 days. S: Sodalite; H: Hershellite. 


\subsection{2. "45-micron clay" as hydroceramic ingredient}

After the failure of Engelhard clay as a potential hydroceramic raw material, clay from another origin was tested. This was obtained from Troy, Idaho in the form of lumps of gray-brown kaolinite. At The Materials Research Laboratory, this batch was then calcined at $500^{\circ} \mathrm{C}$ to yield metakaolinite; ground in a ball-mill for about a week and then sieved. The fraction that passed 45-micron sieve was retained for future testing. This batch of clay was therefore termed "45-micron clay".

Since this clay was a very fine powder similar to Engelhard clay, it was thought that the addition of sodium hydroxide during mixing would have a beneficial effect on the strength of the resulting hydroceramic. The presence of extra sodium thus introduced, was thought to produce strong sodium aluminum silicates. Hence, each of the three calcines was dry- mixed with enough 45-micron clay to produce a calcine: clay ratio of 60:40. Then, one set of samples was mixed with sufficient water to make a stiff paste. In the other set, a twomolar solution of sodium hydroxide replaced de-ionized water during mixing. This gave six samples - two for each waste calcine. All these preparations were cured at a temperature of $115^{\circ} \mathrm{C}$ for various durations, after a pre-cure of $90^{\circ} \mathrm{C}$ for 24 hours. Besides, one sample with Hanford-calcine: clay ratio of 60:40 was mixed with water to produce a stiff paste and was cured at $90^{\circ} \mathrm{C}$ for different time durations. Figure 3-17 shows the leach characteristics of these hydroceramics.

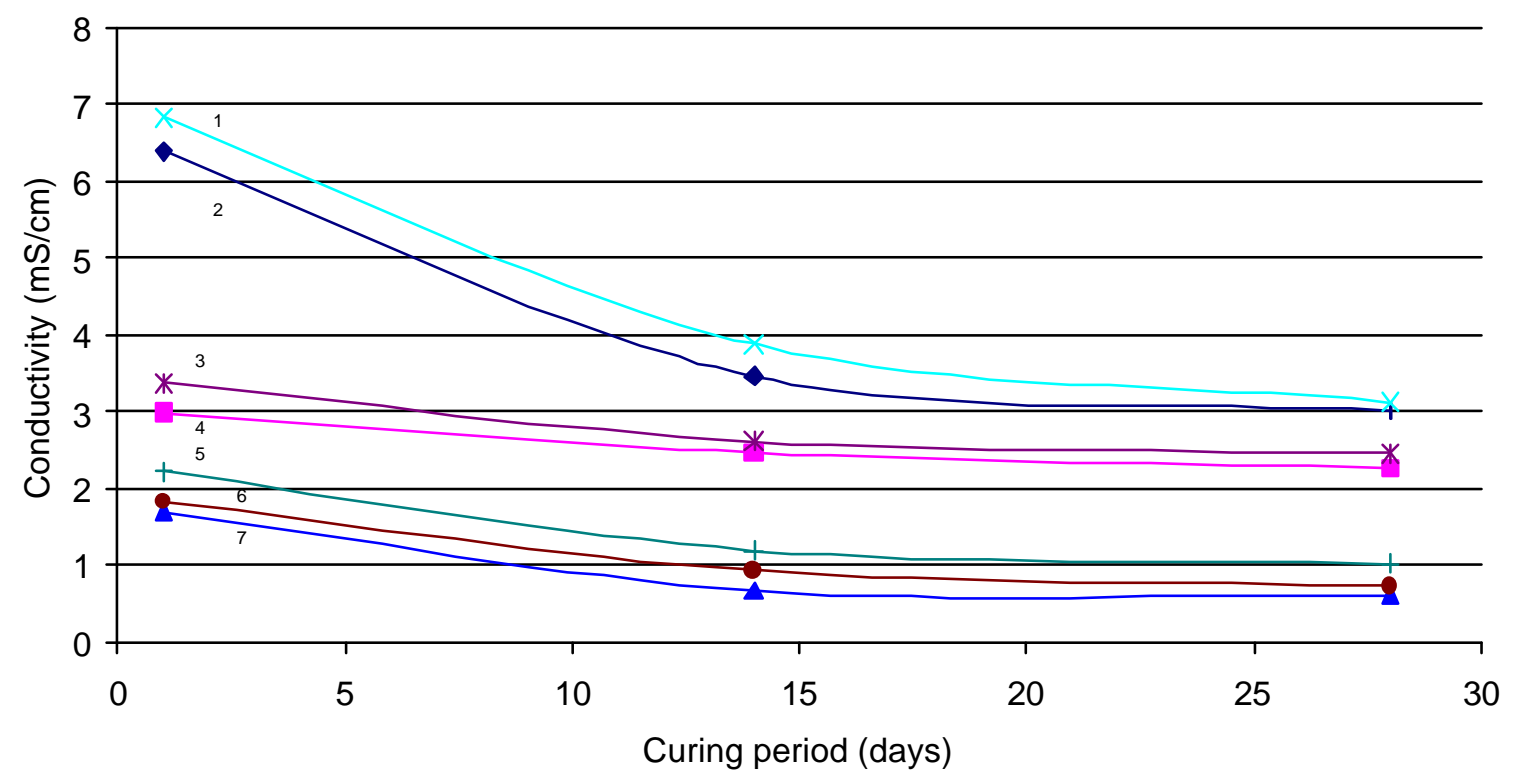

Figure 3-17: Leach curves of hydroceramics obtained from 60-wt\% calcine \#5 derived from the three simulants and 40-wt\% of 45-micron clay; cured at $115^{\circ} \mathrm{C}$ (curves 1,2 , $3,4,6,7)$ or $90^{\circ} \mathrm{C}$ (curve 5) for various durations. Curve 1: Simulant 1 with $2 \mathrm{M} \mathrm{NaOH}$; Curve 2: Simulant 1 with water; Curve 3: Simulant 2 with 2M NaOH; Curve 4: Simulant 2 with water; Curve 5: Simulant 3 with water; Curve 6: Simulant 3 with 2MNaOH; Curve 7: Simulant 3 with water. 
It was observed that at each of the time periods when samples were taken out to conduct the PCT, those samples made with $2 \mathrm{M} \mathrm{NaOH}$ were harder than those made with deionized water. Samples made with Hanford calcine and water would crumble upon moderate pressure in the palm of the hand. However, the sample made with Hanford calcine and $\mathrm{NaOH}$ could only be broken with a hammer. However, as can be seen from the leach studies, the samples with extra $\mathrm{NaOH}$ also gave rise to higher conductivities, owing to increased sodium leaching out of the hydroceramics. The diffraction patterns are displayed in Figure 3-18, Figure 3-19, Figure 3-20, Figure 3-21, Figure 3-22 and Figure 3-23 for comparison.

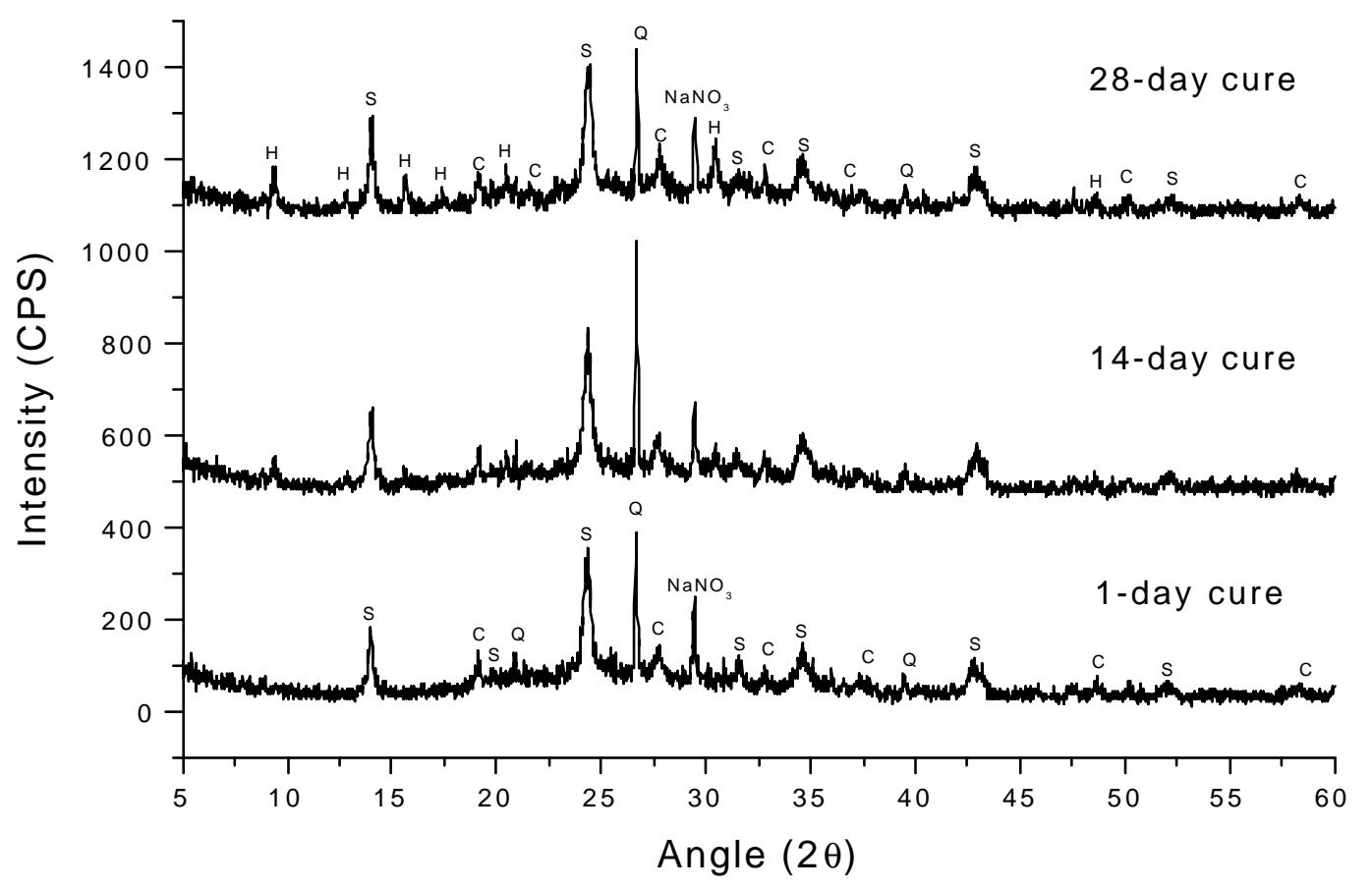

Figure 3-18: X-ray diffraction patterns of hydroceramics obtained from 60-wt\% calcine \#5 derived from Simulant 1 and 40-wt\% of 45-micron clay, with water as mixing agent; cured at $115^{\circ} \mathrm{C}$ for 1 day, 14 days and 28 days. S: Sodalite; H: Hershellite; C: Cancrinite; $Q$ : Quartz; $\mathrm{NaNO}_{3}$ : sodium nitrate.

Figure 3-18 shows the existence of hershellite at 28-day cure whereas it is absent at a 7-day cure. This is not a newly observed phenomenon. A parallel observation was made by Chang and Shih who showed through their zeolite synthesis experiments using fly ash, that the nature of the zeolite formed is dependent on the curing temperature. While at $60^{\circ} \mathrm{C}$, they obtained faujasite, they formed zeolite $\mathrm{P}$ at $90^{\circ} \mathrm{C}[22]$. 


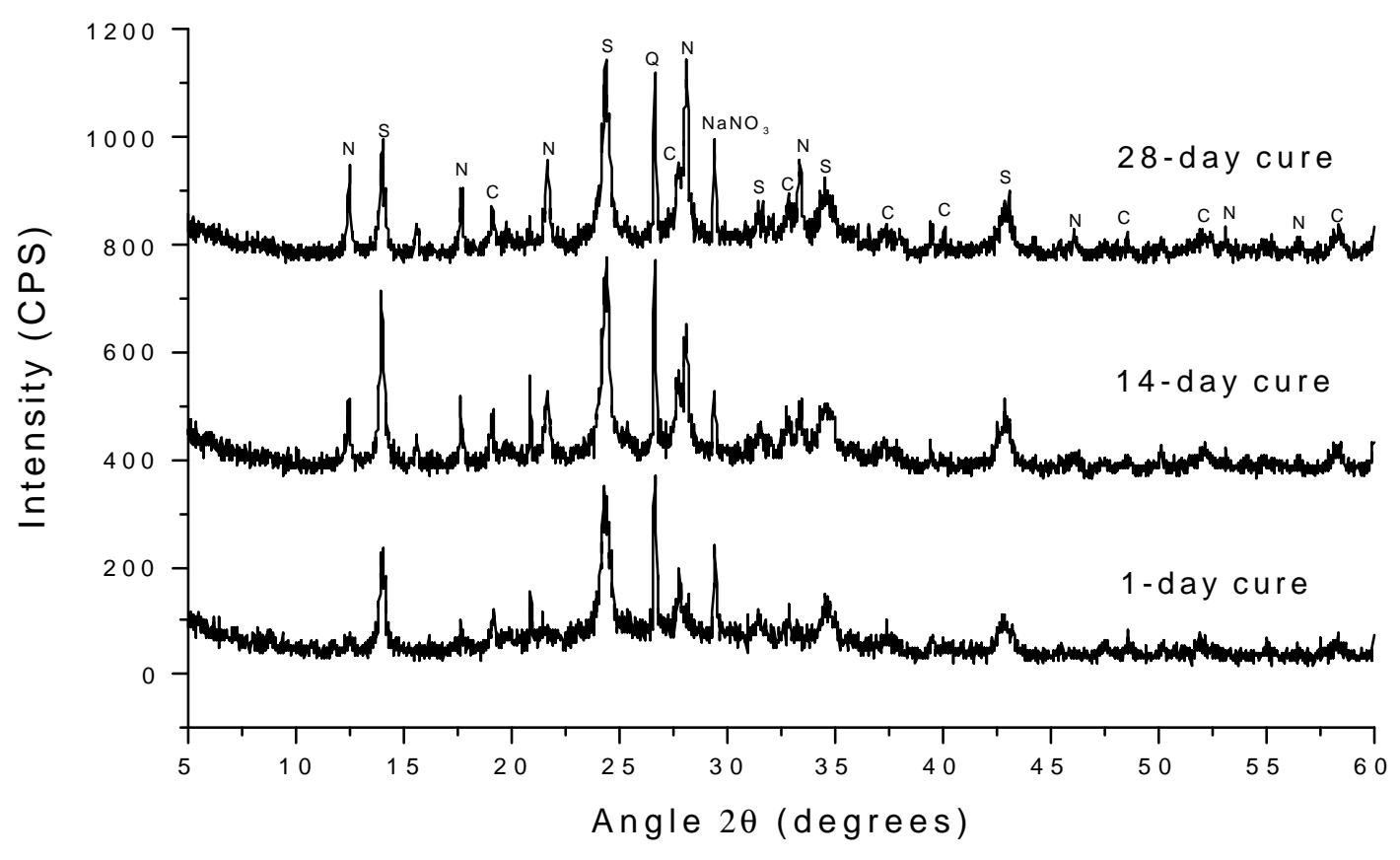

Figure 3-19: X-ray diffraction patterns of hydroceramics obtained from 60-wt\% calcine \#5 derived from Simulant 1 and 40-wt\% of 45-micron clay, with $2 \mathrm{MNaOH}$ as mixing agent; cured at $115^{\circ} \mathrm{C}$ for 1 day, 14 days and 28 days. S: Sodalite; N: Na-P1; C: Cancrinite; Q: Quartz; $\mathrm{NaNO}_{3}$ : sodium nitrate.

A simple observation can be made by comparing Figures 3-20 and 3-22 with Figures 3-21 and 3-23. There appears to be more crystalline peaks, specifically distinct zeolite peaks in the latter two figures. The reason that hydroceramics form salt-substituted sodalites and cancrinites rather than zeolites in samples made with water alone is that this minimal amount of water used to make these grouts causes initial concentrations of soluble salt/hydroxide to be extremely high. This is in line with observations by Siemer et. al. and with Breck's postulate. [6],[23]

This experiment demonstrates that if during the making of hydroceramics, the clay being used is of a quality that produces hydroceramics with excellent leachabilities, but with poor mechanical strengths, then the cautious introduction of concentrated sodium hydroxide may alleviate the problem, with a slight increase in leachable sodium. 


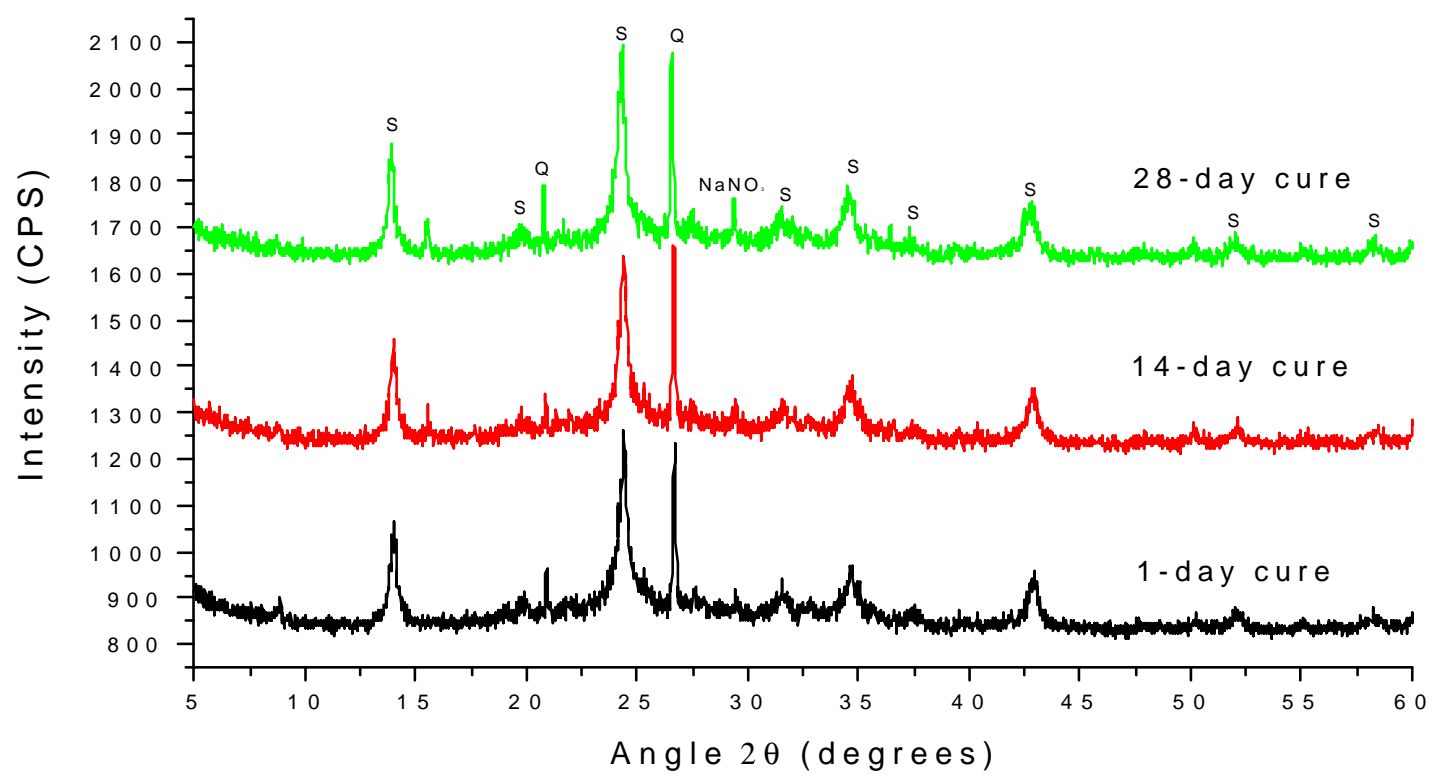

Figure 3-20: X-ray diffraction patterns of hydroceramics obtained from 60-wt\% calcine \#5 derived from Simulant 2 and 40-wt\% of 45-micron clay, with water as mixing agent; cured at $115^{\circ} \mathrm{C}$ for 1 day, 14 days and 28 days. S: Sodalite; Q: Quartz; $\mathrm{NaNO}_{3}$ : sodium nitrate.

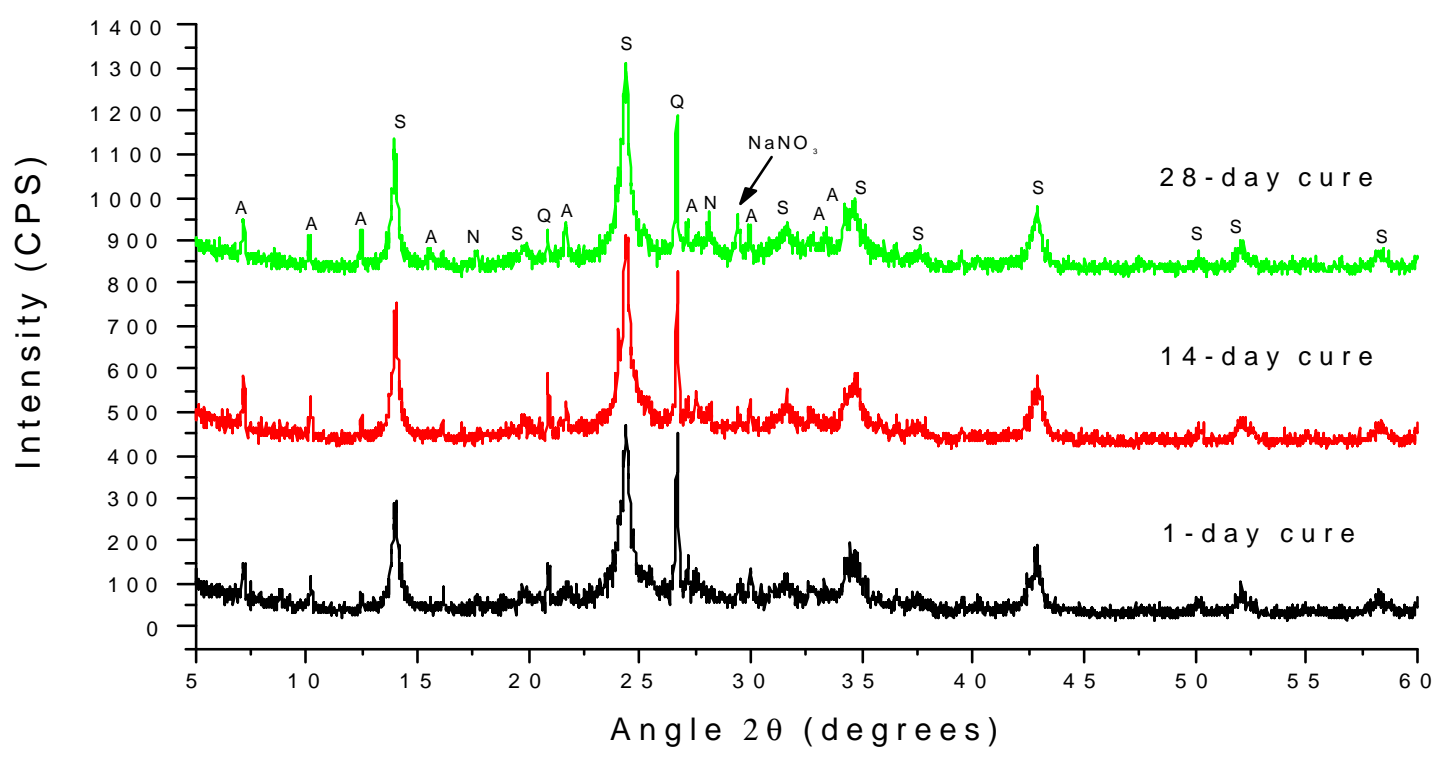

Figure 3-21: X-ray diffraction patterns of hydroceramics obtained from 60-wt\% calcine \#5 derived from Simulant 2 and 40-wt\% of 45-micron clay, with $2 \mathrm{MNaOH}$ as mixing agent; cured at $115^{\circ} \mathrm{C}$ for 1 day, 14 days and 28 days. S: Sodalite; Q: Quartz; A: Zeolite A; $\mathrm{N}$ : $\mathrm{Na}-\mathrm{Pl} ; \mathrm{NaNO}_{3}$ : sodium nitrate. 


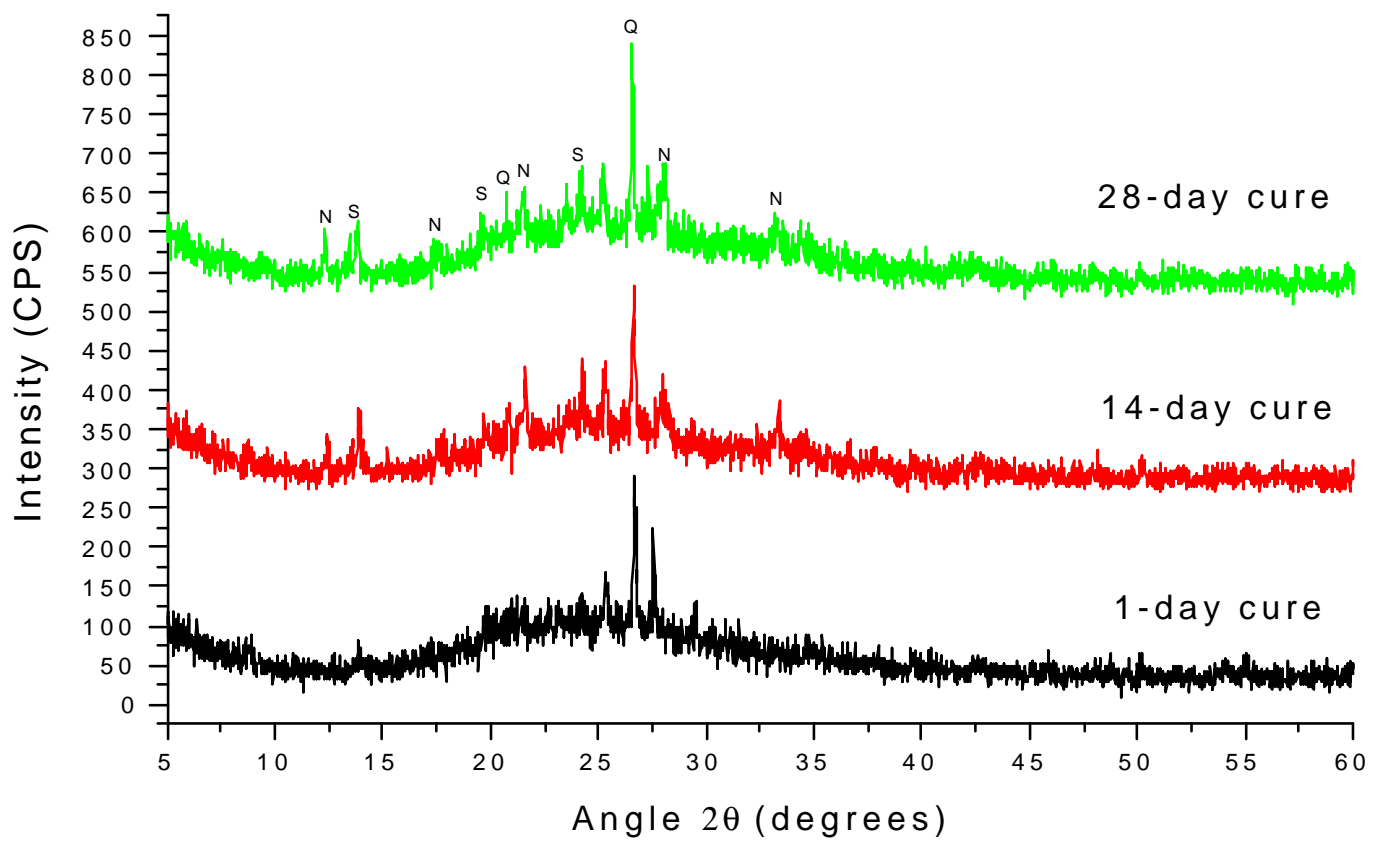

Figure 3-22: X-ray diffraction patterns of hydroceramics obtained from 60-wt\% calcine \#5 derived from Hanford Simulant and 40-wt\% of 45-micron clay, with water as mixing agent; cured at $115^{\circ} \mathrm{C}$ for 1 day, 14 days and 28 days. S: Sodalite; N: Na-P1; Q: Quartz.

\subsubsection{Strength enhancement of hydroceramics derived from Engelhard metakaolinite}

A different approach to aid the hydroceramics' strength would be to try different blends of clays. In this way, a clay that yielded admirable leach characteristics would be mixed with a clay that gave the hydroceramic sufficient strength. Engelhard clay and Troy metakaolinite were the two clays selected to test this hypothesis. Three different proportions of Engelhard clay and Troy metakaolinite were mixed with each other, and then mixed with Hanford calcine and water to produce a thick paste. These three mixtures were duplicated and upon curing at $115^{\circ} \mathrm{C}$ for seven days, produced hydroceramics with different hardnesses and leachabilities. Predictably, the hydroceramics made with a higher percentage of Troy metakaolinite were stronger than those made with higher percentage of Engelhard clay. 


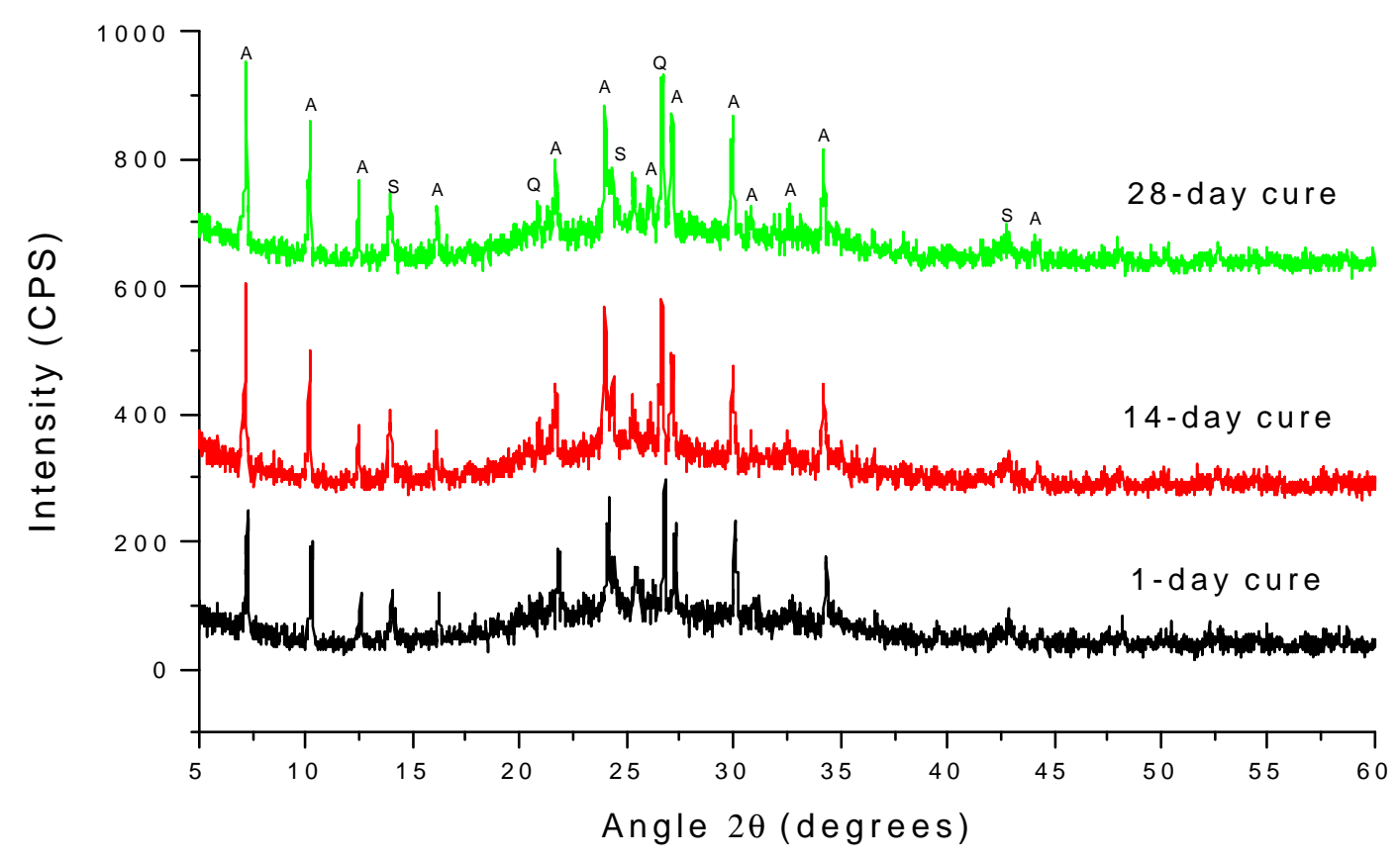

Figure 3-23: X-ray diffraction patterns of hydroceramics obtained from 60-wt\% calcine \#5 derived from Hanford Simulant and 40-wt\% of 45-micron clay, with $2 \mathrm{MNaOH}$ as mixing agent; cured at $115^{\circ} \mathrm{C}$ for 1 day, 14 days and 28 days. S: Sodalite; A: Zeolite A; Q: Quartz.

Another approach to producing hydroceramics with better mechanical properties would be the addition of extra silica. Two silica sources that were readily available in the laboratory received attention. One was a finely ground quartz sand used to manufacture aerated autoclaved concrete, henceforth termed "AAC sand". The other was 10-micron particle size min-U-Sil. Different proportions of Engelhard clay and either AAC sand or min-U-Sil were mixed with Hanford calcine and then cured at $115^{\circ} \mathrm{C}$ to produce hydroceramics. After 7-days and 28-days of curing, PCT was carried out. Figure 3-25 shows the trend in conductivities. Figure 3-26 and Figure 3-27 show the chemical composition of the leachate after PCT. Figure 3-28 and Figure 3-29 display the associated diffraction patterns.

It is relevant at this point to mention that cesium was not tested for in any of the leachates during these and following experiments. The formation of zeolites was a given in all hydroceramics produced in these experiments. Chang and Shih, and Shainberg and Kemper have showed that zeolites and clays have an affinity towards cesium more than for sodium [22], [1]. Therefore, a decreasing trend in sodium concentration in leachates obtained with better hydroceramics indicates that cesium uptake has been achieved by the zeolites and that sodium is now being encapsulated in the remaining channels. 


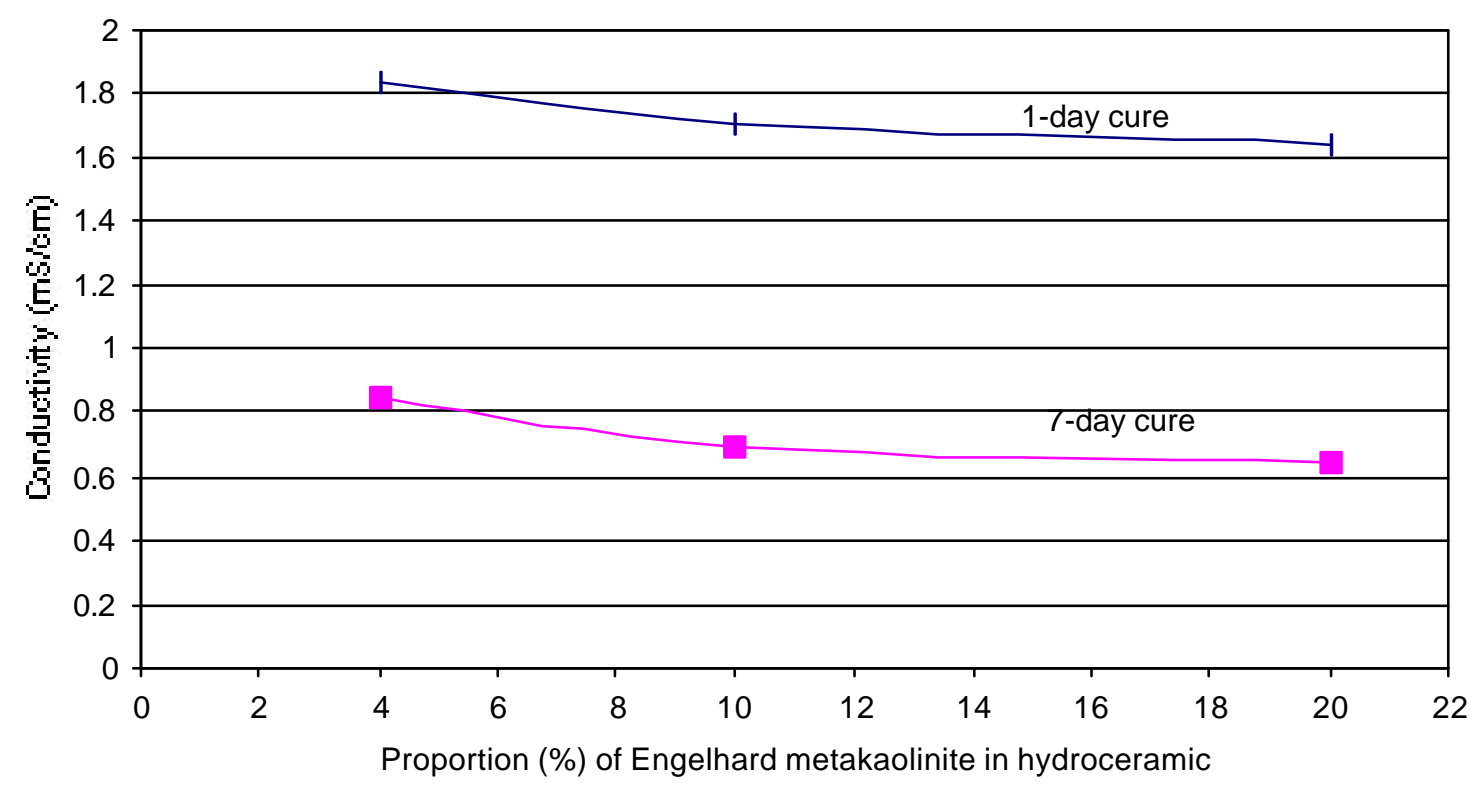

Figure 3-24: Leach curves of hydroceramics obtained from 60-wt\% calcine \#5 derived from Hanford Simulant, and different proportions of Engelhard metakaolinite and Troy metakaolinite together making up 40-wt\%; cured at $115^{\circ} \mathrm{C}$ for 1 day or 7 days.

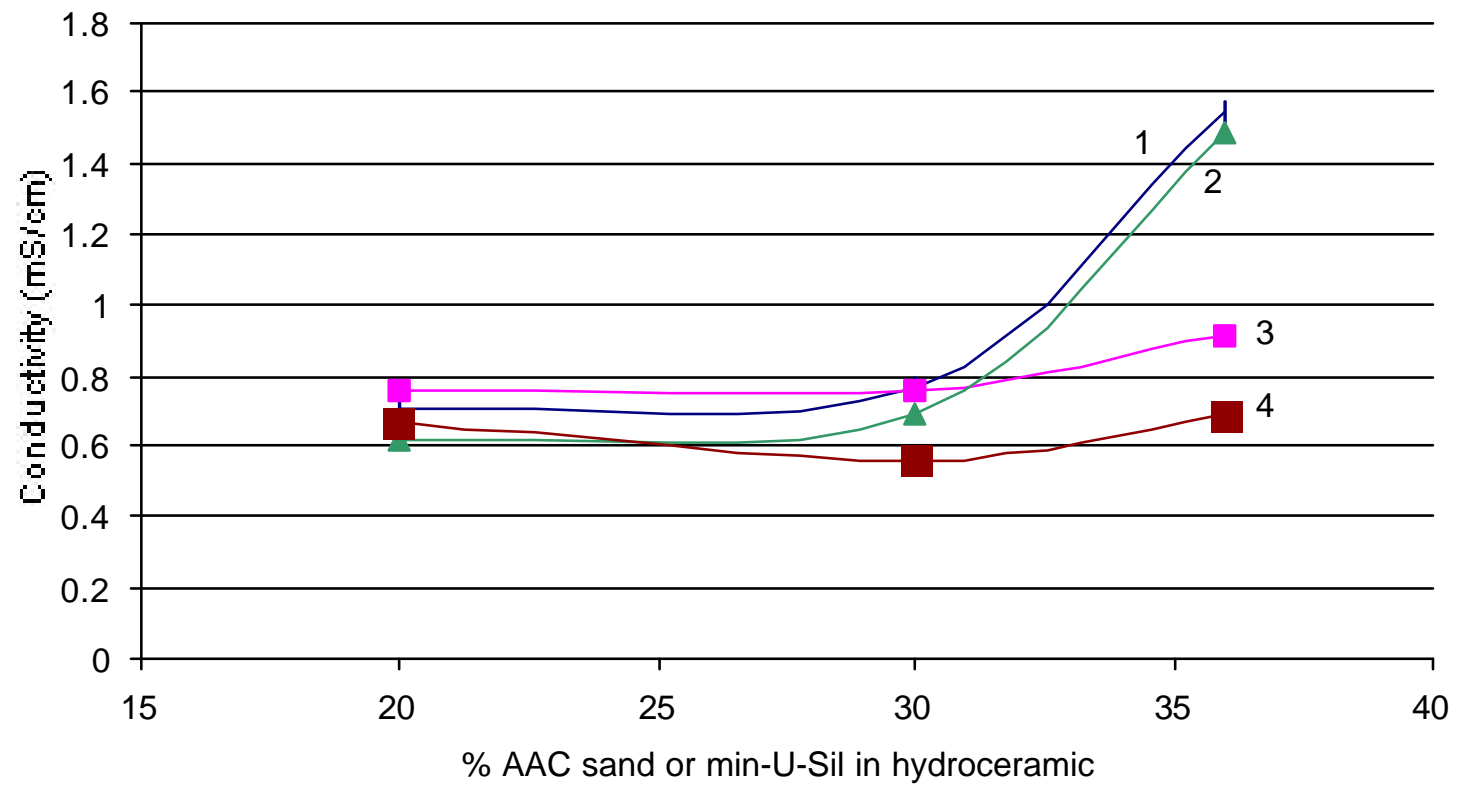

Figure 3-25: Leach curves of hydroceramics obtained from 60-wt\% of calcine \#5 derived from Hanford Simulant, $x$-wt $\%$ of AAC sand or 10-micron Min-U-Sil, and (40-x)wt \% of Engelhard metakaolinite; cured at $115^{\circ} \mathrm{C}$ for 7 days or 28 days. Curve 1: $A A C$ sand, 7-day cure; Curve 2: AAC sand, 28-day cure; Curve 3: 10-micron min-U-Sil, 7-day cure; Curve 4: 10-micron min-U-Sil, 28-day cure. 


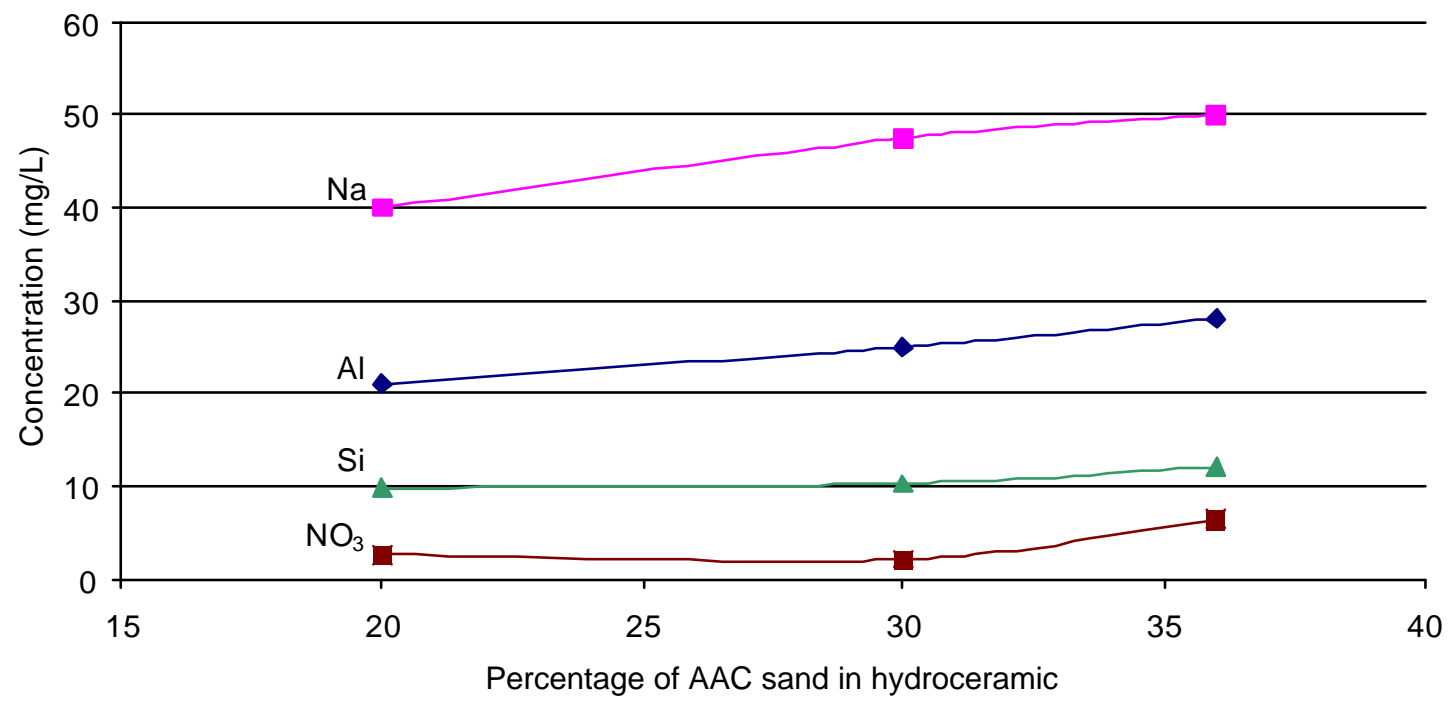

Figure 3-26: Leach analysis curves of hydroceramics obtained from 60-wt\% calcine \#5 derived from Hanford Simulant, $x w t \%$, of AAC sand and (40-x)-wt\% of Engelhard clay; cured at $115^{\circ} \mathrm{C}$ for 28 days.

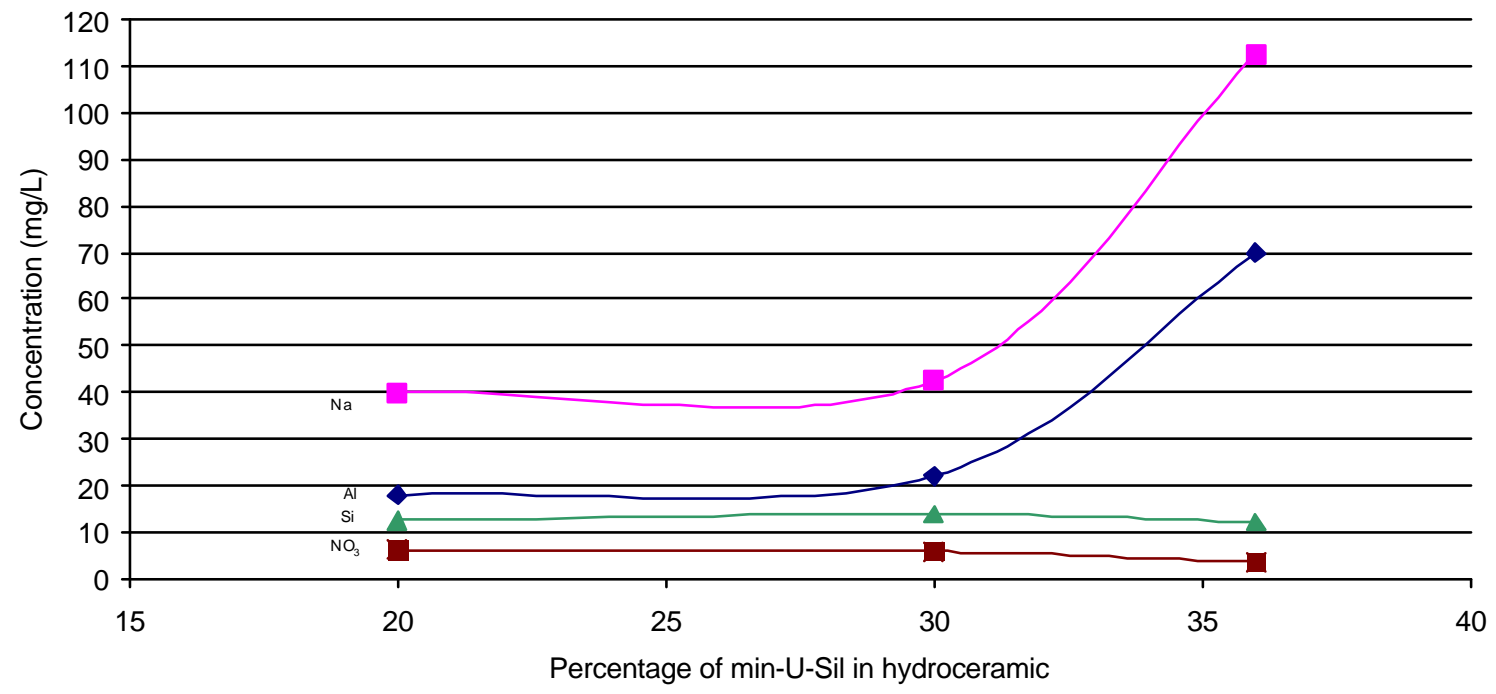

Figure 3-27: Leach analysis curves of hydroceramics obtained from $60-w t \%$ calcine \#5 derived from Hanford Simulant, $x$-wt\%, of 10-micron min-U-Sil and (40-x)$w t \%$ of Engelhard metakaolinite; cured at $115^{\circ} \mathrm{C}$ for 28 days. 


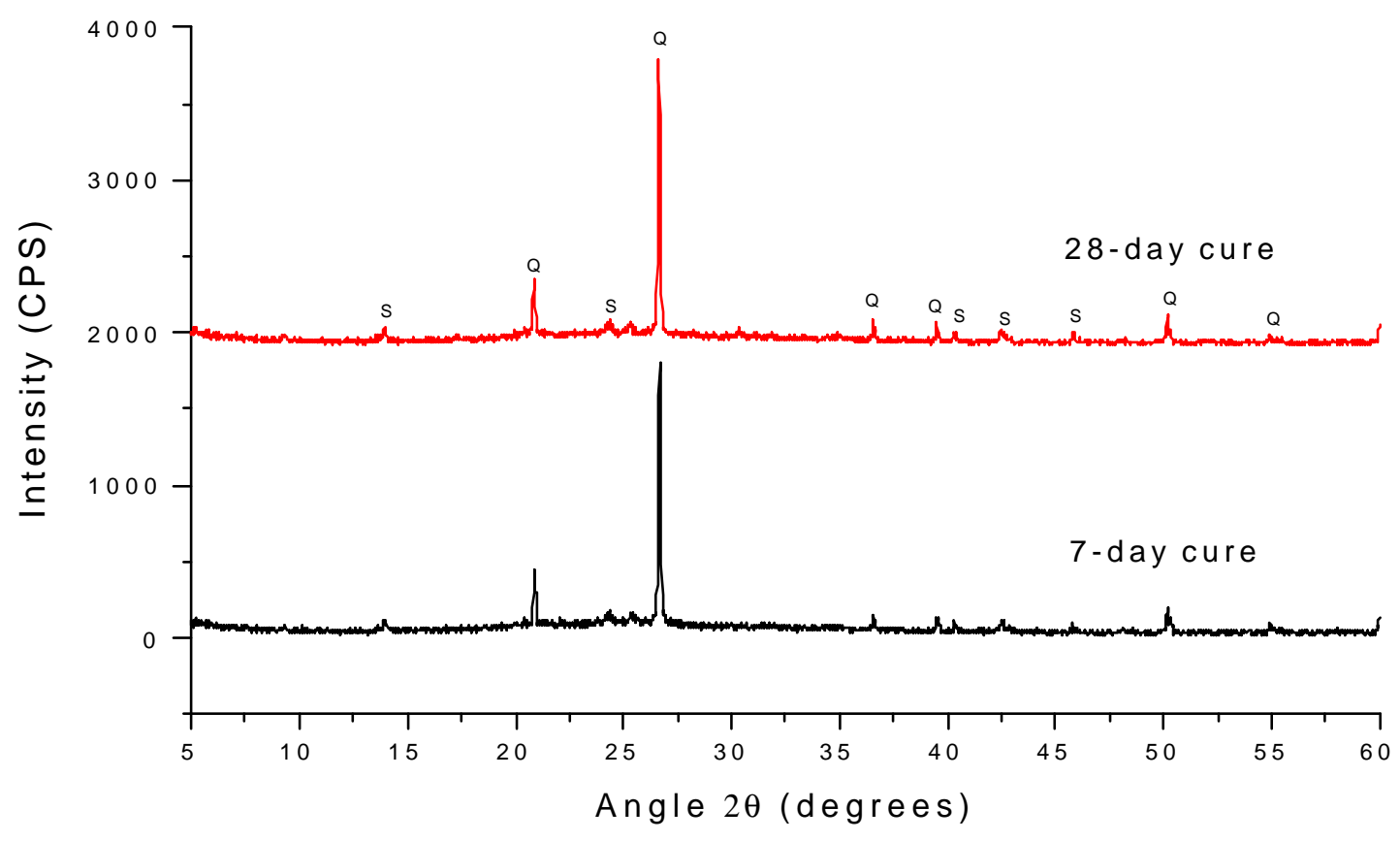

Figure 3-28: X-ray diffraction patterns of hydroceramics obtained from 60-wt\% calcine \#5 derived from Hanford Simulant, 20-wt\% of 10-micron Min-U-Sil, and 20-wt\% of Engelhard metakaolinite; cured at $115^{\circ} \mathrm{C}$ for 7 days or 28 days. S: Sodalite; $Q$ : Quartz.

\subsection{Verification of Temperature-Leachability relation}

Previous experiments, detailed earlier, had indicated that higher curing temperatures would yield hydroceramics with better leachabilities. The $90^{\circ} \mathrm{C}$ temperature was chosen because it represented a low-temperature curing condition. Later, $115^{\circ} \mathrm{C}$ was used because it was on the "other side" of the boiling point scale and represented a moderate-temperature curing situation. After those two temperatures, it was worthy of interest to determine if this temperature-leachability relation would continue at higher temperatures. 


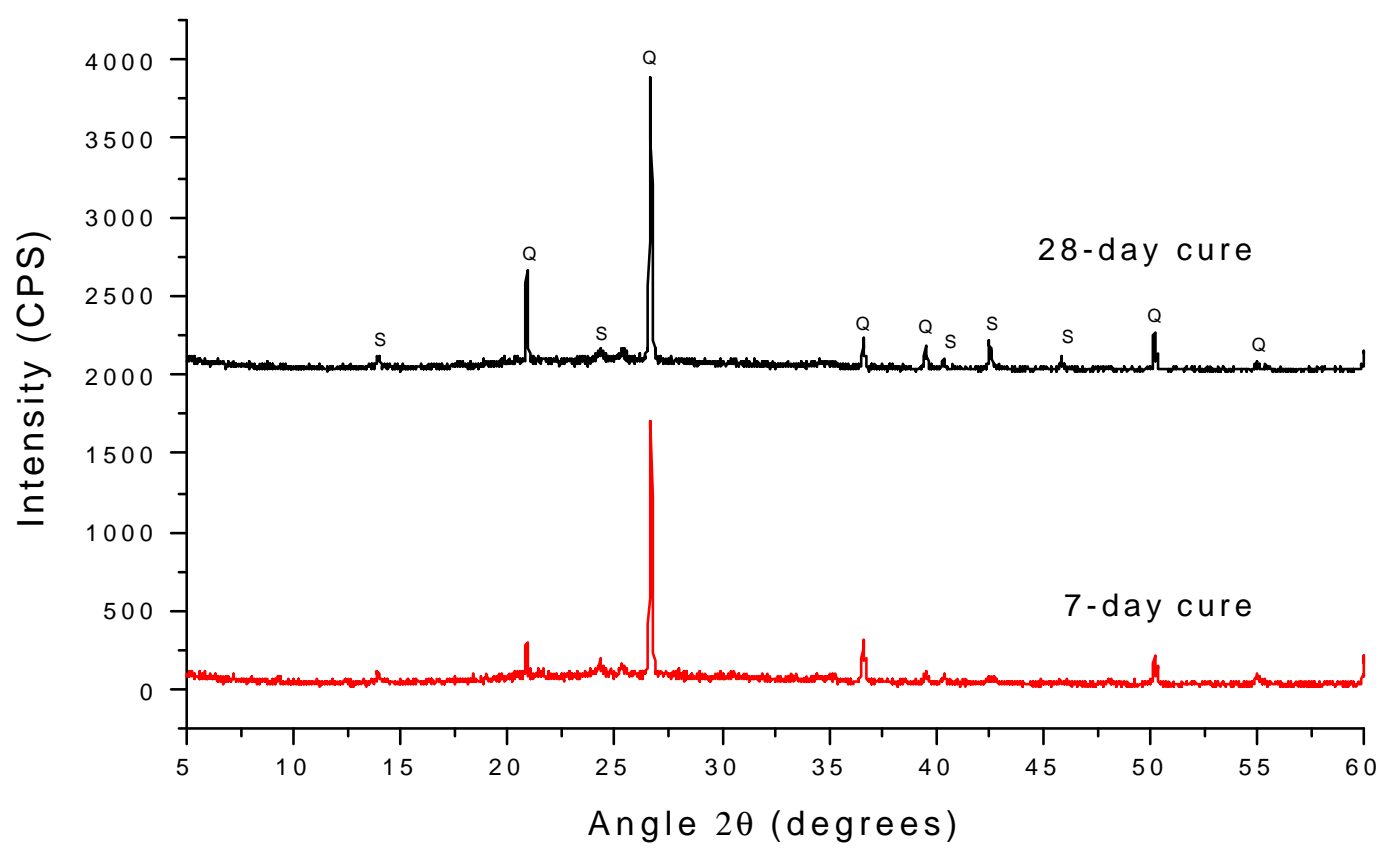

Figure 3-29: X-ray diffraction patterns of hydroceramics obtained from 60-wt\% calcine \#5 derived from Hanford Simulant, 20-wt\% of AAC sand, and 20-wt\% of Engelhard clay; cured at $115^{\circ} \mathrm{C}$ for 7 days or 28 days. S: Sodalite; Q: Quartz.

A temperature of $200^{\circ} \mathrm{C}$ was chosen as being sufficiently high to indicate if such a relation could be verified; at the same time, this temperature would still be categorized as a "moderate temperature" for hydrothermal treatment purposes. The three waste calcines were each mixed in the ratio 60:40 with Troy metakaolinite and sufficient water to make a thick paste. These mixtures were then introduced into Parr bombs for an initial curing at $90^{\circ} \mathrm{C}$ for 24 hours. Then, they were each cured at $200^{\circ} \mathrm{C}$ for various durations. PCT was conducted on the resulting hydroceramics and the leachate was analyzed. Also, their Xray diffraction was measured.

By comparing Figure 3-14 and Figure 3-30, the conductivities at the same curing periods for Simulant 2 are relatively better at $200^{\circ} \mathrm{C}$ than at $115^{\circ} \mathrm{C}$. Again, from the same figure-comparison, for Hanford hydroceramic, there is no appreciable decrease in conductivity.

The X-ray patterns for the three waste hydroceramics are shown in Figure 3-31, Figure 3-32, and Figure 3-33. There are higher crystallinities seen with Simulant 1 and 2, indicating that this higher temperature yields a greater degree of zeolitization. However with Hanford simulant, the appearance of paragonite shows that there is a re-synthesis of clay at high temperature curing. Therefore, a clear generalization cannot be made regarding a link between higher temperature hydrothermal processing and the yield of zeolites. It appears $\mathbf{b}$ be dependent on the amount of sodium available in the waste simulant. The Hanford Simulant contains the least amount of sodium and as a result, not enough was present to produce zeolites in sizeable quantity. 


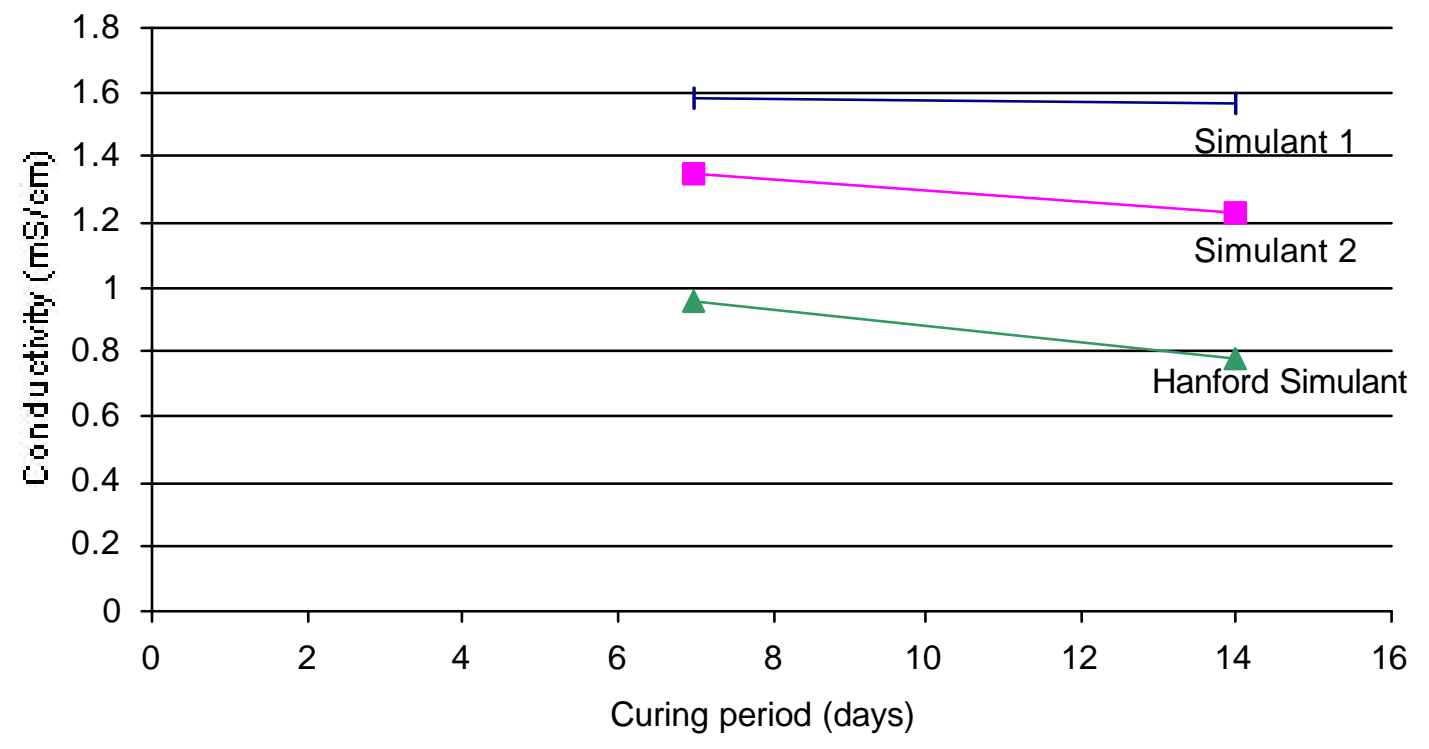

Figure 3-30: Leach analysis curves of hydroceramics obtained from 60-wt\% calcine \#5 derived from Simulants 1, 2, and Hanford Simulant; mixed with 40-wt\% of Troy metakaolinite; cured at $200^{\circ} \mathrm{C}$ for different curing periods.

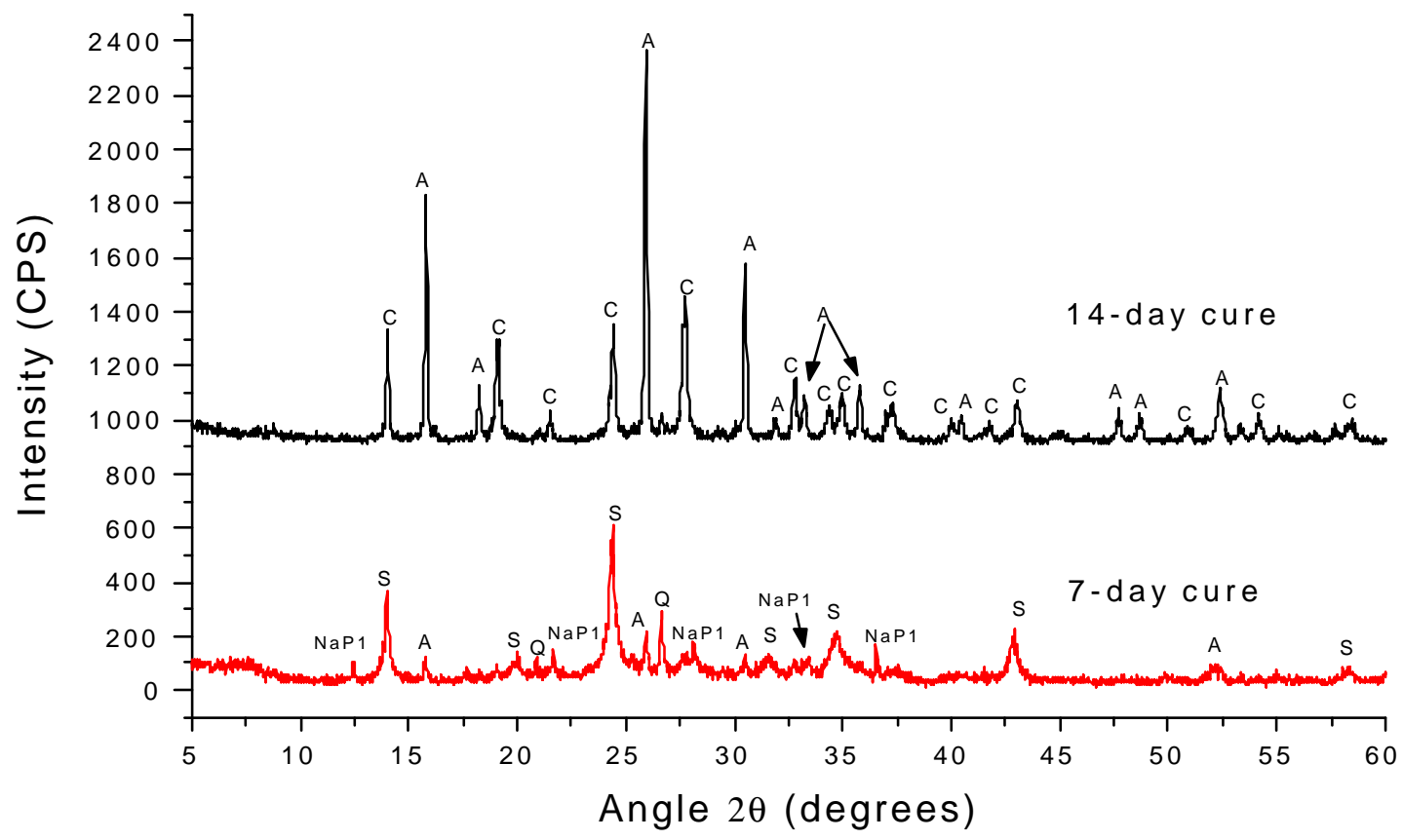

Figure 3-31: X-ray diffraction patterns of hydroceramics obtained from 60-wt\% calcine \#5 derived from Simulant 1 and 40-wt\% of Troy metakaolinite; cured at $200^{\circ} \mathrm{C}$ for 7 days and 14 days. S: Sodalite; Q: Quartz; A: Analcime; NaPl: Na-P1; C: Cancrinite. 


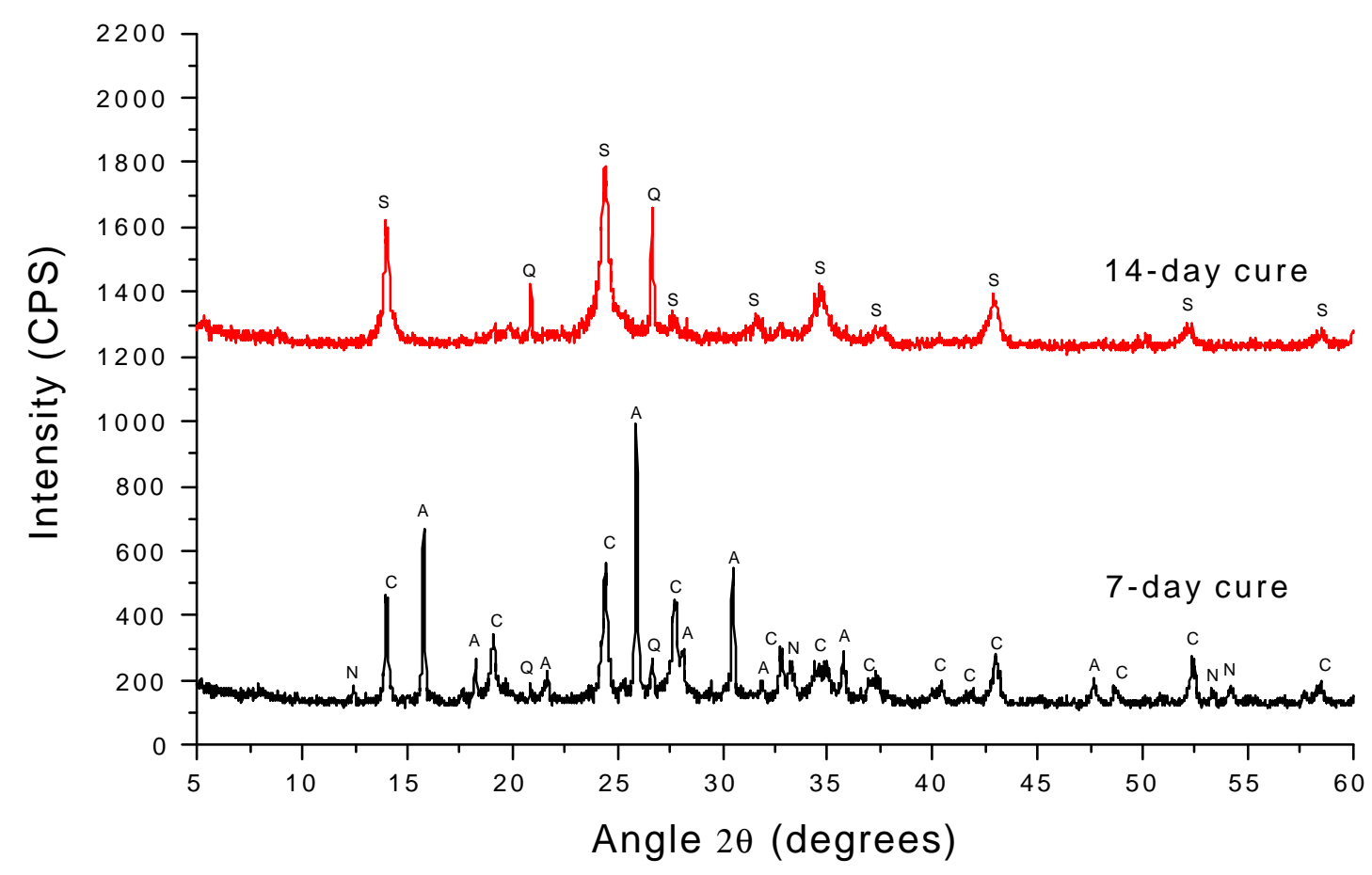

Figure 3-32: X-ray diffraction patterns of hydroceramics obtained from $60-w t \%$ calcine \#5 derived from Simulant 2 and 40-wt\% of Troy metakaolinite; cured at $200^{\circ} \mathrm{C}$ for 7 days and 14 days. S: Sodalite; Q: Quartz; A: Analcime; N: Na-P1; C: Cancrinite.

In the event of hydroceramics becoming a defense waste disposal alternative, two separate paths are encountered in so far as the curing temperature is concerned. A lower temperature processing will ensure safer handling, lower engineering specifications for calciners and furnaces, and possibly lower operating costs. Whereas, a higher temperature curing will perhaps achieve waste form compliance sooner. 


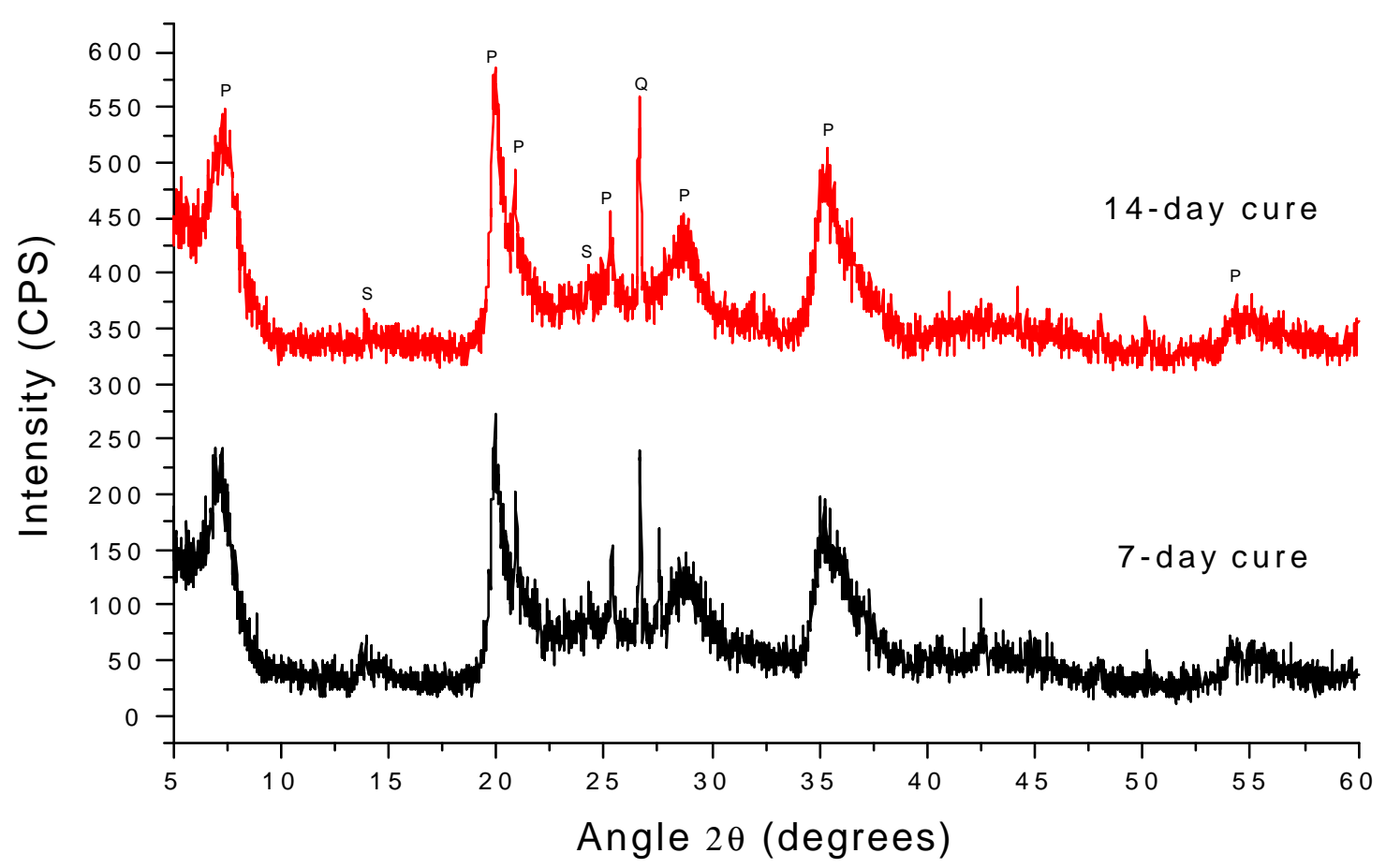

Figure 3-33: X-ray diffraction patterns of hydroceramics obtained from 60-wt\% calcine \#5 derived from Hanford Simulant and 40-wt\% of Troy metakaolinite; cured at $200^{\circ}$ C for 7 days and 14 days. S: Sodalite; Q: Quartz; P: Paragonite.

\subsection{Product Consistency Test on borosilicate glass}

Through all the preceding experiments, the endeavor was to determine and improve upon the leach characteristics of hydroceramics. Although data was available for the leachability of borosilicate glass that was proposed as the DOE's preferred waste form alternative, it was pertinent to test the waste gass in the same laboratory conditions that the hydroceramics were prepared and tested. Therefore, a sample of the borosilicate glass classified as "DWPF (Defense Waste Processing Facility) Environmental Assessment Standard Reference Material - WSRC-NB-92-12 9" was obtained from Westinghouse Savannah River Company, South Carolina. The Product Consistency Test Method B was applied to this glass.

A few deviations were made in so far as obtaining an accurate comparison of the borosilicate glass and the hydroceramics previously tested. In place of three consecutive cycles of washing with ethanol and vibrating the glass-ethanol mixture in an ultrasonic vibrator to remove the fines from the glass surface before testing, four cycles of washing with 200-proof ethanol were carried out. Post leaching, the $\mathrm{pH}$ of the leachate was not 
measured. This is in conformity with the fact that none of the leachates derived from leaching hydroceramics were monitored for $\mathrm{pH}$ changes. Instead, a chemical analysis was performed on the leachate to determine concentrations of various elements. The conductivities of the three leachate samples are shown in Table 3-4. Also, the average chemical compositions of the three samples are displayed.

The glass leachate differs from the hydroceramic leachates in a few ways. There is a high level of boron in the glass leachate, whereas it is virtually absent in the hydroceramic leachate. The amount of nitrate is higher in the latter. This may be due to incomplete denitrification of the waste simulants while making the calcines.

Table 3-4: Chemical analysis of the leachate obtained after a 7-day PCT conducted on borosilicate glass.

\begin{tabular}{|c|c|c|c|c|}
\hline \multicolumn{5}{|c|}{ PCT results of EA glass } \\
\hline \multirow[b]{2}{*}{$\begin{array}{l}\text { Conductivit } \\
\mathrm{y}(\mathrm{mS} / \mathrm{cm})\end{array}$} & \multicolumn{3}{|c|}{ Sample 1Sample 2Sample 3} & $\begin{array}{l}\text { Averaq } \\
\mathrm{e}\end{array}$ \\
\hline & 6.445 & 6.354 & 6.242 & 6.35 \\
\hline $\mathrm{Al}$ & 2.2 & 2.1 & 1.9 & 2.07 \\
\hline B & 140 & 140 & 137.5 & 139.17 \\
\hline $\mathrm{Ca}$ & 1.8 & 2 & 1.55 & 1.78 \\
\hline K & 1.05 & 1.35 & 1.8 & 1.40 \\
\hline $\mathrm{Mg}$ & 0.15 & 0.05 & 0.05 & 0.08 \\
\hline $\mathrm{Na}$ & 400 & 400 & 395 & 398.33 \\
\hline $\mathrm{Si}$ & 180 & 170 & 190 & 180.00 \\
\hline $\mathrm{NO}_{3}$ & 0.5 & 0.4 & 0.3 & 0.40 \\
\hline
\end{tabular}

Aluminum is also higher in the leachates produced from hydroceramic leaching. This is perhaps because of some unused aluminum in the clay while making the hydroceramics. At the same time, calcium, potassium and magnesium appear in the glass leachate. These elements are below detection limits $(0.01 \mathrm{mg} / \mathrm{L})$, or are present in 
insignificant amounts in hydroceramic leach results. Also noticeable are the high levels of sodium and silica in the glass leachate. The conductivities mainly reflect the mobility of the boron, sodium and silica in the leachate. The conductivity of the glass leachate is comparable to hydroceramics prepared during the scoping studies described earlier in this thesis, as seen in a comparison of Table 3-4 and Figure 3-2. However, with the use of Engelhard metakaolinite and quartz supplementation, the values of sodium in the hydroceramic leachates are about a third of those obtained from glass leaching as can be seen from comparing Table 3-4, Figure 3-26 and Figure 3-27.

Through this and other glass leach studies, it appears that while borosilicate glass leaches by an ion exchange process, the dissolution process in hydroceramics involves both ion exchange and hydrolysis [5]. Like most other soil minerals, cancrinites \& sodalites have a much greater affinity for cations than they do for anions. Deionized water satisfies this "hunger" by hydrolyzing to donate hydronium ions to the mineral a process that displaces an equivalent amount of sodium ion from it. Hydrolysis simultaneously creates an equivalent amount of hydroxide ion, the bulk of which then displaces anionic materials (silicate, aluminate, and nitrate) from the mineral; and the remaining hydroxide raises the $\mathrm{pH}$ of the leachate. If the mineral's cation exchange sites are satisfied by other cations from the leachant, both hydrolysis of the water and dissolution of the mineral are suppressed.

\section{Conclusions}

Through this study, we have concluded that hydroceramics made with waste calcines and metakaolinite tended to outperform other waste form alternatives. Hydroceramics, owing to their ceramic structure containing zeolitic phases, accommodate sodium within their matrix with relatively little additional processing. They have low leachability and compare favorably with traditional glass waste forms. Sugar calcination of high-sodium wastes without a "calcination aid" containing aluminum and/or silicon is of questionable benefit. At least $75 \%$ of the sodium required to produce sodalites and cancrinites in the zeolitization phase should be present in the form of oxides, aluminates, or silicates. Calcining the sodium bearing waste is a well-suited way to remove most of the sodium nitrate and nitrite, besides acids and organics thus making the waste more amenable to zeolite encapsulation. In practice, calcination involves the use of a simple rotary kiln or construction of a calcination facility such as the one used by INEEL to calcine its waste.

The effect of temperature on the curing process of hydroceramics is such that with increase in temperature, more zeolites are noticed in the microstructure. However, considering the fact that the hydroceramics will remain in underground repositories essentially forever, a lower temperature of $90^{\circ} \mathrm{C}$ may be chosen for cost and safety reasons. Results suggest that leachabilities of hydroceramics cured at different temperatures tend to converge upon prolonged curing durations. The addition of water during the curing process does not seem to have any perceivable benefit. In fact, leaching of ions could occur into the water vapor when extra water is present in the autoclave. Hence, no extra water should be introduced into the process.

Engelhard and other high purity clays show good leachabilities but poor strengths. It is therefore necessary to choose a metakaolinite such as Troy metakaolinite, which may 
possess some quartz, but nevertheless displays respectable leach effectiveness. Using a blend of clays is one method of counteracting the low strength of hydroceramics caused by one of the constituent clays. However, the addition of a silica source like AAC sand or Min$U-S i l$ shows more promise. Whereas with the presence of even very low proportions of Engelhard clay the strength characteristics of the resulting blended-clay hydroceramic are significantly compromised, with silica addition instead, more crystalline phases are observed, accompanied by a significant increase in hydroceramic strength.

The PCT conducted on the DOE's borosilicate glass showed the high leachability of this particular waste form. It compares poorly with zeolitic hydroceramics.

As a waste form, zeolitic hydroceramics make a significantly better choice than the DOE's current borosilicate glass alternative. The former already consist of the zeolitic "secondary phases" that glasses will eventually decompose to when they come in contact with the geology of the Nevada Test Site, which has been determined to be the final resting place for the nation's nuclear wastes. The experiments in the preceding sections have shown that with longer and longer durations of curing at low temperatures, the leach characteristics of the hydroceramics approach those made at higher temperatures. This points to one more advantage. Since the waste form will remain for a significant period of time in temporary storage areas on site, there is a potential to cure the hydroceramic monoliths at relatively low temperatures during this waiting period, and still be able to achieve desired waste-form characteristics before going "on-road". Thus, the highest temperature required in the entire process is approx. $500^{\circ} \mathrm{C}$ for waste calcination. All curing thereafter needs a temperature that is an order of magnitude less than that $\left(1200^{\circ} \mathrm{C}-1600^{\circ} \mathrm{C}\right)$ needed for vitrification.

The radioactive intensities of DOE's defense wastes are too low to cause damage to cementitious materials (such as hydroceramics), and sufficiently high to promote hydrothermal curing reactions in an insulated interim storage system. [9]

In a drive to achieve volume reduction, vitrification appears to have immediate benefits, in that it reduces the quantity of HLW that needs to be ultimately disposed off. However, it also creates a LLW fraction that is much larger than the original waste burden itself. (It is estimated that the amount of "new" nitric oxide alone will be of the order of 20,000 tons. (Personal communication. Siemer and Grutzeck, April 2000]). This LLW is proposed to be left on-site with only a cursory treatment [5]. With the use of hydroceramics, the entire waste volume - without any separation - can be suitably accommodated in one monolithic waste form. Thus, a reduction in the total waste volume will be conveniently achieved in this manner.

Hanford waste too performs well as a hydroceramic waste form. Therefore, there is substantial evidence that zeolitization is a very viable option not only for Savannah River Laboratory's wastes, but also for other nuclear waste repositories. Because of the easy availability of kaolinite clay and the straightforward processing required to convert kaolinite to metakaolinite, quality control is easy to maintain. The overall low cost and low temperature processing enhance the potential utility of hydroceramics in providing an alternate means for the disposal of sodium bearing wastes. In toto, hydroceramics have acceptably low leachabilities (measured using the PCT and MCC-1 methods) and adequate strength (Siemer et al., 1998; Krishnamurthy, 2000 [2]). In addition there is little or no change when a hydroceramic is subjected to DOE's vapor hydration test. This is due to the fact that the hydroceramic waste form is already in equilibrium with saturated steam. Glass 
of course, is not at equilibrium with steam and tends to form unstable secondary hydration products during the test.

Hydroceramics are perfectly suited for low activity SBW streams that contain high levels of sodium. Rather than being detrimental, as is the case for vitrification, the high sodium content actually increases the ease of producing a hydroceramic waste form. Rather than diluting the waste, one can use the sodium in the waste to its full advantage. During calcination, it should also be possible to reduce the valance states of $\mathrm{Tc}$ and $\mathrm{Np}$ so that they are more amenable to encapsulation as cations rather than their current anionic state. This can be done chemically (adding small amounts of various sulfides) or by control of oxygen fugacities in the calciner.

These observations lead one to reevaluate hydroceramics as a worthy alternative to vitrification for the safe disposal of the nation's radioactive wastes.

\section{REFERENCES}

1. L. E. Brownell, C. H. Kindle, and T. L. Theis. Review of Literature Pertinent to the Aqueous Conversion of Radionuclides to Insoluble Silicates With Selected References and Bibliography (Revised), ARH-2731 REV, (1973).

2. Naveen Krishnamurthy, Johnson Olanrewaju, Michael Grutzeck, Stephen Kwan, and Barry E. Scheetz. Hydroceramic Waste Forms: An Alternative to Glass for Sodium Bearing Wastes. $22^{\text {nd }}$ American Chemical Society National Society Meeting proceedings, Chicago, IL, (2001).

3. American Society for Testing and Materials' Standard Test Methods for Determining Chemical Durability of Nuclear, Hazardous and Mixed Waste Glasses: The Product Consistency Test (PCT). ASTM Designation: C 1285-97.

4. John A. Stone. An Experimental Comparison of Alternative Solid Forms for Savannah River High-Level Wastes In: Scientific Basis for Nuclear Waste Management. Proceedings of The Materials Research Society Annual Meeting, Boston. November 1981.

5. Darryl D. Siemer Why Hydroceramic Solidification Makes More Sense Than Vitrification For INEEL High Level Waste. Unpublished paper (June 2000).

6. Darryl D. Siemer, Michael W. Grutzeck, Della M. Roy, and Barry E. Scheetz. Zeolite Waste Forms Synthesised from Sodium Bearing Waste and Metakaolinite. In: Waste Management Conference Proceedings, Tucson, March (1998).

7. Giuseppe Arena, Annalinda Contino, Antonio Magri, Domenico Sciotto, Giuseppe Spoto, and Alberto Torrisi. Strategies Based on Calixcrowns for the Detection and 
Removal of Cesium Ions from Alkali-Containing Solution. Industrial and Engineering Chemistry Research, 39, 3605-3610 (2000).

8. Executive Summary of Technical Report on the River Protection Project (formally known as the Tank Waste Remediation System) submitted to U.S. Congress in 2001.

9. Michael W. Grutzeck, Darryl D. Siemer. Zeolites Synthesized from Class F Fly Ash and Sodium Aluminate Slurry Journal of American Ceramic Society, 80 [9] 2449-2453 (1997).

10. Darryl. D. Siemer, Marylou D. Gougar, Michael W. Grutzeck, and Barry E. Scheetz. Why a "Hydroceramic' HLW Wasteform makes sense for INEEL. Unpublished paper, (2001).

11. Rodney C. Ewing and Werner Lutze. High-Level Nuclear Waste Immobilization with Ceramics. Ceramics International, 17, 287-293 (1991).

12. Darryl D. Siemer. Conversion of DOE Reprocessing Waste into Hydroceramic Waste Forms. White Paper submitted to INEEL. January (2001).

13. Sherman M. Ponder, Robert Helkowski, and Thomas E. Mallouk. Continuous-Flow Process for the Separation of Cesium from Complex Waste Mixtures. Industrial and Engineering Chemistry Research, 40, 3384-3389 (2001).

14. K. D. Reeve, D. M. Levins, E. J. Ramm, J. L. Woolfrey and W. J. Buykx. The Development and Testing of SYNROC C as a High Level Nuclear Waste Form In: Scientific Basis for Nuclear Waste Management. Proceedings of The Materials Research Society Annual Meeting, Boston. November, (1981).

15. M. Petek, M. M. Abraham, and L. A. Boatner. Lanthanide Orthophosphates as a Matrix for Solidified Radioactive Defense and Reactor Wastes. In: Scientific Basis for Nuclear Waste Management. Proceedings of The Materials Research Society Annual Meeting, Boston. November, (1981).

16. Cementitious Radioactive Waste Hosts Formed under Elevated Temperatures and Pressures (FUETAP Concretes). In: Scientific Basis for Nuclear Waste Management. Proceedings of The Materials Research Society Annual Meeting, Boston. November, (1981).

17. Cementitious Radioactive Waste Hosts Formed under Elevated Temperatures and Pressures (FUETAP Concretes). L. R. Dole, J. G. Moore, G. C. Rogers, G. A. West, H. E. Devaney, M. T. Morgan, E. W. McDaniel, and J. H. Kessler.

18. Darryl D. Siemer, Michael W. Grutzeck, and Barry E. Scheetz. Comparison of Metakaolinite for Making Hydroceramic Waste Forms. Unpublished paper (1999). 
19. A. Palomo and F. P. Glasser. Chemically-bonded Cementitious Materials Based on Metakaolin. Br. Ceram. Trans. J. 91, No.4. P p.107-112. (1992).

20. Leaching Studies of Crystalline Sodium Phases in Nuclear Waste Forms In: Scientific Basis for Nuclear Waste Management. Proceedings of The Materials Research Society Annual Meeting, Boston. November, (1981).

21. Immobilization and Leakage of Krypton Encapsulated in Zeolite or Glass In: Scientific Basis for Nuclear Waste Management. Proceedings of The Materials Research Society Annual Meeting, Boston. November, (1981).

22. Hsiao-Lan Chang and Wei-Heng Shih. A General Method for the Conversion of Fly Ash into Zeolites as Ion Exchangers for Cesium. Industrial and Engineering Chemistry Research, 37, 71-78. (1998).

23. Breck, D. W., Zeolite Molecular Sieves: Structure, Chemistry and Use, Wiley \& Sons, NY (1973).

24. National Research Council Disposition of High-Level Waste and Spent Nuclear Fuel: The Continuing Societal and Technical Challenges. Pp xi, 17, 27, 25, 3. National Academy Press, Washington D.C. (2001).

25. Dyer, A., An Introduction to Zeolite Molecular Sieves, Wiley \& Sons, New York. (1988).

26. Barrer, R. M., Zeolites and Clay Minerals as Sorbents and Molecular Sieves, Academy Press, London, (1978).

27. Dixon, J. B., and S. B. Weed. Minerals in Soil Environments: Soil Science Society of America, Madison, Wis., USA, (1989).

28. Breck, D. W. Zeolite Molecular Sieves, Wiley-Interscience, New York, (1974).

29. National Research Council Committee on Cesium Processing Alternatives for HighLevel Waste at the Savannah River Site Alternatives for High-Level Waste Salt Processing at the Savannah River Site. Pp 1-13, 83. National Academy Press, Washington D.C. (2000). 